\title{
O estado nutricional de adolescentes da rede de ensino público da cidade de Piracicaba (SP) e seus determinantes
}

Stela Verzinhasse Peres

Dissertação apresentada ao Programa de Pós-Graduação em Saúde Pública da Faculdade de Saúde Pública da Universidade de São Paulo para obtenção do título de Mestre em Saúde Pública.

Área de Concentração: Epidemiologia

Orientador: Prof. Tit. Maria do Rosário Dias de Oliveira Latorre.

São Paulo

2007 
É expressamente proibida a comercialização deste documento tanto na sua forma impressa como eletrônica. Sua reprodução total ou parcial é permitida exclusivamente para fins acadêmicos e científicos, desde que na reprodução figure a identificação do autor, título, instituição e ano da dissertação. 
Financiamento da Fundação de Amparo à Pesquisa do Estado de São Paulo Bolsa de Mestrado: processo 05/57417-4

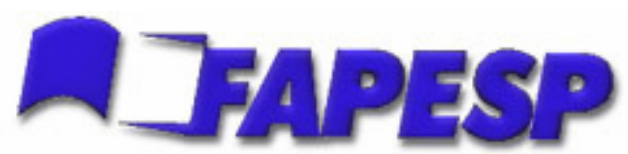




\section{L̇ Jamilia Verzinhasse Peres}

Dedico este trabalho aos meus pais Celoni e Marlene, que fazem a minha vida ser tão especial. Aos meus irmãos Jane, Patrícia e Ulisses pelo incentivo incansável e apoio financeiro. Aos meus sobrinhos Marcello, Isabella, Bárbara, Graziella, José e Guilherme por exigirem de mim uma concentração no estudo durante suas brincadeiras na "casa da vó". Aos cunhados Rui, Domingos e Cristine, sem eles a família não estaria tão grande e maravilhosa. Não posso esquecer do Veron, meu cachorro, pela melhor festa do dia, inexplicavelmente deliciosa.

Por fim, ao novo membro desta família, meu namorado Tiago $L$. Spagnuolo. Obrigada por estar ao meu lado, sempre paciente e carinhoso. 


\section{Agradecimentos}

À professora Maria do Rosário Dias de Oliveira Latorre, minha orientadora, pelo carinho, pelos ensinamentos e, principalmente, pela confiança. Ah! Por todas as broncas que só me ajudaram a crescer.

Ao professor Alex Florindo - parte desta trajetória - pela confiança, incentivo e paciência, até nas perguntas mais descabidas.

Ao professor Aluísio Segurado e à Dra. Delza Nagata da Casa da Aids, onde tudo começou.

Às professoras Betzabeth Slater e Marina Vieira da Silva, por acreditarem em mim.

Às professoras Maria Ignez Saito e Ivani Credidio Trombeta, por todo ensinamento, respeito e carinho durante este processo.

À turma da salinha, que pertence ou pertenceu, Luciana S. Costa, Aline, Maria, Michelline, Marcinha, Carmen, Fernanda, Luciana Gomes, Tati, Vivian, Susana e Leslie. Ô mulherada porreta!!!!

Às minhas fiéis companheiras Fernanda Cruciani e Susana, por estarmos juntas em todos os momentos acadêmicos. 
Aos amigos Neuber e Shamyr, por me ajudarem com os programas estatísticos, pelas risadas e besteiras.

Aos colegas da Nutrição Alexandre, Silvia, Natacha e Priscila, pelo auxilio nos bancos de dados e com a parte nutricional deste trabalho.

Aos meninos (não tão meninos) da informática Daniel, Rodrigo, Pascoal e Sérgio, pela ajuda nos programas estatísticos.

Às secretárias Cátia, Sandra, Bete, Regina e Roberta, pela prontidão.

Aos alunos da rede de ensino público de Piracicaba e ao Dirigente de Ensino Oldack Chaves.

Muito obrigada, sem vocês ... é melhor nem pensar!!!!! 
"Se há esportes que auxiliam o corpo,

Há esportes que ajudam a alma...

A marcha do dever retamente cumprido.

A regata do suor do trabalho.

O exercício do devotamento ao estudo.

O salto do esforço, acima dos obstáculos.

A maratona das boas obras.

O torneio da gentileza.

O mergulho no silêncio, diante da injúria.

O nado da paciência nas horas difíceis.

A ginástica da tolerância perante as ofensas.

O vôo do pensamento às esferas superiores.

E a demonstração de resistência moral nas provas de cada dia."

André Luiz

Trecho do poema Desporto extraído do livro"Capoeira do Engenho à Universidade". 
Peres SV. O estado nutricional de adolescentes da rede de ensino público da cidade de Piracicaba (SP) e seus determinantes [dissertação de mestrado]. São Paulo: Faculdade de Saúde Pública da USP; 2007.

\section{Resumo}

Introdução - O sobrepeso e a obesidade são doenças de características endêmicas, tanto em países desenvolvidos como em países em desenvolvimento e podem coexistir com a desnutrição, principalmente, nas camadas sociais de baixa renda. Objetivo - Estimar as prevalências de desnutrição, sobrepeso e obesidade, segundo sexo e idade, bem como os fatores associados à sua ocorrência em adolescentes de 10 a 14,9 anos de idade, matriculados na rede de ensino público da cidade de Piracicaba, São Paulo, Brasil. Material e Métodos - Este foi um estudo transversal. A amostra foi composta por 269 adolescentes de ambos os sexos (118 meninos e 151 meninas). Foram aplicados questionários para obtenção do consumo alimentar, maturação sexual, nível de atividade física e características demográficas e feita a mensuração de peso e altura. Para a análise estatística utilizou-se o teste de associação pelo qui-quadrado e modelos de regressão multinomial univariados e múltiplos para verificar a relação entre o estado nutricional e as variáveis independentes. Resultados - As prevalências de desnutrição para meninos e meninas foram, respectivamente, $5,1 \%$ e $4,0 \%$. As prevalências de sobrepeso foram de $15,3 \%$ entre os meninos e de $13,2 \%$ entre as meninas. A obesidade apresentou prevalências de $18,6 \%$ em meninos e $11,9 \%$ em meninas. $O$ fator que apresentou associação com a presença de desnutrição nos meninos foi a idade, verificando-se que a faixa etária de 13,0 a 14,9 anos apresentou maior proporção de desnutridos em relação a faixa etária de 10,0 a 12,9 anos (respectivamente $14,3 \% \times 0,0 \% ; p=0,028$ ). Os fatores que mostraram associação com a desnutrição para as meninas foram o estágio puberal $(O R=10,20 ; p=0,005)$ e horas diante da televisão por dia $(O R=6,13$; $p=0,019$ ). Para o sobrepeso e obesidade, a ingestão de energia mostrou associação com a obesidade, ajustada pela idade e tempo em minutos por dia de prática de atividade física $\left(\mathrm{OR}_{\text {ajustada }}=6,74 ; p=0,013\right)$ no grupo masculino. Nas adolescentes a obesidade foi associada ao números de horas diante de televisão por dia, ajustada pela idade ingestão de energia e tempo em minutos por dia de prática de atividade física $\left(\mathrm{OR}_{\text {ajustada }}=5,39 ; \mathrm{p}=\right.$ 0,006 ). Conclusões - Os achados do presente estudo evidenciaram que as prevalências de desnutrição são baixas, enquanto que, as prevalências de sobrepeso e obesidade são preocupantes, demonstrando o processo de transição nutricional no qual a cidade de Piracicaba se encontra. Dentre os fatores associados à estes agravos, destacam-se aqueles passíveis de modificação, ao se adotar hábitos de vida saudáveis como evitar o consumo 
excessivo de alimentos com alto valor calórico, bem como a redução do número de horas assistindo televisão.

Descritores: Desnutrição, Sobrepeso, Obesidade, Adolescentes, Fatores de Risco. 
Peres SV. Nutritional status determinants in adolescents from public schools of Piracicaba (SP-Brazil) [dissertation]. São Paulo (BR): Faculdade de Saúde Pública da Universidade de São Paulo; 2007.

\section{Abstract}

Background - The overweight and obesity are occurring in developed as in developing countries. It can coexist with the undernutrition, mainly, in the lower social class. Objective - To estimate the prevalences of undernutrition, overweight and obesity, according to sex and age, and to determine demographics, of lifestyle characteristics and dietary intake associated to nutritional status in adolescents aged 10 to 14,9 years who were attending a public school in Piracicaba (SP - Brazil). Material and Methods - This was a cross-sectional study. The sample was composed by 269 adolescents of both sex (118 boys and 151 girls). Demographic and anthropometric data, dietary habits, sexual maturation, physical activity, physical inactivity were collected using questionnaires. The statistical analyses were done using chi-square test and univariate and multiple multinomial regression models. Results - The prevalences of undernutrition on boys was $5,1 \%$ and on girls was $4.0 \%$. Prevalence of overweight in boys and girls were $15.3 \%$ and $13.2 \%$, respectively. The prevalence of obesity was $18.6 \%$ in boys and $11,9 \%$ in girls. The undernutrition was associated with age on boys (respectively, 14,3\% x $0,0 \% ; p=0,028$ ). The undernutrition was associated with pubertal status $(O R=10,20 ; p=0,005)$ and hours of television watching $(O R=6,13 ; p=0,019)$ among girls. The factors associated with obesity was energy intake in boys $\left(\mathrm{OR}_{\text {adjusted }}=6,72 ; \mathrm{p}=0,013\right)$ and hours of television watching in girls $\left(\mathrm{OR}_{\text {adjusted }}=5,39 ; \mathrm{p}=0,006\right)$. Conclusions - The prevalence of undernutrition are low and the prevalences of overweight and obesity were high in adolescents; demonstrating the process of nutrition transition in Piracicaba. The results showed that undernutrition determinants are age, on boys and pubertal status and hours of television watching, on girls. The obesity determinants were energy intake among boys and hours of television watching among girls. These findings indicate that the preventive intervention programmes should emphasize the healthy practices.

Descriptors: Undernutrition, Overweight, Obesity, Adolescents, Risk Factors 


\section{ÍNDICE}

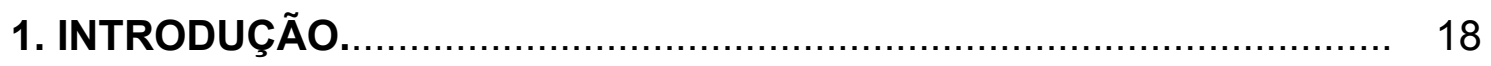

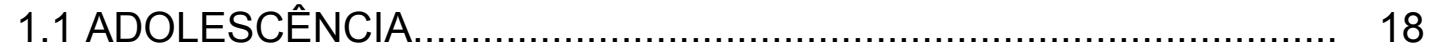

1.2 PREVALÊNCIA DE SOBREPESO, OBESIDADE E DESNUTRIÇÃO

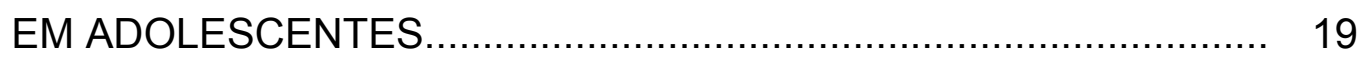

1.3 FATORES ASSOCIADOS AO SOBREPESO, OBESIDADE E DESNUTRIÇÃO EM ADOLESCENTES............................................ 21

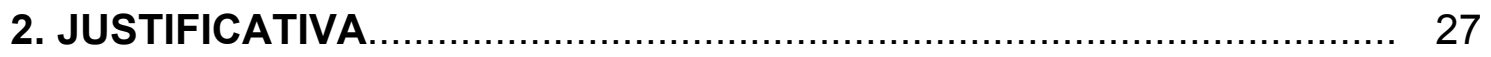

3. OBJETIVOS

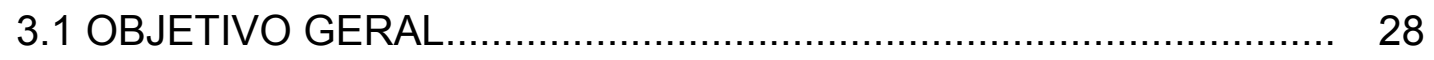

3.2 OBJETIVO ESPECÍFICOS .................................................... 28

4. MATERIAL E MÉTODOS............................................................. 29

4.1 DELINEAMENTO DO ESTUDO................................................... 29

4.2 POPULAÇÃO E LOCAL DO ESTUDO............................................ 29

4.2.1 Tamanho da Amostra........................................................... 30

4.3 METODOLOGIA .............................................................. 31

4.3.1 Consumo Alimentar.......................................................... 32

4.3.2 Maturação Sexual............................................................. 33

4.3.3 Dados Antropométricos....................................................... 34

4.3.4 Atividade Física............................................................ 36

4.3.4.1 Inatividade Física..................................................... 37

4.4 VARIÁVEIS DE ESTUDO.......................................................... 38

4.5 ANÁLISE ESTATÍSTICA............................................................ 40

4.6 PROGRAMAS COMPUTACIONAIS UTILIZADOS.......................... 41

4.7 CONSIDERAÇÕES ÉTICAS...................................................... 42

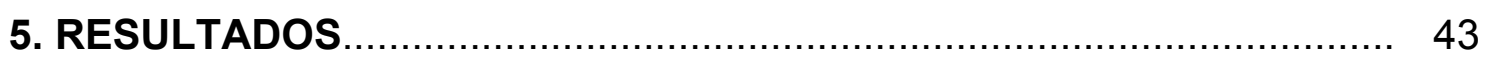

5.1 CARACTERIZAÇÃO DA AMOSTRA........................................ 43

5.2 O ESTADO NUTRICIONAL.......................................................... 49

5.3 FATORES ASSOCIADOS A DESNUTRIÇÃO................................ 50

5.3.1 Fatores Associados a Desnutrição para o Sexo Masculino....... 50 
5.3.2 Fatores Associados a Desnutrição para o Sexo Feminino 54

5.4 FATORES ASSOCIADOS AO SOBREPESO E OBESIDADE......

5.4.1 Fatores Associados ao Sobrepeso e Obesidade para o Sexo Masculino.

5.4.2 Fatores Associados ao Sobrepeso e Obesidade para o Sexo Feminino 66

6. DISCUSSÃO 75

6.1 ASPECTOS METODOLÓGICOS 76

6.1.1 Delineamento do Estudo 76

6.1.2 Avaliação do Estado Nutricional.. 77

6.1.3 Avaliação das variáveis independentes. 79

6.2 ASPECTOS EPIDEMIOLÓGICOS. 82

6.2.1 Caracterização da Amostra. 82

6.2.2 Análise do Estado Nutricional.. 90

6.2.3 Fatores Associados a Desnutrição. 91

6.2.4 Fatores Associados ao Sobrepeso e a Obesidade. 95

7. CONCLUSÕES 102

8. REFERÊNCIAS 104 ANEXOS 115

Anexo 1 - Questionário para pais e/ou responsáveis. Identificação da família condições de vida do escolar.

Anexo 2 - Questionário de Freqüência Alimentar para Adolescentes(QFAA)

Anexo 3 - Questionário para Avaliação da Maturação Sexual (desenhos de Tanner)

Anexo 4 - Questionário de Avaliação da Atividade Física para Adolescentes (QAFA)

Anexo 5 - Documento de aprovação do Comitê de Ética em Pesquisa da Faculdade de Saúde Pública da Universidade de São Paulo (pesquisa mãe)

Anexo 6 - Documento de aprovação do Comitê de Ética em Pesquisa da 
Faculdade de Saúde Pública da Universidade de São Paulo (pesquisa atual)

Anexo 7 - Documento de aprovação do Dirigente Regional de ensino de Piracicaba 142

Anexo 8 - Termo de Consentimento Livre e Esclarecido. 


\section{Lista de Quadros}

páginas

Quadro 1 - Classificação da maturação sexual para os estágios de

Tanner (1962)

Quadro 2 - Classificação do estado nutricional segundo percentis do Índice de Massa Corporal para adolescentes. 


\section{Lista de Tabelas}

páginas

Tabela 1 - Número e porcentagem de adolescentes, segundo sexo, características demográficas e maturação sexual. Piracicaba, 2005........

Tabela 2 - Número e porcentagem de adolescentes, segundo sexo e tipo de prática esportiva. Piracicaba, 2005.

Tabela 3 - Estatística descritiva dos adolescentes, segundo as variáveis antropométricas e de estilo de vida. Piracicaba, 2005

Tabela 4 - Estatística descritiva dos adolescentes, segundo variáveis de consumo. Piracicaba, 2005

Tabela 5 - Prevalência $(P)$ e os respectivos intervalos de 95\% de confiança de adolescentes, segundo sexo e estado nutricional. Piracicaba, 2005

Tabela 6 - Número e porcentagem de adolescentes do sexo masculino, segundo características demográficas e de maturação sexual. Piracicaba, 2005.

Tabela 7 - Número e porcentagem de adolescentes do sexo masculino, segundo e características escolares. Piracicaba, 2005

Tabela 8 - Número e porcentagem de adolescentes do sexo masculino, segundo características de prática de atividade física/exercício. Piracicaba, 2005.

Tabela 9 - Número e porcentagem de adolescentes do sexo masculino, 
segundo características de inatividade física. Piracicaba, 2005.

Tabela 10 - Estatística descritiva do consumo de energia e macronutrientes, segundo sexo masculino. Piracicaba, 2005..................

Tabela 11 - Número e porcentagem de adolescentes do sexo feminino, segundo características demográficas e de maturação sexual. Piracicaba, 2005.

Tabela 12 - Número e porcentagem de adolescentes do sexo feminino, segundo características escolares. Piracicaba, 2005.

Tabela 13 - Número e porcentagem de adolescentes do sexo feminino, segundo características de prática de atividade física/exercício. Piracicaba, 2005.

Tabela 14 - Número e porcentagem de adolescentes do sexo feminino, segundo características de inatividade física. Piracicaba, 2005.

Tabela 15 - Estatística descritiva do consumo de energia e macronutrientes, segundo sexo feminino. Piracicaba, 2005.

Tabela 16 - Número e porcentagem de adolescentes do sexo masculino, segundo características demográficas e de maturação sexual. Piracicaba, 2005

Tabela 17 - Número e porcentagem de adolescentes do sexo masculino, segundo características escolares. Piracicaba, 2005..............

Tabela 18 - Número e porcentagem de adolescentes do sexo masculino, segundo características de prática de atividade física/exercício. Piracicaba, 2005 
Tabela 19 - Número e porcentagem de adolescentes do sexo masculino, segundo características de inatividade física. Piracicaba, 2005

Tabela 20 - Estatística descritiva do consumo de energia e macronutrientes, segundo sexo masculino. Piracicaba, 2005.

Tabela 21 - Resultados da análise univariada de regressão logística multinomial para o sexo masculino. Piracicaba, 2005

Tabela 22 - Resultados da análise múltipla de regressão logística multinomial para o sexo masculino. Piracicaba, 2005

Tabela 23 - Número e porcentagem de adolescentes do sexo feminino, segundo características demográficas e de maturação sexual. Piracicaba, 2005

Tabela 24 - Número e porcentagem de adolescentes do sexo feminino, segundo características escolares. Piracicaba, 2005

Tabela 25 - Número e porcentagem de adolescentes do sexo feminino, segundo características de prática de atividade física/exercício. Piracicaba, 2005

Tabela 26 - Número e porcentagem de adolescentes do sexo feminino, segundo características de inatividade física. Piracicaba, 2005.

Tabela 27 - Estatística descritiva do consumo de energia e macronutrientes, segundo sexo feminino. Piracicaba, 2005.

Tabela 28 - Resultados da análise univariada de regressão logística multinomial para o sexo feminino. Piracicaba, 2005 
Tabela 29 - Resultados da análise múltipla de regressão logística multinomial para o sexo feminino. Piracicaba, 2005................................. 


\section{INTRODUÇÃO}

\subsection{ADOLESCÊNCIA}

De acordo com o critério cronológico estabelecido pela Organização Mundial de Saúde (OMS), a adolescência se caracteriza por dois períodos: a fase inicial, que compreende dos 10 aos 14 anos de idade e, fase final, entre 15 e 19 anos de idade (WHO, 1995).

Nessas fases, o adolescente passa por um processo de mudanças no qual ocorre seu desenvolvimento biológico e psicossocial (WHO, 1995).

No conjunto de manifestações biológicas há a transformação conhecida como puberdade. De acordo com MARSHALL E TANNER - apud POIT (2001), na puberdade se apresentam as fases de aceleração e desaceleração do esqueleto e de órgãos internos: o indivíduo adquire $50 \%$ do seu peso adulto, $20 \%$ da estatura final e $50 \%$ do esqueleto ósseo definitivo. Além disso, ocorre o desenvolvimento das gônadas, dos órgãos reprodutivos e o surgimento das características sexuais secundárias, bem como o desenvolvimento dos sistemas circulatório e respiratório.

Além das marcantes transformações biológicas, a adolescência é marcada pela transição psicossocial, que depende da vivência social e histórica do indivíduo e torna-se um divisor entre a infância e a vida adulta. Neste processo estão inseridos a aquisição da identidade, a sexualidade, o grupo de 
amigos, os valores, a experiência e a experimentação de novas condutas, relacionando o adolescente com o seu mundo, procurando este, definir-se por meio de suas atividade, suas aspirações e relações afetivas (OSÓRIO, 1992; MARTINS et al., 2003).

\subsection{PREVALÊNCIA DE SOBREPESO, OBESIDADE E DESNUTRIÇÃO EM ADOLESCENTES}

Estima-se que, em todo o mundo, 10\% dos jovens entre 5 e 17 anos de idade se encontram dentro dos índices de sobrepeso ou obesidade, ou seja, IMC $\geq$ percentil 85 e $\geq$ percentil 90, respectivamente (WHO \& IDF, 2005). O estudo realizado por JASSEN et al. (2005) com 137.593 jovens de 10 a 16 anos em diferentes países, mostra que há alta incidência de sobrepeso e obesidade nos países da América do Norte, oeste europeu e Grã-Bretanha.

A pesquisa de FONSECA e MATTOS (2005), na qual participaram 5697 adolescentes portugueses (10 a 17 anos de idade), mostrou que $14,4 \%$ da amostra estavam com sobrepeso e $1,6 \%$ eram obesos.

OGDEN et al. (2006) verificaram que, entre os adolescentes, houve aumento na prevalência de sobrepeso (IMC $\geq$ percentil 85$)$ e obesidade (IMC $\geq$ percentil 95) entre os anos de 1999 e 2004 nos Estados Unidos. Para estes adolescentes na faixa-etária de 12 a 19 anos, as prevalências, segundo o 
NHANES 1999-2000, 2001-2002 e 2003-2004, foram respectivamente, 30,0\%, $31,1 \%$ e 34,3 para sobrepeso, e de $14,8 \%, 16,7 \%$ e $17,4 \%$ para obesidade.

No Brasil, o índice de sobrepeso e obesidade, em crianças e adolescentes de 6 a 18 anos de idade, na década de 1970 era de 4\%, triplicando para 13\% no ano de 1997 (WHO e IDF, 2005). Segundo os dados da Pesquisa de Orçamentos Familiares (POF 2002-2003), publicados em 2006, a prevalência de sobrepeso foi de $12,3 \%$ e de obesidade $2,3 \%$ entre adolescentes de 10 a 19 anos.

FONSECA et al. (1998) analisaram 391 alunos com idades entre 15 e 17 anos, de uma escola de classe média em Niterói, Rio de Janeiro, e verificaram a prevalência de sobrepeso em $12,1 \%$ dos meninos e em $7,2 \%$ das meninas (valor do IMC igual ou superior ao percentil 85).

Na pesquisa realizada por RAMOS e FILHO (2003), com 1334 jovens de 11 a 18 anos de idade residentes no município de Bragança Paulista-SP, a prevalência encontrada foi de $7,3 \%$ para sobrepeso e 3,5\% para obesidade.

O estudo de SILVA et al. (2005), realizado com pré-escolares, escolares e adolescentes, mostra que $10,8 \%$ dos adolescentes apresentavam sobrepeso e $4,9 \%$ eram obesos.

Uma outra questão importante é que a desnutrição pode co-existir com o sobrepeso e a obesidade. Em estudo realizado em Istambul, Turquia, com 510 jovens entre 12 e 13 anos de idade, encontrou-se a prevalência de desnutrição 
de $15,3 \%$ da amostra, enquanto que $10,6 \%$ estava com sobrepeso e $1,6 \%$ era obesa (MANIOS et al., 2005).

No Brasil, uma pesquisa realizada por MONTEIRO et al. (2002) entre os anos de 1975 e 1997, nas regiões Nordeste e Sudeste, analisou a porcentagem de crianças desnutridas ao longo das décadas. Em 1975, 34\% das crianças eram desnutridas, passando para 18,2\% em 1989 e 11,4\% em 1996.

Os dados mais recentes mostram que, entre os adolescentes brasileiros de 10 a 19 anos, a prevalência de baixo peso é de 7,3\% (POF 2002-2003, 2006).

\subsection{FATORES ASSOCIADOS AO SOBREPESO, OBESIDADE E DESNUTRIÇÃO EM ADOLESCENTES}

O sobrepeso e a obesidade têm origens multifatoriais, com destaque para os fatores genéticos e ambientais (CHEN e DIETZ, 2002).

A questão genética contribui com, aproximadamente, 25 a $30 \%$ dos fatores associados à obesidade (MCARDLE et al., 1996). FRISANCHO (2000) descreve que crianças filhas de pais obesos são $80 \%$ mais suscetíveis a obesidade, enquanto que, nos filhos de pais eutróficos, esta porcentagem é de 9\%. TERRES et al. (2006) constataram, em uma pesquisa realizada em Pelotas-RS com adolescentes entre 15 e 18 anos, que filhos de pais obesos 
apresentam maior frequência de sobrepeso e obesidade em relação a filhos de pais eutróficos.

Outro fator a ser considerado é o hábito alimentar familiar. Na adolescência observa-se a preferência por refeições rápidas, compostas em sua maioria, por alimentos altamente calóricos como lanches e refrigerantes. DOILE e FELDMAN (1997) e STUBBS e LEE (2004) referem que está conduta é estimulada e introduzida na dieta dos adolescentes por meio das mães, parentes e amigos. Da mesma maneira, o comportamento sedentário dos pais influencia diretamente o nível de atividade física do adolescente (ORNELAS et al., 2007).

Relacionados ao excesso de peso corporal, estão, também, os fatores socioeconômicos. De acordo com POPKIN (2002a) um novo padrão de sociedade emerge mais industrializada e com maior renda per capita. Estudos em nações em desenvolvimento apontaram a elevada prevalência de obesidade nos extratos da população de maior renda e escolaridade e em áreas mais urbanizadas (WHO, 2000; POPKIN, 2002b; DRACHLER et al., 2003).

Ainda neste sentido, os dados da POF 2002-2003 (2006) mostram que no Brasil há um incremento médio de $4,1 \%$ na freqüência de obesidade, quando a renda salarial familiar está acima de cinco salários míninos. Este aumento, no entanto, é de apenas de $0,4 \%$ na prevalência de obesidade para extratos de menor renda (abaixo de cinco salários míninos). 
A mudança no padrão alimentar é outro aspecto que pode estar associado ao sobrepeso e obesidade. Atualmente, a grande disponibilidade e acessibilidade de alimentos excessivamente calóricos, como salgadinhos, refrigerantes e lanches, torna freqüente seu consumo entre os adolescentes (BIRCH et al., 2002).

Por outro lado, questões do tipo densidade energética, saciedade e palatabilidade dos alimentos podem ser presentes nas escolhas alimentares por parte dos jovens (WHO, 2000). Segundo SCHRAUWEN e WESTERTERP (2000) a alta palatabilidade e o baixo poder de saciedade dos alimentos ricos em lipídios promovem uma ingestão excessiva de energia. Outro aspecto levantado é o baixo poder oxidativo das gorduras, que promove assim, um balanço energético positivo, com acúmulo de gordura num curto período.

Na pesquisa de CROWE et al. (2004), também é descrito que alimentos ricos em gorduras tendem a ser mais densos energeticamente e podem promover um excesso de ingestão energética denominada passive overcomsuption. Já as dietas ricas em proteínas e carboidratos exercem maior saciedade e promovem a inibição da ingestão energética (ASTRUP, 1999).

Em estudo realizado no Brasil por LEVY-COSTA et al. (2005), com os dados obtidos da Pesquisa de Orçamento Familiar - POF (2002-2003), mostrou que o consumo de alimentos foi, em média, maior em residentes das zonas rurais do país $(2400 \mathrm{kcal})$ do que nas zonas urbanas (1700 kcal). Por outro lado, também foi observado que os alimentos excessivamente calóricos são 
consumidos em maior quantidade nas regiões urbanas e estão associados ao nível socioeconômico. Neste mesmo estudo, observou-se que as famílias de classes sociais mais altas ingeriam cinco vezes mais bebidas altamente calóricas, como os refrigerantes, do que estratos sociais de menor renda (LEVY-COSTA et al., 2005).

Outro fator associado ao sobrepeso e à obesidade é a inatividade física ou sedentarismo. Nota-se que, nas últimas décadas, o tempo livre para o lazer, cada vez mais é utilizado para assistir televisão e jogar video-game. Além disso, em países industrializados observa-se que atividades da vida diária e ocupacionais requerem menor dispêndio energético (ANDERSEN et al., 1998). Neste contexto, PRATT et al. (1999) e GORDON-LARSEN et al. (2000) citam como proxy de comportamento sedentário muitas horas assistindo televisão e/ou usando video-game. BIDDLE e SALLIS - apud HALLAL (2006) consideram como sedentária a pessoa que pratica menos de trezentos minutos por semana de atividade física no lazer ou de locomoção.

No estudo com adolescentes realizado por FONSECA et al. (1998), as horas diante da televisão e vídeo-game, em meninos, tiveram associação positiva com o aumento do IMC $(\beta=0,23 ; p=0,05)$.

JASSEN et al. (2005) descreveram a relação entre assistir televisão, declínio da atividade física e sobrepeso. FLEMING-MORAN e THIAGARAJAH (2005) também verificaram que assistir televisão por mais de duas horas ao dia 
e praticar atividade física menos de três vezes na semana, torna os adolescentes mais suscetíveis ao sobrepeso.

Com isso, a ingestão de alimentos ricos em lipídios e com alta densidade energética, associada a um estilo de vida sedentário, gera um desequilíbrio energético, quando o consumo excede o gasto (WHO, 2000).

Nos países em desenvolvimento, em que pesa o fato de estudos sobre os fatores associados ao sobrepeso e obesidade nos adolescentes ser de extrema importância, a transição nutricional e socioeconômica mostra a coexistência da desnutrição, sobrepeso e obesidade (DOAK et al., 2005). E a desnutrição, também pode estar relacionada a fatores socioeconômicos. De fato, SINGH et al. (1999) e CABALLERO (2001) relatam que a desnutrição ocorre, principalmente, em países menos desenvolvidos e em classes sociais de baixa renda, nas quais o acesso ao ensino e à alimentação é restrito e são altos os índices de doenças infecciosas. Dentro desses fatores se apresentam o baixo peso ao nascer, a carência protéico-calórica e a deficiência de macronutrientes (BAQUI e BLACK, 2002; MONTEIRO et al., 2002, MANARY e SOLOMONS, 2004).

Desta maneira, MONTEIRO et al. (2002) verificaram que moradores da região Nordeste que estão no quartil mais baixo de renda são os mais suscetíveis à presença de desnutrição.

Em estudo realizado no Senegal, com 80 garotas entre 13 e 15 anos de idade, constatou-se que as adolescentes encontravam-se mais desnutridas, 
com menor estatura e em estágios de maturação sexual atrasados em relação às meninas de mesma idade que viviam em países desenvolvidos. Ainda nesta pesquisa, porém comparando as adolescentes que residiam nas zonas rurais e urbanas, foi verificado que as meninas das regiões urbanas apresentavam 3,5 $\mathrm{kg}$ a mais de peso corporal, possuíam maior desenvolvimento muscular e eram mais ativas fisicamente (GARNIER e BÉNÉFICE, 2001).

SHI et al. (2005) relataram a presença de desnutrição, sobrepeso e obesidade associada a fatores socioeconômicos e geográficos em adolescentes chineses de 12 a 14 anos de idade. O nível de escolaridade paterno mostrou associação com o sobrepeso e a obesidade $(p=0,008)$, bem como famílias com menos de 3 pessoas $(p=0,015)$. Quanto às diferenças geográficas, o sobrepeso/obesidade foi maior em meninos moradores da zona urbana, do que residentes das zonas rurais (20,9\% e 14,5\%). A presença de desnutrição foi de $5,6 \%$ para o sexo feminino e $4,9 \%$ para o sexo masculino.

Outro fato já apresentado foi a co-existência de desnutrição e sobrepeso/obesidade dentro de um mesmo grupo familiar. DOAK et al. (2005) indicam que os fatores que contribuem para este fenômeno são as condições socioeconômicas nas quais há falhas no acesso aos cuidados à saúde e na disponibilidade e acesso a alimentos saudáveis. No estudo citado, a presença do sobrepeso/obesidade foi verificada em países como China e Indonésia e foram associados a famílias de baixa renda e residentes das zonas urbanas que recebem auxílio de profissionais da área de saúde. 


\section{JUSTIFICATIVA}

Em 2004, iniciou-se uma pesquisa na cidade de Piracicaba, interior de São Paulo, com adolescentes entre 10 e 14 anos de idade. Piracicaba é uma cidade com altos índices de renda, pois o IDH (Índice de Desenvolvimento Humano) de renda é de 0,795 e o de educação é 0,913. O seu PIB per capita anual é de R $\$ 12.905,82$ (IBGE, 2000). No entanto apresenta um contingente razoável de população de baixa renda. Segundo dados do Plano das Nações Unidas para o Desenvolvimento (PNUD, 2000) cerca de 44\% da população está no nível de pobreza e o grau de desigualdade encontra-se em $0,540(0,0=$ pior ;1,0 = melhor). Tal contraste pode refletir na co-existência de desnutrição, sobrepeso e obesidade.

Nota-se que os estudos com adolescentes são escassos no país, pois a mortalidade e a morbidade por doenças transmissíveis e não transmissíveis, na adolescência, são eventos de baixa incidência, tendo assim, menor visibilidade junto a área de Saúde. Todavia, a adolescência é o período no qual ocorrem as principais alterações entre a infância e a vida adulta, e o estado nutricional pode refletir as condições de saúde do indivíduo (BARBOSA, 1985).

$\mathrm{Na}$ revisão de literatura, não se encontrou estudo no Brasil que abrangesse a faixa etária estudada (10 a 14 anos de idade) e que identificassem os fatores associados, não só ao sobrepeso e obesidade, mas à desnutrição. 


\section{OBJETIVOS}

\subsection{OBJETIVO GERAL}

Estudar o estado nutricional de adolescentes de 10 a 14,9 anos matriculados na rede de ensino público, residentes em Piracicaba (SP).

\subsection{OBJETIVOS ESPECÍFICOS}

- Estimar as prevalências de desnutrição, sobrepeso e obesidade, segundo sexo;

- Analisar os fatores demográficos, de atividade física, de ingestão de energia e de macronutrientes associados à ocorrência de desnutrição, segundo sexo;

- Analisar os fatores demográficos, de atividade física, de ingestão de energia e de macronutrientes associados à ocorrência de sobrepeso e obesidade, segundo sexo. 


\section{MATERIAL E MÉTODOS}

\subsection{DELINEAMENTO DO ESTUDO}

Este é um estudo transversal que fez parte do segundo momento de uma coorte acompanhada na pesquisa "Consumo dietético e atividade física como determinantes das mudanças do índice de massa corporal de uma coorte de adolescentes matriculados na rede pública de ensino da cidade de Piracicaba, SP”. Esta pesquisa foi financiada pela Fundação de Amparo à Pesquisa do Estado de São Paulo (FAPESP) sob o protocolo 02/9521-9 e a aluna foi bolsista FAPESP (protocolo 05/57417-4).

\subsection{POPULAÇÃO E LOCAL DO ESTUDO}

Foram incluídos adolescentes residentes em Piracicaba de ambos os sexos, matriculados em escolas da rede pública de ensino da cidade de Piracicaba, com idade variando entre 10 e 14,9 anos. A coleta de dados foi realizada no período de fevereiro de 2005 a julho de 2006. 


\subsubsection{Tamanho da Amostra}

Segundo o último censo do IBGE (2000), o município de Piracicaba apresentava uma população de 329.158 habitantes, distribuídos de forma homogênea segundo sexo. Dispõe de 70 escolas da rede pública de ensino localizadas em sete regiões, incluindo duas de zona rural. De acordo com informações fornecidas pela Secretaria de Estado da Educação, encontravamse matriculados 40.550 alunos em Piracicaba no ano de 2003.

Para o cálculo da amostra, foram consideradas as seguintes informações: prevalência de sobrepeso em população semelhante (15\%), erro tipo I de $5 \%$ e de erro tipo II de $20 \%$ (LUDWIG et al., 2001).

O procedimento de amostragem foi do tipo aleatório simples, estratificado por séries $\left(1^{\mathrm{a}}\right.$ a $4^{\mathrm{a}}$ série e $5^{\mathrm{a}}$ a $8^{\mathrm{a}}$ série$)$, sendo realizada em duas etapas. $\mathrm{Na}$ primeira etapa, as unidades primárias de amostragem (UPA), que correspondem às escolas do município, foram ordenadas segundo as regiões. Foram sorteadas 11 escolas, considerando que dez estavam localizadas na zona urbana e uma na zona rural.

$\mathrm{Na}$ segunda etapa da amostragem, foram ordenadas as unidades secundárias de amostragem, que correspondem às classes (séries) das escolas. Em cada UPA, sortearam-se as classes por amostragem aleatória simples. De cada classe selecionada, realizou-se um sorteio de determinado número de alunos, dependendo do porte da escola. 
Considerando que seria esperado identificar alunos com idades entre 10 e 14 anos a partir da $4^{\mathrm{a}}$ série, foram sorteados, no total, 130 alunos de $4^{\mathrm{a}}$ série, 86 de $5^{a}$ série, 78 de $6^{a}$ série, 84 de $7^{a}$ série e 42 de $8^{a}$ série, totalizando 420 alunos.

Dos 420 alunos entrevistados na primeira fase, 303 participaram desta segunda etapa, tendo uma perda no seguimento da amostra de $27,8 \%$. Destes, 33 foram excluídos por estarem fora da faixa etária (10 a 14,9 anos) e um por pertencer a $4^{\mathrm{a}}$. série do ensino fundamental II. Com isso, a amostra deste estudo totalizou 269 escolares, 118 meninos (43,9\%) e 151 meninas $(56,1 \%)$.

\subsection{METODOLOGIA}

Após a identificação das 11 escolas foram encaminhadas cartas-convites aos diretores, expondo os objetivos da pesquisa. Todas as escolas manifestaram-se favoráveis quanto a participação no estudo.

Num primeiro momento, a equipe de pesquisadores se dirigia as escolas para fornecer explicações aos adolescentes sobre o motivo do estudo e entregar-Ihes um questionário contendo perguntas referentes às condições socioeconômicas e familiares e o termo de consentimento livre e esclarecido. Solicitou-se que ambos os documentos fossem preenchidos e assinados pelos pais ou responsável, e devolvidos à direção da escola. Após esta fase, foi 
agendado com a direção das escolas dois dias para serem realizadas as entrevistas.

No dia da entrevista, os pesquisadores se dirigiam até as classes sorteadas e convocavam os alunos que haviam devolvido o termo de consentimento livre e esclarecido assinado. Os participantes desta etapa, respondiam os questionários referentes às características demográficas (Anexo 1), consumo alimentar (Anexo 2), maturação sexual (Anexo 3) e atividade física (Anexo 4) e realizavam a aferição das medidas antropométricas. Essas entrevistas foram realizadas em espaço reservado, durante o horário de aula, com duração aproximada de 60 minutos. Cada entrevistador ficou responsável por um instrumento de coleta.

Os participantes foram entrevistados por alunos de graduação e profissionais de Nutrição e de Educação Física devidamente treinados.

\subsubsection{Consumo Alimentar}

A avaliação do consumo alimentar habitual foi realizada por meio da aplicação do Questionário de Freqüência Alimentar para Adolescentes (QFAA) (Anexo 2), validado por SLATER et al. (2003). Trata-se de um questionário de freqüência alimentar semi-quantitativo, contendo 94 alimentos e sete opções de freqüência de consumo: nunca, menos de uma vez ao mês, de 1 a 3 vezes no mês, 1 vez por semana, de 2 a 4 vezes por semana, 1 vez ao dia e 2 ou mais 
vezes ao dia. Para facilitar a obtenção de respostas dos entrevistados foi utilizado um material fotográfico elaborado para o estudo, apresentando diferentes utensílios comumente utilizados na alimentação, como pratos, copos e colheres.

$\mathrm{Na}$ análise dos dados foram excluídos os adolescentes com valores de consumo energético correspondentes a ingestões abaixo de 500 kcal e acima de 7000 kcal conforme recomendação de LUDWIG et al (2001). Para se obter o valor real dos carboidratos, lipídeos e proteínas foi realizado o cálculo de ajuste pela energia.

\subsubsection{Maturação Sexual}

As informações sobre maturação foram coletadas por meio dos desenhos propostos por Tanner (TANNER, 1962). Os alunos receberam uma cópia da figura que está no Anexo 3 e foram orientados a assinalarem aquela que mais se assemelhava à percepção que ele tem de si próprio. As características de maturação sexual secundárias foram avaliadas pelo desenvolvimento da genitália e da pilosidade pubiana para os meninos. Entre as meninas foi verificado o desenvolvimento das mamas e a pilosidade pubiana.

A classificação em impúberes e púberes adotada neste trabalho foi a proposta pela Organização Mundial da Saúde (WHO 1995) e que leva em 
consideração o desenvolvimento das mamas para o sexo feminino e da genitália para o sexo masculino, conforme apresentado no Quadro 1.

Quadro 1 - Classificação da maturação sexual para os estágios de Tanner (1962).

\begin{tabular}{|l|l|c|}
\hline SEXO & \multicolumn{1}{|c|}{ ESTÁGIO } & CLASSIFICAÇÃO \\
\hline \multirow{2}{*}{ Feminino } & Mamas estágio M1 & Impúberes \\
\cline { 2 - 3 } & Mamas estágio M2 a M5 & Púberes \\
\hline \hline \multirow{2}{*}{ Masculino } & Genitália estágios G1 & Impúberes \\
\cline { 2 - 3 } & Genitália estágios G2 a G5 & Púberes \\
\hline
\end{tabular}

Fonte: Adaptado de WHO (1995).

\subsubsection{Dados Antropométricos}

As medidas antropométricas foram obtidas por meio da aferição do peso $(\mathrm{kg})$ e da altura $(\mathrm{cm})$ dos adolescentes.

Para avaliação do peso corporal, os adolescentes utilizaram roupas leves e ficaram descalços, posicionados sobre uma balança eletrônica do tipo plataforma, da marca $\operatorname{Tanita}^{\circledR}$, com capacidade para $150 \mathrm{~kg}$ e sensibilidade de 100 gramas. 
Para a aferição da altura foi utilizado um estadiômetro da marca Seca ${ }^{\circledR}$, com escala em milímetros. O mesmo foi fixado em um suporte de madeira, confeccionado para o estudo com a finalidade de manter um ângulo reto entre o piso e a parede. Nesta medição, os indivíduos se mantiveram com os pés unidos, calcanhares encostados na parede, em postura ereta, com olhar fixo no horizonte, sem flectir ou estender a cabeça. O ápice da orelha e o canto externo do olho ficaram em linha paralela, formando um ângulo reto com a barra do estadiômetro. Em seguida, posicionou-se a barra horizontal do estadiômetro até mantê-la apoiada sobre a cabeça e foi efetuada a leitura da altura em centímetros.

O peso $(\mathrm{kg})$ e a altura $(\mathrm{cm})$ foram aferidos em duplicata, sendo adotado o valor médio das duas medidas para o cálculo do Índice de Massa Corporal (IMC). Este foi calculado como a relação entre o peso (em quilogramas) e o quadrado da altura (em metros).

IMC = PESO (kg)/ $\operatorname{ALTURA}^{2}(\mathrm{~m})$

O indice de massa corporal foi utilizado para classificar o estado nutricional dos adolescentes, de acordo com as recomendações da WHO (1995). Estas recomendações foram baseadas nas curvas de referência do National Center Health Statistics (CDC, 2000). 
Quadro 2 - Classificação do estado nutricional segundo percentis do Índice de Massa Corporal para adolescentes.

\begin{tabular}{|l|c|}
\hline PERCENTIL & CLASSIFICAÇÃO \\
\hline abaixo do percentil 5 & desnutrição \\
\hline entre os percentis 5 e 84,9 & eutrofia \\
\hline entre os percentis 85 e 94,9 & sobrepeso \\
\hline acima ou igual ao percentil 95 & obesidade \\
\hline
\end{tabular}

Fonte: Adaptado de WHO (1995)

\subsubsection{Atividade Física}

A atividade física foi avaliada por meio da aplicação do Questionário de Avaliação da Atividade Física para Adolescentes (QAFA) (Anexo 3), validado por FLORINDO et. al (2006). O questionário é formado por 28 questões, abertas e fechadas, divididas em três blocos. As perguntas fechadas são referentes a pratica ou não de atividade física e/ou exercício físico, e as perguntas abertas correspondem ao tipo de atividade, duração e freqüência. Compõem também o instrumento, questões sobre Educação Física Escolar, atividades de locomoção e praticas sedentárias composta por horas de televisão, uso de video-game e de computador. 
O valor total de minutos de atividade física foi calculado multiplicando-se, para cada uma das variáveis da atividade física e locomoção, o número de minutos por dia vezes a freqüência por semana. Com isso, obteve-se o total de minutos por semana que o adolescente praticava em cada atividade. Somandose os minutos de todas as atividades obteve-se o total de minutos de atividade física que cada adolescente praticava por semana (FLORINDO et al, 2006).

De acordo com PATE et al. (1998), considera-se que até 299 minutos por semana de atividade física o adolescente pode ser considerado sedentário e a partir de 300 minutos por semana de atividade física pode ser considerado ativo.

Também se avaliou a atividade física como categórica dicotômica (não pratica; pratica), e como tempo em minutos de atividade física e/ou exercício físico em minutos por dia, multiplicando-se o número de atividades físicas pela freqüência semanal, somando-se os três blocos e dividindo o valor pelos sete dias da semana. Assim, obtiveram-se os minutos por dia de pratica de atividade física e/ou exercício físico realizado pelo adolescente, categorizados em $<60$ minutos/dia e $\geq 60$ minutos/dia.

\subsubsection{Inatividade Física}

A inatividade física foi calculada pela soma das horas por dia assistidas de televisão e dividadas entre os sete dias da semana. Para classificar a 
variável, utilizou-se a recomendação da American Academy Pediatrics (2001), que limita o uso da televisão em até duas horas por dia.

As variáveis uso do video-game e do computador foram avaliadas como categóricas dicotômicas (sim; não).

\subsection{VARIÁVEIS DE ESTUDO}

\section{Variáveis dependentes}

$1^{\circ}$ Modelo: presença de desnutrição, considerada sim quando o adolescente estava abaixo do percentil 5 e eutrófico quando estava entre os percentis 5 e 84,9 .

$2^{\circ}$ Modelo: presença de sobrepeso e obesidade

Esta foi uma variável com três categorias assim definidas:

- Sobrepeso: entre os percentis 85 e 94,9;

- Obesidade: acima do percentil 95;

- Eutrófico: entre os percentis 5 e 84,9. 


\section{$\underline{\text { Variáveis independentes }}$}

- Demográficas: sexo: masculino; feminino;

Idade: 10 a 12 anos; 13,0 a 14,9 anos.

- Escolaridade: $5^{\mathrm{a}}$ a $6^{\mathrm{a}}$ série; $7^{\mathrm{a}}$ a $8^{\mathrm{a}}$ série;

- Período: manhã; tarde/noite;

- Maturação sexual: impúbere; púbere;

- Prática de atividade física e exercícios: não pratica; pratica;

- Escore de atividade física semanal: sedentário; ativo;

- Tempo em minutos por dia de prática de atividade física: < $60 \mathrm{~min} / \mathrm{dia} ; \geq$ $60 \mathrm{~min} / \mathrm{dia}$;

- Horas diante da televisão: até 2 horas/dia; igual ou acima de 2 horas/dia;

- Uso do video-game: não; sim;

- Uso do computador: não; sim;

- Consumo energético (kcal) em tercis: 1200,00 a 2500,99;

$$
\begin{aligned}
& 2501,00 \text { a } 3800,99 ; \\
& 3801,00 \text { a } 7000,00 .
\end{aligned}
$$

- Consumo de macronutrientes (g) em tercis:

Carboidrato: 330,00 a 467,99;

468,00 a 492,99;

493,00 a $685,00$.

Proteína: 52,00 a 98,99; 
99,00 a 111,99

112,00 a $188,00$.

Gordura: 49,00 a 117,99 ;

118,00 a 128,99

129,00 a $208,00$.

\subsection{ANÁLISE ESTATÍSTICA}

Na primeira etapa foi realizada a análise descritiva dos dados por meio das freqüências e porcentagens, e medidas de tendência central e dispersão, média, desvio-padrão, mediana, mínino e máximo.

Foram calculadas as prevalências de desnutrição, sobrepeso e obesidade e os respectivos intervalos de $95 \%$ de confiança.

Fórmula $\mathrm{IC}_{95 \%}$ para prevalência:

$$
\hat{p} \pm Z_{\alpha / 2} \sqrt{\frac{\hat{p}(1-\hat{p})}{n}}
$$

Fonte: Berquó et al. (1981)

Para avaliar a aderência das variáveis quantitativas à distribuição normal foi aplicado o teste de Komolgorov-Smirnov. 
Realizou-se a análise de regressão linear simples proposta por JAIME (2001), como ajuste das variáveis de consumo de macronutrientes, a fim de se retirar o efeito da energia.

Foi realizado o teste de diferenças de médias entre as variáveis quantitativas segundo sexo. Como os dados não haviam apresentado distribuição normal, utilizou-se o teste não-paramétrico de Mann-Whitney e para a análise de diferenças de três médias, utilizou-se o teste não-paramétrico Kruskal-Wallis.

A análise de associação entre os fatores demográficos, de escolaridade, de maturação sexual, atividade física e inatividade física foram feitas pelo teste de associação pelo qui-quadrado. Quando alguma casela apresentou valor igual a zero utilizou-se o teste de Fisher.

Foi feita a análise de regressão logística multinomial para verificar a associação das variáveis independentes com a ocorrência do sobrepeso e da obesidade.

\subsection{PROGRAMAS COMPUTACIONAIS UTILIZADOS}

- Epi Data versão 3.02 para Windows: digitação do banco de dados, exceto dados referentes ao consumo alimentar;

- Dietsys versão 4.01: digitação dos dados de consumo alimentar e cálculo da composição nutricional; 
- Epilnfo versão 6.04 para DOS: consistência do banco de dados;

- SPSS versão 12.0 para Windows: análise descritiva, teste de normalidade, teste de diferenças de médias e análise univariada e múltipla de regressão logística multinomial.

\subsection{CONSIDERAÇÕES ÉTICAS}

A pesquisa mãe foi aprovada pelo Comitê de Ética em Pesquisa da Faculdade de Saúde Pública da Universidade de São Paulo (Anexo 5) e este subprojeto também foi aprovado por esse comitê (Anexo 6). Foi também autorizada a sua realização pelo Dirigente Regional de Ensino de Piracicaba (Anexo 7).

Foi solicitada, aos pais ou responsáveis dos adolescentes, a assinatura do Termo de Consentimento Livre e Esclarecido (Anexo 8), sendo que somente participaram aqueles que apresentaram o referido documento assinado à equipe de pesquisa.

Não foi realizado nenhum procedimento invasivo e os adolescentes podiam deixar de participar do estudo em qualquer momento da realização do mesmo.

Os pesquisadores se comprometem a manter em sigilo toda informação recebida. 


\section{RESULTADOS}

\subsection{CARACTERIZAÇÃO DA AMOSTRA}

A população de estudo foi composta por 269 adolescentes de 10 a 14,9 anos de idade, sendo $118(43,9 \%)$ meninos e $151(56,1)$ meninas. As características demográficas e da maturação sexual estão apresentadas na Tabela 1.

Entre os meninos o ano escolar mais freqüente foi a $6^{a}$ série $(38 \%)$ seguido da $5^{\text {a }}$. série do ensino fundamental II e 50,8\% cursavam o período da manhã. A faixa-etária de 13 a 13,9 anos de idade apresentou o maior número de escolares (31,4\%) e 97,5\% dos adolescentes eram púberes (Tabela 1).

Nas meninas houve predomínio da $5^{a}$ série $(40,4 \%)$ do ensino fundamental II e $88 \%$ da amostra pertenciam ao período vespertino e noturno. As categorias de idade 10 a 11,9 anos e 12 a 12,9 anos representaram mais da metade das escolares $(58,3 \%)$ e apenas $4,6 \%$ das meninas eram pré-púberes (Tabela 1). A idade da menarca variou de 9,0 a 13,0 anos, com média de 11,7 anos $(d p=0,9)$ e mediana de 12,0 anos. 
Tabela 1 - Número e porcentagem de adolescentes, segundo sexo, características demográficas e maturação sexual. Piracicaba, 2005.

\begin{tabular}{|c|c|c|c|c|c|c|c|}
\hline \multirow[t]{2}{*}{ Variável } & \multirow[t]{2}{*}{ categoria } & \multicolumn{2}{|c|}{ masculino } & \multicolumn{2}{|c|}{ feminino } & \multicolumn{2}{|c|}{ total } \\
\hline & & $n^{0}$ & $\%$ & $n^{0}$ & $\%$ & $n^{0}$ & $\%$ \\
\hline ano & 5 & 33 & 28,0 & 61 & 40,4 & 94 & 34,9 \\
\hline \multirow[t]{3}{*}{ escolar } & 6 & 38 & 32,2 & 36 & 23,8 & 74 & 27,5 \\
\hline & 7 & 30 & 25,4 & 29 & 19,2 & 59 & 21,9 \\
\hline & 8 & 17 & 14,4 & 25 & 16,6 & 42 & 15,7 \\
\hline \multirow[t]{2}{*}{ período } & manhã & 60 & 50,8 & 63 & 41,7 & 123 & 45,7 \\
\hline & tarde/noite & 58 & 49,2 & 88 & 58,3 & 146 & 54,3 \\
\hline idade & 10 a 11,9 & 23 & 19,5 & 50 & 33,1 & 73 & 27,1 \\
\hline \multirow[t]{3}{*}{ (anos) } & 12 a 12,9 & 34 & 28,8 & 38 & 25,2 & 72 & 26,8 \\
\hline & 13 a 13,9 & 37 & 31,4 & 24 & 15,9 & 61 & 22,7 \\
\hline & 14 a 14,9 & 24 & 20,3 & 39 & 25,8 & 63 & 23,4 \\
\hline estágio & impúbere & 2 & 1,7 & 7 & 4,6 & 25 & 9,3 \\
\hline \multirow[t]{2}{*}{ puberal } & púbere & 115 & 97,5 & 144 & 95,4 & 243 & 90,3 \\
\hline & ignorado & 1 & 0,8 & -- & -- & 1 & 0,4 \\
\hline \multirow[t]{4}{*}{ menarca } & $\operatorname{sim}$ & -- & -- & 82 & 54,3 & 82 & 54,3 \\
\hline & não & -- & -- & 68 & 45,0 & 68 & 45,0 \\
\hline & ignorado & & & 1 & 0,7 & 1 & 0,7 \\
\hline & otal & 118 & 100,0 & 151 & 100,0 & 269 & $\overline{100,0}$ \\
\hline
\end{tabular}

Na Tabela 2 é observado o número e porcentagem de adolescentes segundo sexo e tipo de prática esportiva. Dos 269 escolares, 204 (75,8\%) 
praticavam uma modalidade esportiva. As práticas mais comuns para os escolares do sexo masculino foram o futebol $(64,4 \%)$, a natação $(7,6 \%)$ e o vôlei (5,9\%). Entre as meninas destaca-se o vôlei $(25,8 \%)$, futebol $(13,6 \%)$ e basquete $(7,3 \%)$. O deslocamento a pé ou de bicicleta para determinados lugares foi referido por $78,0 \%$ dos meninos e $74,2 \%$ das meninas.

Tabela 2 - Número e porcentagem de adolescentes, segundo sexo e tipo de prática esportiva. Piracicaba, 2005.

\begin{tabular}{|c|c|c|c|c|c|c|}
\hline \multirow[t]{2}{*}{ Tipo de prática } & \multicolumn{2}{|c|}{ masculino } & \multicolumn{2}{|c|}{ feminino } & \multicolumn{2}{|c|}{ total } \\
\hline & $n^{\circ}$ & $\%^{*}$ & $n^{\circ}$ & $\%^{* *}$ & $n^{\circ}$ & $\%^{* * \star}$ \\
\hline Futebol & 76 & 264,4 & 20 & 13,6 & 96 & 477,1 \\
\hline Vôlei & 7 & 5,9 & 39 & 25,8 & 46 & 22,5 \\
\hline Natação & 9 & 7,6 & 8 & 5,3 & 17 & 8,3 \\
\hline Basquete & 1 & 0,8 & 11 & 7,3 & 12 & 5,9 \\
\hline Handebol & 1 & 0,8 & -- & -- & 1 & 0,8 \\
\hline Bicicleta & 2 & 1,7 & 5 & 3,3 & 7 & 3,4 \\
\hline Skate & 1 & 0,8 & -- & -- & 1 & 0,8 \\
\hline Corrida & 2 & 1,7 & 3 & 2,0 & 5 & 2,5 \\
\hline Caminhada & -- & -- & 1 & 0,7 & 1 & 0,7 \\
\hline Danças & 1 & 0,8 & 4 & 2,7 & 4 & 2,0 \\
\hline Kung Fu & -- & -- & 1 & 0,7 & 1 & 0,7 \\
\hline Capoeira & -- & -- & 1 & 0,7 & 1 & 0,7 \\
\hline Musculação & 3 & 2,5 & 1 & 0,7 & 4 & 2,0 \\
\hline Caminhada & -- & -- & 1 & 0,7 & 1 & 0,7 \\
\hline Ginásticas & -- & -- & 4 & 2,7 & 4 & 2,7 \\
\hline Pula-cord/queim & -- & -- & 2 & 1,4 & 2 & 1,4 \\
\hline Loc a pé ou bic & 92 & 78,0 & 112 & 74,2 & 204 & 75,8 \\
\hline
\end{tabular}


As medidas de tendência central e de dispersão são mostradas nas Tabelas 3 (variáveis antropométricas e de estilo de vida) e 4 (variáveis de consumo).

Das medidas antropométricas, os meninos tiveram maior média para altura $(1,60 \mathrm{~cm} \times 1,50 \mathrm{~cm} ; \mathrm{p}=0,031)$. Também foram observadas maiores médias para escore semanal de atividade física $(696,1 \mathrm{~min} / \mathrm{dia} \times 358,9 \mathrm{~min} / \mathrm{dia}$; $p<0,001)$, uso médio de video-game em minutos por dia $(140,8 \mathrm{~min} / \mathrm{dia} \times 90,0$ $\min / \mathrm{dia} ; \mathrm{p}=0,002)$ e em vezes por semana $(4,43 \mathrm{vz} / \mathrm{sem} \times 2,9 \mathrm{vz} / \mathrm{sem} ; \mathrm{p}=$ $<0,001)$ (Tabela 3).

As médias de peso, horas diante da televisão nos dias da semana, horas diante da televisão nos finais de semana, minutos por dia no computador e vezes na semana em uso do computador foram semelhantes entre os meninos e as meninas (respectivamente, $p=0,113, p=0,956, p=0,413, p=966, p=$ 0,169). Na análise referente a Educação Física Escolar em minutos por semana as médias foram iguais para os sexos $(p=1,000)$ (Tabela 3$)$.

Em relação as variáveis de consumo, a média para ingestão de gordura foi superior entre as meninas $(126,4 \mathrm{~g} \times 120,2 \mathrm{~g} ; \mathrm{p}=0,029)$, enquanto que a ingestão de carboidrato foi maior entre os meninos $(487,7 \mathrm{~g} \times 477,8 \mathrm{~g}$; $\mathrm{p}=$ 0,046). As médias de energia e proteína foram semelhantes entre os grupos (respectivamente, $p=0,054, p=0,772$ ), destacando-se que a diferença nas médias de consumo de energia esteve próxima à significância estatística (Tabela 4). 
Tabela 3 - Estatística descritiva dos adolescentes, segundo as variáveis antropométricas e de estilo de vida. Piracicaba, 2005.

\begin{tabular}{|c|c|c|c|c|c|c|c|c|c|c|c|c|c|}
\hline \multirow[t]{2}{*}{ Variável } & \multicolumn{4}{|c|}{ masculino } & \multicolumn{4}{|c|}{ feminino } & \multirow{2}{*}{$\mathbf{p}$} & \multicolumn{4}{|c|}{ total } \\
\hline & $\mathrm{n}^{\circ}$ & média (dp) & mediana & min-max & $n^{\circ}$ & média (dp) & mediana & min-max & & $\mathrm{n}^{\circ}$ & media (dp) & mediana & min-max \\
\hline $\begin{array}{l}\text { Média peso } \\
\text { corporal (kg) }\end{array}$ & $\overline{c 118}$ & $52,1(16,2)$ & $\begin{array}{c}49,7 \\
\end{array}$ & $27,7-142,0$ & 151 & "48,4 (11,7) & $\begin{array}{c}48,1 \\
\end{array}$ & $28,4-92,3$ & 0,133 & 269 & $50,03(13,94)$ & $4=48,40$ & $27,70-142,00$ \\
\hline $\begin{array}{l}\text { Média da altura } \\
(\mathrm{cm})\end{array}$ & 118 & $1,6(0,1)$ & 1,6 & $1,3-1,9$ & 151 & $1,5(0,1)$ & 1,5 & $1,3-1,8$ & 0,031 & 269 & $1,55(0,09)$ & 1,54 & $1,34-1,86$ \\
\hline $\begin{array}{l}\text { EFEscolar } \\
\mathrm{min} / \mathrm{sem}\end{array}$ & 113 & $100,0(0,0)$ & 100,0 & $100,0-100,0$ & 143 & $100,0(0,0)$ & 100,0 & $100,0-100,0$ & 1,000 & 256 & $100,00(0,00)$ & 100,00 & 100,00 \\
\hline $\begin{array}{l}\text { EFEscolar } \\
\text { aulas/sem }\end{array}$ & 113 & $2,0(0,0)$ & 2,0 & $2,0-2,0$ & 143 & $2,0(0,0)$ & 2,0 & $2,0-2,0$ & 1,000 & 256 & $2,00(0,00)$ & 2,00 & 2,00 \\
\hline $\begin{array}{l}\text { EFEscolar } \\
\mathrm{min} / \mathrm{dia}\end{array}$ & 113 & $50,0(0,0)$ & 50,0 & $50,0-50,0$ & 143 & $50,0(0,0)$ & 50,0 & $50,0-50,0$ & 1,000 & 256 & $50,00(0,00)$ & 50,00 & 50,00 \\
\hline $\begin{array}{l}\text { Escore semanal } \\
\mathrm{AF}\end{array}$ & 118 & $696,1(675,4)$ & 542,5 & $0,0-3780,0$ & 151 & $358,9(330,2)$ & 300,0 & $0,0-1620$ & $<0,001$ & 269 & $506,78(536,90)$ & 385,00 & $0,00-3780,00$ \\
\hline $\begin{array}{l}\text { Televisão } \\
\text { h/dia/sem }\end{array}$ & 118 & $3,4(2,2)$ & 3,0 & $0,0-13,0$ & 151 & $3,4(2,3)$ & 3,0 & $0,0-12,0$ & 0,956 & 269 & $3,40(2,28)$ & 3,00 & $0,00-13,00$ \\
\hline $\begin{array}{l}\text { Televisão } \\
\text { h/fim/sem }\end{array}$ & 118 & $5,3(4,3)$ & 4,0 & $0,0-20,0$ & 151 & $5,5(5,6)$ & 4,0 & $0,0-30,0$ & 0,413 & 269 & $5,37(5,10)$ & 4,00 & $0,00-30,00$ \\
\hline $\begin{array}{l}\text { Vídeo-game } \\
\mathrm{min} / \text { dia }\end{array}$ & 79 & $140,8(98,8)$ & 120,0 & $20,0-420,0$ & 47 & $90,0(71,0)$ & 60,0 & $20,0-360,0$ & 0,002 & 126 & $121,83(92,48)$ & 105,00 & $20,00-420,00$ \\
\hline $\begin{array}{l}\text { Video-game } \\
\text { vez/sem }\end{array}$ & 79 & $4,43(2,2)$ & 4,0 & $1,0-7,0$ & 47 & $2,9(2,2)$ & 2,0 & $1,0-7,0$ & $<0,001$ & 126 & $3,87(2,28)$ & 3,87 & $1-7$ \\
\hline $\begin{array}{l}\text { Computador } \\
\mathrm{min} / \text { dia }\end{array}$ & 45 & $132,22(102,6)$ & 120,0 & $0,0-480$ & 54 & $148,0(164,1)$ & 90,0 & $30,0-900,0$ & 0,966 & 99 & $140,81(139,10)$ & 120,00 & $10,00-900,00$ \\
\hline $\begin{array}{l}\text { Computador } \\
\text { vez/sem }\end{array}$ & 45 & $3,51(2,2)$ & 2,0 & $1,0-7,0$ & 54 & $2,8(1,7)$ & 2,0 & $1,0-7,0$ & 0,169 & 99 & $3,13(1,94)$ & 2,00 & $1-7$ \\
\hline
\end{tabular}

EF - Educação Física; AF - Atividade Física; TV - Televisão. 
Tabela 4 - Estatística descritiva dos adolescentes, segundo variáveis de consumo. Piracicaba, 2005.

\begin{tabular}{|c|c|c|c|c|c|c|c|c|c|c|c|c|c|}
\hline \multirow[t]{2}{*}{ Variável } & \multicolumn{4}{|c|}{ masculino } & \multicolumn{4}{|c|}{ feminino } & \multirow{2}{*}{$\mathbf{p}$} & \multicolumn{4}{|c|}{ total } \\
\hline & $\mathbf{N}^{\circ}$ & média (dp) & mediana & $\min -\max$ & $\mathbf{N}^{\circ}$ & média (dp) & mediana & $\min -\max$ & & $\mathbf{N}^{\circ}$ & media (dp) & mediana & $\min -\max$ \\
\hline $\begin{array}{l}\text { Consumo } \\
\text { energia(kcal) }\end{array}$ & 112 & $3225,9(1395,8)$ & 2859,4 & $1297,5-6946,7$ & 145 & $3477,5(1290,8)$ & 3253,2 & $1211,2-6862,6$ & 0,054 & 257 & $3367,9(1340,7)$ & 3101,9 & $121211,2-6946,7$ \\
\hline $\begin{array}{l}\text { Consumo } \\
\text { proteína(kg) }\end{array}$ & 112 & $106,4(17,7)$ & 106,0 & $53,5-151,9$ & 145 & $107,3(21,8)$ & 104,9 & $52,6-187,4$ & 0,772 & 257 & $106,9(20,1)$ & 105,5 & $52,6-187,4$ \\
\hline $\begin{array}{l}\text { Consumo } \\
\text { gordura(kg) }\end{array}$ & 112 & $120,2(18,7)$ & 120,8 & "49,9-168,8 & 145 & $126,4(18,0)$ & 125,2 & $75,1-207,6$ & 0,029 & 257 & $123,7(18,5)$ & 123,9 & $499,9-207,6$ \\
\hline $\begin{array}{l}\text { Consumo } \\
\text { carboidra(kg) }\end{array}$ & 112 & $487,7(49,6)$ & 483,2 & $343,8-684,1$ & 145 & $473,6(45,4)$ & 477,8 & $338,7-602,1$ & 0,046 & 257 & $479,7(47,7)$ & 479,7 & $338,7-684,1$ \\
\hline
\end{tabular}




\subsection{O ESTADO NUTRICIONAL}

O gráfico 1 apresenta a prevalência média e os intervalos de confiança de adolescentes conforme sexo e estado nutricional.

Gráfico 1 - Prevalências e os respectivos intervalos de 95\% de confiança, segundo sexo e estado nutricional. Piracicaba, 2005.

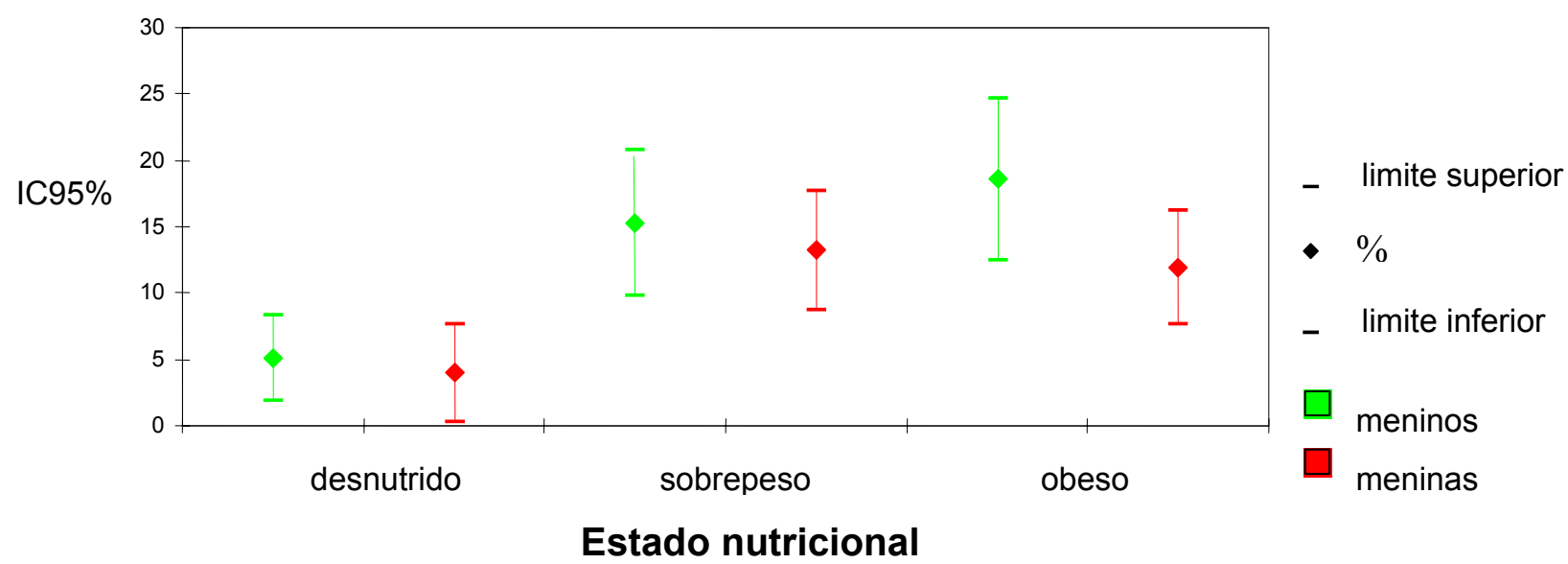

Observa-se que as prevalências de desnutrição entre meninos e meninas foram semelhantes (respectivamente, $5,1 \%$ e $4,0 \%$ ), o mesmo ocorrendo em relação ao sobrepeso (respectivamente, $15,3 \%$ e 13,2). Quanto a obesidade, maior prevalência foi encontrada entre os meninos (respectivamente, 18,6\% e 11,9\%) (Tabela 5). 
Tabela 5 - Prevalência $(P)$ e os respectivos intervalos de $95 \%$ de confiança de adolescentes, segundo sexo e estado nutricional. Piracicaba, 2005.

\begin{tabular}{lcccccc}
\hline \multirow{2}{*}{$\begin{array}{l}\text { Estado } \\
\text { nutricional }\end{array}$} & \multicolumn{2}{c}{ masculino } & \multicolumn{2}{c}{ feminino } & \multicolumn{2}{c}{ total } \\
\cline { 2 - 7 } & $\mathbf{P}$ & {$\left[\mathbf{I C}_{95 \%}\right]$} & $\mathbf{P}$ & {$\left[\mathbf{I \mathbf { C } _ { 9 5 \% } ]}\right.$} & $\mathbf{P}$ & {$\left[\mathbf{I C}_{95 \%}\right]$} \\
\hline \hline desnutrido & 5,1 & {$[1,92 ; 8,28]$} & 4,0 & {$[0,32 ; 7,68]$} & 4,5 & {$[2,43 ; 6,57]$} \\
sobrepeso & 15,3 & {$[9,79 ; 20,81]$} & 13,2 & {$[8,67 ; 17,73]$} & 14,1 & {$[10,44 ; 17,76]$} \\
obeso & 18,6 & {$[12,52 ; 24,68]$} & 11,9 & {$[7,61 ; 16,19]$} & 14,9 & {$[11,14 ; 18,66]$} \\
\hline
\end{tabular}

\subsection{FATORES ASSOCIADOS A DESNUTRIÇÃO}

\subsubsection{Fatores Associados a Desnutrição para o Sexo Masculino}

Na Tabela 6 é apresentada a relação entre características demográficas e de maturação sexual com a presença de desnutrição nos escolares do sexo masculino. Houve diferença estatisticamente significativa na proporção de desnutridos, segundo faixa etária. Verificou-se uma proporção maior de desnutridos na faixa etária de 13,0 a 14,9 anos, quando comparadas com a faixa etária de 10,0 a 12,9 anos (respectivamente 14,3\% x 0,0\%; $p=0,028$ ). Não houve diferença significativa entre os impúberes e os púberes na porcentagem de desnutrição $(p=1,000)$. 
Tabela 6 - Número e porcentagem de adolescentes do sexo masculino, segundo características demográficas e de maturação sexual. Piracicaba, 2005.

\begin{tabular}{|c|c|c|c|c|}
\hline \multirow[t]{2}{*}{ Variável } & \multirow[t]{2}{*}{ categoria } & \multicolumn{2}{|c|}{ Estado nutricional } & \multirow[b]{2}{*}{$\mathbf{p}$} \\
\hline & & $\begin{array}{c}\text { desnutrido } \\
\text { n (\%) }\end{array}$ & $\begin{array}{c}\text { eutrófico } \\
\text { n (\%) }\end{array}$ & \\
\hline \multirow[t]{2}{*}{ idade (anos) } & 10,0 a 12,9 & $0(0,0)$ & $36(100,0)$ & 0,028 \\
\hline & 13,0 a 14,9 & $6(14,3)$ & $36(85,7)$ & \\
\hline \multirow[t]{2}{*}{ estágio puberal } & impúbere & $0(0,0)$ & $2(100,0)$ & 1,000 \\
\hline & púbere & $6(7,9)$ & $70(92,1)$ & \\
\hline \multicolumn{2}{|c|}{ Total } & $6(7,7)$ & $72(92,3)$ & \\
\hline
\end{tabular}

O ano escolar $(p=0,642)$ e período $(p=0,166)$, não apresentaram associação estatisticamente significativa com a presença de desnutrição (Tabela 7).

Não houve associação significativa para nenhuma das variáveis de atividade física e exercício físico com a presença de desnutrição (Tabela 8). 
Tabela 7 - Número e porcentagem de adolescentes do sexo masculino, segundo e características escolares. Piracicaba, 2005.

\begin{tabular}{|c|c|c|c|c|}
\hline \multirow[t]{2}{*}{ Variável } & \multirow[t]{2}{*}{ categoria } & \multicolumn{2}{|c|}{ Estado nutricional } & \multirow[b]{2}{*}{$\mathbf{p}$} \\
\hline & & $\begin{array}{c}\text { desnutrido } \\
\text { n (\%) }\end{array}$ & $\begin{array}{c}\text { eutrófico } \\
\text { n (\%) }\end{array}$ & \\
\hline ano escolar & $5^{\mathrm{a}}$ a $6^{\mathrm{a}}$ & $3(6,5)$ & $403(93,5)$ & 0,642 \\
\hline (séries) & $7^{\mathrm{a}}$ a $8^{\mathrm{a}}$ & $3(9,4)$ & $29(90,6)$ & \\
\hline \multirow[t]{2}{*}{ período } & manhã & $1(2,9)$ & $33(97,1)$ & 0,166 \\
\hline & tarde/noite & $5(11,4)$ & $39(88,6)$ & \\
\hline \multicolumn{2}{|c|}{ Total } & $6(7,7)$ & $72(92,3)$ & \\
\hline
\end{tabular}

Tabela 8 - Número e porcentagem de adolescentes do sexo masculino, segundo características de prática de atividade física e exercício físico. Piracicaba, 2005.

\begin{tabular}{|c|c|c|c|c|}
\hline \multirow[t]{2}{*}{ Variável } & \multirow[t]{2}{*}{ categoria } & \multicolumn{2}{|c|}{ Estado nutricional } & \multirow[b]{2}{*}{$\mathbf{p}$} \\
\hline & & $\begin{array}{c}\text { desnutrido } \\
\text { n (\%) }\end{array}$ & $\begin{array}{c}\text { eutrófico } \\
n(\%)\end{array}$ & \\
\hline $\begin{array}{l}\text { prática de } \\
\text { AF/exercícios }\end{array}$ & $\begin{array}{l}\text { não pratica } \\
\text { pratica }\end{array}$ & $\begin{array}{l}0(0,0) \\
6(9,0)\end{array}$ & $\begin{array}{c}11(100,0) \\
61(91,0)\end{array}$ & 0,586 \\
\hline $\begin{array}{l}\text { tempo } \mathrm{min} / \mathrm{dia} \\
\text { pratica AF/exercic }\end{array}$ & $\begin{array}{l}<60 \mathrm{~min} / \mathrm{dia} \\
\geq 60 \mathrm{~min} / \mathrm{dia}\end{array}$ & $\begin{array}{l}0(0,0) \\
6(9,4)\end{array}$ & $\begin{array}{c}14(100,0) \\
58(90,6)\end{array}$ & 0,584 \\
\hline $\begin{array}{l}\text { escore AF } \\
\text { semanal }\end{array}$ & $\begin{array}{l}\text { sedentário } \\
\text { ativo }\end{array}$ & $\begin{array}{l}0(0,0) \\
6(8,2)\end{array}$ & $\begin{array}{l}5(100,0) \\
67(91,8)\end{array}$ & 1,000 \\
\hline \multicolumn{2}{|c|}{ Total } & $6(7,7)$ & $72(92,3)$ & \\
\hline
\end{tabular}


Não houve associação significativa entre a variável horas diante da televisão por dia e uso do computador com a presença de desnutrição (respectivamente, $p=0,493, p=0,454)$. Destaca-se que o uso de video-game que ficou no limite da significância estatística $(p=0,059)$ (Tabela 9).

Tabela 9 - Número e porcentagem de adolescentes do sexo masculino, segundo características de inatividade física. Piracicaba, 2005.

\begin{tabular}{llccc}
\hline Variável & categoria & \multicolumn{2}{c}{ Estado nutricional } & \multirow{2}{*}{ p } \\
\cline { 3 - 4 } & & desnutrido & eutrófico & \\
\hline horas diante & até 2 h/dia & $1(14,3)$ & $6(85,7)$ & 0,493 \\
da TV por dia & $\geq 2$ h/dia & $5(7,0)$ & $66(93,0)$ & \\
uso de & sim & $2(3,8)$ & $51(96,2)$ & 0,059 \\
vídeo-game & não & $4(16,0)$ & $21(84,0)$ & \\
usa o & sim & $3(10,7)$ & $25(89,3)$ & 0,454 \\
computador & não & $3(6,0)$ & $47(94,0)$ & \\
& & & & \\
\hline
\end{tabular}

Observa-se, na Tabela 10, que as médias de consumo de energia ( $p=$ $0,096)$, carboidrato $(p=0,118)$, proteína $(p=0,143)$ e gordura $(p=0,185)$ não apresentaram diferença estatisticamente significativa com a presença de desnutrição. 
Não foi feita a análise múltipla, pois havia somente seis meninos com desnutrição.

Tabela 10 - Estatística descritiva do consumo de energia e macronutrientes, segundo sexo masculino. Piracicaba, 2005.

\begin{tabular}{lccc}
\hline Variável & \multicolumn{2}{c}{ Estado nutricional } & p \\
\cline { 2 - 3 } & $\begin{array}{l}\text { desnutrido } \\
\text { média (dp) }\end{array}$ & $\begin{array}{c}\text { eutrófico } \\
\text { média (dp) }\end{array}$ & 0,096 \\
\hline \hline Energia (kcal) & $2221,7(426,3)$ & $3392,6(1532,2)$ & 0,118 \\
Carboidrato (g) & $462,7(35,82)$ & $493,4(54,0)$ & 0,143 \\
Proteína (g) & $113,6(9,8)$ & $104,1(18,0)$ & \\
Gordura $(\mathrm{g})$ & $128,1(13,6)$ & $117,9(20,1)$ & 0,185 \\
\hline
\end{tabular}

\subsubsection{Fatores Associados a Desnutrição para o Sexo Feminino}

Para o sexo feminino foi verificada a associação entre a presença de desnutrição e estágio puberal. Houve uma proporção maior de desnutridos nas meninas impúberes em relação às púberes (respectivamente, $28,6 \% \times 3,8 \%$, $p=0,005)$ e a menarca ficou no limiar significativo $(p=0,056)$. Apenas a idade 
não mostrou associação significativa com a presença de desnutrição $(p=0,486)$ (Tabela 11).

$\mathrm{Na}$ Tabela 12 , verifica-se que tanto o ano escolar $(p=0,544)$ quanto o período $(p=0,218)$, não tiveram associação significativa com a presença de desnutrição.

Tabela 11 - Número e porcentagem de adolescentes do sexo feminino, segundo características demográficas e de maturação sexual. Piracicaba, 2005.

\begin{tabular}{llccc}
\hline Variável & categoria & \multicolumn{2}{c}{ Estado nutricional } & \multirow{2}{*}{$\mathbf{p}$} \\
\cline { 3 - 4 } & & desnutrido & eutrófico & \\
\hline idade (anos) & 10,0 a 12,9 & $4(6,0)$ & $63(94,0)$ & 0,706 \\
& 13,0 a 14,9 & $2(4,3)$ & $44(95,7)$ & \\
estágio puberal & impúbere & $2(28,6)$ & $5(71,4)$ & 0,005 \\
& púbere & $4(3,8)$ & $102(96,2)$ & \\
menarca & & & & \\
& sim & $1(1,6)$ & $60(98,4)$ & 0,056 \\
& não & $5(9,8)$ & $46(90,2)$ & \\
\hline & & & & \\
\hline
\end{tabular}

Para as variáveis prática de atividade física e exercício físico $(p=0,300)$, tempo em minutos por dia de prática de atividade física $(p=0,634)$ e escore de atividade física semanal $(p=0,589)$, não foram encontradas diferenças 
estatisticamente significativas relacionadas a ocorrência de desnutrição (Tabela 13).

Tabela 12 - Número e porcentagem de adolescentes do sexo feminino, segundo características escolares. Piracicaba, 2005.

\begin{tabular}{llccc}
\hline Variável & categoria & \multicolumn{2}{c}{ Estado nutricional } & \\
\cline { 3 - 4 } & & desnutrido & eutrófico & p \\
& & $\mathbf{n}(\%)$ & $\mathbf{n ~ ( \% )}$ & \\
\hline \hline $\begin{array}{l}\text { ano escolar } \\
\text { (séries) }\end{array}$ & $5^{\mathrm{a}}$ a $6^{\mathrm{a}}$ & $4(5,5)$ & $69(94,5)$ & 0,913 \\
& $7^{\mathrm{a}}$ a $8^{\mathrm{a}}$ & $2(5,0)$ & $38(95,0)$ & \\
período & & & & \\
& manhã & $1(2,2)$ & $45(97,8)$ & 0,218 \\
& tarde/noite & $5(7,5)$ & $62(92,5)$ & \\
& & & & \\
\hline
\end{tabular}


Tabela 13 - Número e porcentagem de adolescentes do sexo feminino, segundo características de prática de atividade física e exercício físico. Piracicaba, 2005.

\begin{tabular}{llccc}
\hline Variável & categoria & \multicolumn{2}{c}{ Estado nutricional } & \\
\cline { 3 - 4 } & & $\begin{array}{c}\text { desnutrido } \\
\mathbf{n}(\%)\end{array}$ & $\mathbf{p}$ \\
& & $3(8,6)$ & $32(91,4)$ & 0,300 \\
\hline \hline prática de & não pratica & $3(3,8)$ & $75(96,2)$ & \\
AF/exercícios & pratica & & & \\
tempo min/dia & $<60$ min/dia & $3(6,5)$ & $43(93,5)$ & 0,634 \\
pratica AF/exercic & $\geq 60$ min/dia & $3(4,5)$ & $64(95,5)$ & \\
& & & & \\
escore AF & sedentário & $0(0,0)$ & $17(100,0)$ & 0,589 \\
semanal & ativo & $6(6,2)$ & $90(93,8)$ & \\
& & & & \\
\hline
\end{tabular}

Observa-se, na Tabela 14, que a variável horas diante da televisão por dia possui associação estatisticamente significativa com a presença de desnutrição. Uma proporção maior de desnutridos foi verificada entre as adolescentes que assistem até duas horas de televisão por dia (respectivamente, $16,7 \% \times 3,2 \%, p=0,019)$.

Em relação ao uso de video-game $(p=0,250)$ e computador $(p=0,950)$, não foram encontradas diferenças estatisticamente significativas com a presença de desnutrição (Tabela 14). 
Tabela 14 - Número e porcentagem de adolescentes do sexo feminino, segundo características de inatividade física. Piracicaba, 2005.

\begin{tabular}{llccc}
\hline Variável & categoria & \multicolumn{2}{c}{ Estado nutricional } & \multirow{2}{*}{ p } \\
\cline { 3 - 4 } & & desnutrido & eutrófico & \\
\hline horas diante & até 2 h/dia & $3(16,7)$ & $15(83,3)$ & 0,019 \\
da TV por dia & $\geq 2$ h/dia & $3(3,2)$ & $92(96,8)$ & \\
uso de & & & & \\
video-game & sim & $3(9,2)$ & $30(90,8)$ & 0,250 \\
não & $3(3,7)$ & $77(96,3)$ & \\
usa o & & & & \\
computador & sim & $2(5,1)$ & $37(94,9)$ & 0,950 \\
& não & $4(5,4)$ & $70(94,6)$ & \\
\hline
\end{tabular}

Não houve diferença estatisticamente significativa entre as médias de consumo de energia, carboidrato, proteína e gordura com a presença de desnutrição (respectivamente, $p=0,171 ; p=0,883 ; p=0,601 ; p=0,376)$ (Tabela 15).

Não foi feita a análise múltipla, pois havia somente seis meninas com desnutrição. 
Tabela 15 - Estatística descritiva do consumo de energia e macronutrientes, segundo sexo feminino. Piracicaba, 2005.

\begin{tabular}{lccc}
\hline Variável & \multicolumn{2}{c}{ Estado nutricional } & p \\
\cline { 2 - 3 } & $\begin{array}{l}\text { desnutrido } \\
\text { média (dp) }\end{array}$ & $\begin{array}{c}\text { eutrófico } \\
\text { média (dp) }\end{array}$ & \\
\hline \hline Energia (kcal) & $3946,4(1022,0)$ & $3395,5(1359,4)$ & 0,171 \\
Carboidrato (g) & $472,4(60,5)$ & $475,3(42,9)$ & 0,883 \\
Proteína (g) & $110,8(18,5)$ & $106,6(21,0)$ & 0,601 \\
Gordura (g) & $124,3(26,6)$ & $126,6(17,9)$ & 0,376 \\
\hline
\end{tabular}

\subsection{FATORES ASSOCIADOS AO SOBREPESO E A OBESIDADE}

5.4.1 Fatores Associados ao Sobrepeso e a Obesidade para o Sexo Masculino

$\mathrm{Na}$ análise realizada para os escolares do sexo masculino não foram encontradas associações significativas da ocorrência de sobrepeso e obesidade e faixa etária $(p=0,633)$ ou estágio puberal $(p=0,350)$ relacionadas (Tabela 16). 
Tabela 16 - Número e porcentagem de adolescentes do sexo masculino, segundo características demográficas e de maturação sexual. Piracicaba, 2005.

\begin{tabular}{|c|c|c|c|c|c|}
\hline \multirow[t]{3}{*}{ Variável } & \multirow[t]{3}{*}{ Categoria } & \multicolumn{3}{|c|}{ Estado nutricional } & \multirow{3}{*}{ p } \\
\hline & & eutrófico & sobrepeso & obeso & \\
\hline & & n (\%) & n (\%) & n (\%) & \\
\hline \multirow[t]{2}{*}{ idade (anos) } & 10,0 a 12,9 & $36(63,2)$ & $8(14,0)$ & $13(22,8)$ & 0,633 \\
\hline & 13,0 a 14,9 & $36(65,5)$ & $10(18,2)$ & $9(16,3)$ & \\
\hline \multirow[t]{2}{*}{ estágio puberal* } & impúbere & $2(100,0)$ & $0(0,0)$ & $0(0,0)$ & 0,576 \\
\hline & púbere & $70(64,2)$ & $17(15,6)$ & $22(20,2)$ & \\
\hline \multicolumn{2}{|c|}{ Total } & $72(64,9)$ & $18(15,3)$ & $22(19,8)$ & \\
\hline
\end{tabular}

* há um valor ignorado no estado nutricional sobrepeso

Não houve associação estatisticamente significativa com a presença de sobrepeso e obesidade e as variáveis ano escolar $(p=0,852)$ e período $(p=$ 0,136) (Tabela 17).

As variáveis prática de atividade física e exercício físico, tempo em minutos de pratica de atividade física e escore de atividade física semanal, não mostraram associação significativa com a presença de sobrepeso e obesidade (respectivamente, $p=0,722, p=0,630, p=0,906)$ (Tabela 18).

Na Tabela 19, as variáveis horas diante da televisão por dia $(p=0,643)$, uso de video-game $(p=0,235)$ e uso do computador $(p=0,655)$, não apresentaram associação estatisticamente significativa com a presença de sobrepeso e obesidade. 
Tabela 17 - Número e porcentagem de adolescentes do sexo masculino, segundo características escolares. Piracicaba, 2005.

\begin{tabular}{|c|c|c|c|c|c|}
\hline \multirow[t]{3}{*}{ Variável } & \multirow[t]{3}{*}{ Categoria } & \multicolumn{3}{|c|}{ Estado nutricional } & \multirow{3}{*}{$\mathbf{p}$} \\
\hline & & eutrófico & sobrepeso & obeso & \\
\hline & & n (\%) & n (\%) & n (\%) & \\
\hline ano escolar & $5^{a}$ a $6^{a}$ & $43(63,3)$ & $12(17,6)$ & $13(19,1)$ & 0,852 \\
\hline (séries) & $7^{a}$ a $8^{a}$ & $29(65,9)$ & $6(13,6)$ & $9(20,5)$ & \\
\hline \multirow[t]{2}{*}{ período } & manhã & $33(55,9)$ & $11(18,7)$ & $15(25,4)$ & 0,136 \\
\hline & tarde/noite & $39(73,6)$ & $7(13,2)$ & $7(13,2)$ & \\
\hline \multicolumn{2}{|c|}{ Total } & $72(64,9)$ & $18(15,3)$ & $22(19,8)$ & \\
\hline
\end{tabular}

Tabela 18 - Número e porcentagem de adolescentes do sexo masculino, segundo características de prática de atividade física e exercício físico. Piracicaba, 2005.

\begin{tabular}{|c|c|c|c|c|c|}
\hline \multirow[t]{2}{*}{ Variável } & \multirow[t]{2}{*}{ Categoria } & \multicolumn{3}{|c|}{ Estado nutricional } & \multirow[b]{2}{*}{$\mathbf{p}$} \\
\hline & & $\frac{\text { eutrófico }}{\mathrm{N}(\%)}$ & $\begin{array}{c}\text { sobrepeso } \\
\mathbf{N}(\%)\end{array}$ & $\begin{array}{c}\text { obeso } \\
\mathrm{N}(\%)\end{array}$ & \\
\hline $\begin{array}{l}\text { prática de } \\
\text { AF/exercícios }\end{array}$ & $\begin{array}{l}\text { não pratica } \\
\text { pratica }\end{array}$ & $\begin{array}{l}11(73,4) \\
61(62,9)\end{array}$ & $\begin{array}{c}2(13,3) \\
16(16,5)\end{array}$ & $\begin{array}{c}2(13,3) \\
20(20,6)\end{array}$ & 0,722 \\
\hline $\begin{array}{l}\text { tempo } \mathrm{min} / \mathrm{dia} \\
\text { pratica AF/exercic }\end{array}$ & $\begin{array}{l}<60 \mathrm{~min} / \mathrm{dia} \\
\geq 60 \mathrm{~min} / \mathrm{dia}\end{array}$ & $\begin{array}{l}14(73,7) \\
58(62,4)\end{array}$ & $\begin{array}{c}2(10,5) \\
16(17,2)\end{array}$ & $\begin{array}{c}3(15,8) \\
19(20,4)\end{array}$ & 0,630 \\
\hline $\begin{array}{l}\text { escore AF } \\
\text { semanal }\end{array}$ & $\begin{array}{l}\text { sedentário } \\
\text { ativo }\end{array}$ & $\begin{array}{c}5(62,5) \\
67(64,5)\end{array}$ & $\begin{array}{c}1(12,5) \\
17(16,3)\end{array}$ & $\begin{array}{c}2(25,0) \\
20(19,2)\end{array}$ & 0,906 \\
\hline \multicolumn{2}{|c|}{ Total } & $72(64,9)$ & $18(15,3)$ & $22(19,8)$ & \\
\hline
\end{tabular}


Tabela 19 - Número e porcentagem de adolescentes do sexo masculino, segundo características de inatividade física. Piracicaba, 2005.

\begin{tabular}{llcccc}
\hline Variável & Categoria & \multicolumn{3}{c}{ Estado nutricional } & \\
& & eutrófico & sobrepeso & obeso & p \\
\cline { 3 - 5 } & & $\mathbf{n ~ ( \% )}$ & $\mathbf{n ~ ( \% )}$ & $\mathbf{n ~ ( \% )}$ & \\
\hline \hline horas diante & até 2 h/dia & $6(60,0)$ & $1(10,0)$ & $3(30,0)$ & 0,643 \\
da TV por dia & $\geq 2$ h/dia & $66(64,7)$ & $17(16,7)$ & $19(18,6)$ & \\
uso de & sim & $51(66,2)$ & $14(18,2)$ & $12(15,6)$ & 0,235 \\
video-game & não & $21(60,0)$ & $4(11,4)$ & $10(28,6)$ & \\
usa o & sim & $25(59,5)$ & $7(16,7)$ & $10(23,8)$ & 0,655 \\
computador & não & $47(67,2)$ & $11(15,7)$ & $12(17,1)$ & \\
& & & & & \\
\hline
\end{tabular}

A Tabela 20 mostra que não houve diferença estatisticamente significativa entre as médias dos macronutrientes e a presença de sobrepeso e obesidade. 
Tabela 20 - Estatística descritiva do consumo de energia e macronutrientes, segundo sexo masculino. Piracicaba, 2005.

\begin{tabular}{lcccc}
\hline Variável & \multicolumn{3}{c}{ Estado nutricional } & \\
& eutrófico & sobrepeso & obeso & p \\
\cline { 2 - 4 } & média (dp) & média (dp) & média (dp) & \\
\hline \hline Energia (kcal) & $3392,6(1532,2)$ & $3196,8(1375,9)$ & $2997,0(967,1)$ & 0,807 \\
Carboidrato (g) & $493,4(54,0)$ & $475,9(47,3)$ & $485,8(36,3)$ & 0,512 \\
Proteína (g) & $104,1(18,0)$ & $114,3(20,9)$ & $105,4(13,8)$ & 0,215 \\
& & & & \\
Gordura (g) & $117,9(20,1)$ & $122,9(19,1)$ & $123,0(14,2)$ & 0,419 \\
& & & & \\
\hline
\end{tabular}


Na Tabela 21 são apresentadas as odds ratio (OR's) e os respectivos intervalos de 95\% de confiança da análise univariada de regressão logística multinomial para o sexo masculino. A variável consumo de energia (kcal/dia) foi a única que apresentou associação estatisticamente significativa com a ocorrência de obesidade $(\mathrm{OR}=5,40)$. Por apresentar caselas igual a zero para o sobrepeso e obesidade, a regressão logística multinomial univariada não foi realizada na variável estágio puberal.

$\mathrm{Na}$ análise múltipla esse efeito permaneceu independente da idade e tempo em minutos por dia de prática de atividade física $\left(\mathrm{OR}_{\mathrm{ajustada}}=6,74\right)$. Meninos que consomem entre 2501,00 a 3800,99 kcal de energia possuem uma chance maior de apresentarem obesidade em relação aos que consomem entre 1200,00 a 2500,99 kcal. Todas as demais variáveis não apresentaram associação significativa com a presença do sobrepeso e obesidade (Tabela 22). 
Tabela 21 - Resultados da análise univariada de regressão logística multinomial para o sexo masculino. Piracicaba, 2005.

\begin{tabular}{|c|c|c|c|}
\hline Variável & categoria & $\begin{array}{ll} & \text { sobrepeso } \\
\text { OR }^{*}(\text { IC95\%) }\end{array}$ & $\begin{array}{cc} & \text { obeso } \\
\text { OR }^{*} & \text { (IC95\%) }\end{array}$ \\
\hline idade (anos) & $\begin{array}{l}10,0 \text { a } 12,9 \\
13,0 \text { a } 14,9\end{array}$ & $\begin{array}{l}0,80(0,28 ; 2,26) \\
1.0\end{array}$ & $\begin{array}{l}1,44(0,55 ; 3,80) \\
1.0\end{array}$ \\
\hline $\begin{array}{l}\text { ano escolar } \\
\text { (séries) }\end{array}$ & $\begin{array}{l}5^{\mathrm{a}} \text { a } 6^{\mathrm{a}} \\
7^{\mathrm{a}} \text { a } 8^{\mathrm{a}}\end{array}$ & $\begin{array}{l}1,35(0,46 ; 4,00) \\
1.0\end{array}$ & $\begin{array}{l}0,97(0,37 ; 2,57) \\
1.0\end{array}$ \\
\hline período & $\begin{array}{l}\text { manhã } \\
\text { tarde/noite }\end{array}$ & $\begin{array}{l}1,86(0,65 ; 5,33) \\
1.0\end{array}$ & $\begin{array}{l}2,53(0,92 ; 6,95) \\
1.0\end{array}$ \\
\hline $\begin{array}{l}\text { prática de } \\
\text { AF/exercícios }\end{array}$ & $\begin{array}{l}\text { não pratica } \\
\text { pratica }\end{array}$ & $\begin{array}{l}0,69(0,14 ; 3,45) \\
1.0\end{array}$ & $\begin{array}{l}0,56(0,11 ; 2,72) \\
1.0\end{array}$ \\
\hline $\begin{array}{l}\text { tempo min/dia } \\
\text { pratica AF/exercic }\end{array}$ & $\begin{array}{l}<60 \mathrm{~min} / \mathrm{dia} \\
\geq 60 \mathrm{~min} / \mathrm{dia}\end{array}$ & $\begin{array}{l}0,52(0,11 ; 2,52) \\
1.0\end{array}$ & $\begin{array}{l}0,65(0,17 ; 2,52) \\
1.0\end{array}$ \\
\hline escore AF semanal & $\begin{array}{l}\text { sedentário } \\
\text { ativo }\end{array}$ & $\begin{array}{l}0,79(0,09 ; 7,20) \\
1.0\end{array}$ & $\begin{array}{l}1,34(0,24 ; 7,44) \\
1.0\end{array}$ \\
\hline $\begin{array}{l}\text { horas diante } \\
\text { da TV por dia }\end{array}$ & $\begin{array}{l}\text { até } 2 \mathrm{~h} / \mathrm{dia} \\
\geq 2 \mathrm{~h} / \mathrm{dia}\end{array}$ & $\begin{array}{l}0,65(0,07 ; 5,74) \\
1.0\end{array}$ & $\begin{array}{l}1,74(0,40 ; 7,61) \\
1.0\end{array}$ \\
\hline uso de video-game & $\begin{array}{l}\text { não } \\
\text { sim }\end{array}$ & $\begin{array}{l}0,69(0,20 ; 2,36) \\
1.0\end{array}$ & $\begin{array}{l}2,02(0,76 ; 5,40) \\
1.0\end{array}$ \\
\hline uso do computador & $\begin{array}{l}\text { não } \\
\text { sim }\end{array}$ & $\begin{array}{l}0,84(0,29 ; 2,42) \\
1.0\end{array}$ & $\begin{array}{l}0,64(0,24 ; 1,68) \\
1.0\end{array}$ \\
\hline $\begin{array}{l}\text { consumo de } \\
\text { energia (kcal) } \\
\text { (tercil) }\end{array}$ & $\begin{array}{l}1200,00 \text { a } 2500,99 \\
2501,00 \text { a } 3800,99 \\
3801,00 \text { a } 7000,00\end{array}$ & $\begin{array}{l}1,39(0,42 ; 4,54) \\
0,90(0,20 ; 4,13) \\
1.0\end{array}$ & $\begin{array}{l}3,12(0,76 ; 12,80) \\
5,40(1,27 ; 23,05) \\
1.0\end{array}$ \\
\hline $\begin{array}{l}\text { consumo de } \\
\text { carboidrato (g) } \\
\text { (tercil) }\end{array}$ & $\begin{array}{l}330,00 \text { a } 467,99 \\
468,00 \text { a } 492,99 \\
493,00 \text { a } 685,00\end{array}$ & $\begin{array}{l}2,18(0,62 ; 7,66) \\
0,75(0,19 ; 2,95) \\
1.0\end{array}$ & $\begin{array}{l}1,24(0,30 ; 5,11) \\
2,05(0,66 ; 6,37) \\
1.0\end{array}$ \\
\hline $\begin{array}{l}\text { consumo de } \\
\text { proteína }(\mathrm{g}) \\
\text { (tercil) }\end{array}$ & $\begin{array}{l}52,00 \text { a } 98,99 \\
99,00 \text { a } 111,99 \\
112,00 \text { a } 188,00\end{array}$ & $\begin{array}{l}0,49(0,13 ; 1,95) \\
0,60(0,18 ; 2,08) \\
1.0\end{array}$ & $\begin{array}{l}1,15(0,34 ; 3,92) \\
0,82(0,24 ; 2,83) \\
1.0\end{array}$ \\
\hline $\begin{array}{l}\text { consumo de } \\
\text { gordura }(\mathrm{g}) \\
\text { (tercil) }\end{array}$ & $\begin{array}{l}49,00 \text { a } 117,99 \\
118,00 \text { a } 128,99 \\
129,00 \text { a } 208,00\end{array}$ & $\begin{array}{l}0,58(0,16 ; 2,11) \\
0,46(0,12 ; 1,78) \\
1.0\end{array}$ & $\begin{array}{l}0,41(0,11 ; 1,53) \\
0,71(0,22 ; 2,31) \\
1.0\end{array}$ \\
\hline
\end{tabular}


Tabela 22 - Resultados da análise múltipla de regressão logística multinomial para o sexo masculino. Piracicaba, 2005.

\begin{tabular}{|c|c|c|c|}
\hline \multirow[t]{2}{*}{ Variável } & \multirow[t]{2}{*}{ categoria } & sobrepeso & obeso \\
\hline & & OR* $^{*} \quad($ IC95\%) & OR $^{*} \quad($ IC95\%) \\
\hline consumo de & 1200,00 a 2500,99 & $1,37(0,40 ; 4,65)$ & $3,62(0,85 ; 15,39)$ \\
\hline energia (kcal/dia) & 2501,00 a 3800,99 & $0,96(0,20 ; 4,63)$ & $6,74(1,50 ; 30,20)$ \\
\hline (tercil) & 3801,00 a 7000,00 & 1.0 & 1.0 \\
\hline \multirow[t]{2}{*}{ idade (anos) } & 10,0 a 12,9 & $1,00(0,33 ; 3,03)$ & $2,01(0,70 ; 5,72)$ \\
\hline & 13,0 a 14,9 & 1.0 & 1.0 \\
\hline tempo $\mathrm{min} / \mathrm{dia}$ & $<60 \mathrm{~min} / \mathrm{dia}$ & $0,25(0,03 ; 2,03)$ & $0,60(0,14 ; 2,49)$ \\
\hline pratica AF/exercic & $\geq 60 \mathrm{~min} / \mathrm{dia}$ & 1.0 & 1.0 \\
\hline
\end{tabular}

OR*: eutrófico é categoria de referência.

5.4.2 Fatores associados ao Sobrepeso e a Obesidade para o Sexo Feminino

Verifica-se, Tabela 23, que não houve associação estatisticamente significativa na proporção de adolescentes com sobrepeso e obesidade, segundo faixa etária, estágio puberal e menarca (respectivamente, $p=0,927, p=$ $0,399, p=0,871)$. 
Tabela 23 - Número e porcentagem de adolescentes do sexo feminino, segundo características demográficas e de maturação sexual. Piracicaba, 2005.

\begin{tabular}{|c|c|c|c|c|c|}
\hline \multirow[t]{3}{*}{ Variável } & \multirow[t]{3}{*}{ Categoria } & \multicolumn{3}{|c|}{ Estado nutricional } & \multirow{3}{*}{$\mathbf{p}$} \\
\hline & & eutrófico & sobrepeso & obeso & \\
\hline & & n (\%) & n (\%) & n (\%) & \\
\hline \multirow[t]{2}{*}{ idade (anos) } & 10,0 a 12,9 & $63(75,0)$ & $11(13,1)$ & $10(11,9)$ & 0,927 \\
\hline & 13,0 a 14,9 & $44(72,1)$ & $9(14,8)$ & $8(13,1)$ & \\
\hline \multirow[t]{2}{*}{ estágio puberal* } & impúbere & $5(100,0)$ & $0(0,0)$ & $0(0,0)$ & 0,399 \\
\hline & púbere & $102(72,9)$ & $20(14,3)$ & $18(12,8)$ & \\
\hline \multirow[t]{2}{*}{ menarca } & $\operatorname{sim}$ & $60(74,1)$ & $12(14,8)$ & $9(11,1)$ & 0,871 \\
\hline & não & $46(73,0)$ & $8(12,7)$ & $9(14,3)$ & \\
\hline \multicolumn{2}{|c|}{ Total } & $107(73,8)$ & $20(13,8)$ & $18(12,4)$ & \\
\hline
\end{tabular}

* há um valor ignorado no estado nutricional sobrepeso.

Referente aos dados sobre as características escolares, ano escolar $(p=$ $0,537$ ) e período ( $p=0,791)$, não houve associação significativa com a presença de sobrepeso e obesidade (Tabela 24). 
Tabela 24 - Número e porcentagem de adolescentes do sexo feminino, segundo características escolares. Piracicaba, 2005.

\begin{tabular}{|c|c|c|c|c|c|}
\hline \multirow[t]{3}{*}{ Variável } & \multirow[t]{3}{*}{ Categoria } & \multicolumn{3}{|c|}{ Estado nutricional } & \multirow{3}{*}{$\mathbf{p}$} \\
\hline & & eutrófico & sobrepeso & obeso & \\
\hline & & n (\%) & n (\%) & n (\%) & \\
\hline \multirow[t]{2}{*}{ ano escolar } & $5^{a}$ a $6^{a}$ & $69(74,2)$ & $11(11,8)$ & $13(14,0)$ & 0,537 \\
\hline & $7^{a}$ a $8^{a}$ & $38(73,1)$ & $9(17,3)$ & $5(9,6)$ & \\
\hline \multirow[t]{2}{*}{ período } & manhã & $45(72,6)$ & $8(12,9)$ & $9(14,5)$ & 0,791 \\
\hline & tarde/noite & $62(74,7)$ & $12(14,5)$ & $9(10,8)$ & \\
\hline \multicolumn{2}{|c|}{ Total } & $107(73,8)$ & $20(13,8)$ & $18(12,4)$ & \\
\hline
\end{tabular}

$\mathrm{Na}$ Tabela 25 os resultados indicam não haver associação significativa entre a presença de sobrepeso e obesidade com as variáveis independentes, pratica de atividade física e exercício físico $(p=0,459)$, tempo em minutos por dia de pratica de atividade física $(p=0,576)$ e escore semanal de atividade física $(p=0,757)$. 
Tabela 25 - Número e porcentagem de adolescentes do sexo feminino, segundo características de prática de atividade física e exercício físico. Piracicaba, 2005.

\begin{tabular}{llcccc}
\hline Variável & Categoria & \multicolumn{3}{c}{ Estado nutricional } & \\
& & eutrófico & sobrepeso & obeso & p \\
\cline { 3 - 5 } & & $\mathbf{n ~ ( \% )}$ & $\mathbf{n ~ ( \% )}$ & $\mathbf{n ~ ( \% )}$ & \\
\hline \hline prática de & não pratica & $32(68,1)$ & $7(14,9)$ & $8(17,0)$ & 0,459 \\
AF/exercícios & pratica & $75(76,5)$ & $13(13,3)$ & $10(10,2)$ & \\
& & & & & \\
tempo min/dia & $<60$ min/dia & $43(69,4)$ & $10(16,1)$ & $9(14,5)$ & 0,576 \\
pratica AF/exercic & $\geq 60$ min/dia & $64(77,1)$ & $10(12,0)$ & $9(10,9)$ & \\
& & & & & \\
escore AF semanal & sedentário & $17(68,0)$ & $4(16,0)$ & $4(16,0)$ & 0,757 \\
& ativo & $90(75,0)$ & $16(13,3)$ & $14(11,7)$ & \\
\hline \multicolumn{7}{c}{ Total } & & & & \\
\hline
\end{tabular}

Em relação as características de inatividade física, houve diferença estatisticamente significativa na proporção de sobrepeso e obesidade, segundo a variável horas diante da televisão por dia $(p=0,034)$. A categoria assistir TV por mais de duas horas ao dia obteve uma proporção maior de adolescentes com sobrepeso quando comparada a categoria assistir TV até duas horas por dia (respectivamente, $14,2 \% \times 12,0 \%$ ), enquanto que, entre os obesos foi de $28 \% \times 9,1 \%$. O uso de video-game $(p=0,541)$ e o uso de computador $(p=$ 
0,862) não apresentaram associação estatisticamente significativa com a presença de sobrepeso e obesidade (Tabela 26).

Tabela 26 - Número e porcentagem de adolescentes do sexo feminino, segundo características de inatividade física. Piracicaba, 2005.

\begin{tabular}{|c|c|c|c|c|c|}
\hline \multirow[t]{3}{*}{ Variável } & \multirow[t]{3}{*}{ Categoria } & \multicolumn{3}{|c|}{ Estado nutricional } & \multirow{3}{*}{$\mathbf{p}$} \\
\hline & & eutrófico & sobrepeso & obeso & \\
\hline & & n (\%) & n (\%) & n (\%) & \\
\hline horas diante & até $2 \mathrm{hr} / \mathrm{dia}$ & $15(60,0)$ & $3(12,0)$ & $7(28,0)$ & \multirow[t]{2}{*}{0,034} \\
\hline da TV por dia & $\geq 2 \mathrm{hr} / \mathrm{dia}$ & $92(76,7)$ & $17(14,2)$ & $11(9,1)$ & \\
\hline uso de & $\operatorname{sim}$ & $30(68,2)$ & $8(18,2)$ & $6(13,6)$ & \multirow[t]{2}{*}{0,541} \\
\hline vídeo-game & não & $77(76,2)$ & $12(11,9)$ & $12(11,9)$ & \\
\hline usa o & $\operatorname{sim}$ & $37(71,2)$ & $8(15,4)$ & $7(13,4)$ & \multirow[t]{2}{*}{0,862} \\
\hline computador & não & $70(75,3)$ & $12(12,9)$ & $11(11,8)$ & \\
\hline \multicolumn{2}{|c|}{ Total } & $107(73,8)$ & $20(13,8)$ & $18(12,4)$ & \\
\hline
\end{tabular}

Verifica-se, na Tabela 27, que não houve diferença significativa entre as médias de consumo de energia $(p=0,257)$, carboidrato $(p=0,395)$, proteína $(p=$ $0,282)$ e gordura $(p=0,899)$ com a ocorrência de sobrepeso e obesidade. 
Tabela 27 - Estatística descritiva do consumo de energia e macronutrientes, segundo sexo feminino. Piracicaba, 2005.

\begin{tabular}{lcccc}
\hline Variável & \multicolumn{3}{c}{ Estado nutricional } & \\
& eutrófico & sobrepeso & obeso & p \\
\cline { 2 - 4 } & média (dp) & média (dp) & média (dp) & \\
\hline \hline Energia (kcal) & $3395,5(1359,4)$ & $3796,1(1061,2)$ & $3449,2(1184,4)$ & 0,257 \\
Carboidrato (g) & $475,3(42,9)$ & $464,0(49,7)$ & $474,2(52,0)$ & 0,395 \\
Proteína (g) & $106,6(21,0)$ & $114,3(25,3)$ & $102,5(22,7)$ & 0,282 \\
& & & & \\
Gordura (g) & $126,6(17,9)$ & $126,5(16,2)$ & $125,9(18,5)$ & 0,899 \\
& & & & \\
\hline
\end{tabular}


Na Tabela 28 são apresentados os resultados da regressão logística multinomial univariada. Observa-se que apenas a variável horas diante de televisão por dia apresentou associação significativa, assistir até duas horas de TV por dia pode ser fator de risco para obesidade $(\mathrm{OR}=3,90)$. As demais variáveis não apresentaram associação estatisticamente significativa com a presença de sobrepeso e obesidade. Por existir caselas com o valor igual a zero para sobrepeso e obesidade, a regressão logística multinomial não foi realizada para a variável estágio puberal (Tabela 28).

$\mathrm{Na}$ análise múltipla a variável horas diante da televisão por dia permaneceu significativa $\left(\mathrm{OR}_{\mathrm{ajustada}}=5,39\right)$ em relação aos obesos e o consumo de energia tanto para o sobrepeso quanto para a obesidade ficaram no limite da significância ( $p=0,059 ; p=0,051$, respectivamente) ajustados pelo total de minutos por dia praticados de atividade física e exercício físico (Tabela 29). 
Tabela 28 - Resultados da análise univariada de regressão logística multinomial para o sexo feminino. Piracicaba, 2005.

\begin{tabular}{|c|c|c|c|}
\hline Variável & categoria & $\begin{array}{ll} & \text { sobrepeso } \\
\text { OR }^{*} \quad\left(I C_{95 \%}\right)\end{array}$ & $\begin{array}{cc}\text { obeso } \\
\text { OR }^{*} \quad\left(\mathrm{IC}_{95 \%}\right)\end{array}$ \\
\hline idade (anos) & $\begin{array}{l}10,0 \text { a } 12,9 \\
13,0 \text { a } 14,9\end{array}$ & $\begin{array}{l}0,85(0,33 ; 2,23) \\
1.0\end{array}$ & $\begin{array}{l}0,87(0,32 ; 2,39) \\
1.0\end{array}$ \\
\hline menarca & $\begin{array}{l}\text { sim } \\
\text { não }\end{array}$ & $\begin{array}{l}1,15(0,43 ; 3,04) \\
1.0\end{array}$ & $\begin{array}{l}0,77(0,28 ; 2,10) \\
1.0\end{array}$ \\
\hline ano escolar & $\begin{array}{l}5^{a} \text { a } 6^{a} \\
7^{a} \text { a } 8^{a}\end{array}$ & $\begin{array}{l}0,67(0,26 ; 1,77) \\
1.0\end{array}$ & $\begin{array}{l}1,43(0,47 ; 4,32) \\
1.0\end{array}$ \\
\hline período & $\begin{array}{l}\text { manhã } \\
\text { tarde/noite }\end{array}$ & $\begin{array}{l}0,92(0,35 ; 2,43) \\
1.0\end{array}$ & $\begin{array}{l}1,38(0,51 ; 3,75) \\
1.0\end{array}$ \\
\hline $\begin{array}{l}\text { prática de } \\
\text { AF/exercícios }\end{array}$ & $\begin{array}{l}\text { não pratica } \\
\text { pratica }\end{array}$ & $\begin{array}{l}1,26(0,46 ; 3,46) \\
1.0\end{array}$ & $\begin{array}{l}1,88(0,68 ; 5,19) \\
1.0\end{array}$ \\
\hline $\begin{array}{l}\text { tempo } \mathrm{min} / \text { dia } \\
\text { pratica AF/exercic }\end{array}$ & $\begin{array}{l}<60 \mathrm{~min} / \mathrm{dia} \\
\geq 60 \mathrm{~min} / \mathrm{dia}\end{array}$ & $\begin{array}{l}1,49(0,57 ; 3,88) \\
1.0\end{array}$ & $\begin{array}{l}1,49(0,55 ; 4,05) \\
1.0\end{array}$ \\
\hline escore AF semanal & $\begin{array}{l}\text { sedentário } \\
\text { ativo }\end{array}$ & $\begin{array}{l}1,32(0,39 ; 4,45) \\
1.0\end{array}$ & $\begin{array}{l}1,51(0,44 ; 5,16) \\
1.0\end{array}$ \\
\hline $\begin{array}{l}\text { horas diante } \\
\text { da TV por dia }\end{array}$ & $\begin{array}{l}\text { até } 2 \mathrm{~h} / \mathrm{dia} \\
\geq 2 \mathrm{~h} / \mathrm{dia}\end{array}$ & $\begin{array}{l}1,08(0,28 ; 4,15) \\
1.0\end{array}$ & $\begin{array}{l}3,90(1,31 ; 11,65) \\
1.0\end{array}$ \\
\hline uso de video-game & $\begin{array}{l}\text { não } \\
\text { sim }\end{array}$ & $\begin{array}{l}0,58(0,22 ; 1,57) \\
1.0\end{array}$ & $\begin{array}{l}0,78(0,27 ; 2,27) \\
1.0\end{array}$ \\
\hline uso do computador & $\begin{array}{l}\text { não } \\
\text { sim }\end{array}$ & $\begin{array}{l}0,79(0,30 ; 2,11) \\
1.0\end{array}$ & $\begin{array}{l}0,83(0,30 ; 2,32) \\
1.0\end{array}$ \\
\hline $\begin{array}{l}\text { consumo de } \\
\text { energia (kcal) } \\
\text { continuação }\end{array}$ & $\begin{array}{l}1200 \text { a } 2500,99 \\
2501,00 \text { a } 3800,99\end{array}$ & $\begin{array}{l}0,22(0,04 ; 1,08) \\
0,55(0,19 ; 1,60)\end{array}$ & $\begin{array}{l}0,60(0,18 ; 2,07) \\
0,39(0,12 ; 1,31)\end{array}$ \\
\hline (tercil) & 3801,00 a 7000,00 & 1.0 & 1.0 \\
\hline $\begin{array}{l}\text { consumo de } \\
\text { carboidrato (g) } \\
\text { (tercil) }\end{array}$ & $\begin{array}{l}330,00 \text { a } 467,99 \\
468,00 \text { a } 492,99 \\
493,00 \text { a } 685,00\end{array}$ & $\begin{array}{l}2,13(0,66 ; 6,85) \\
0,48(0,11 ; 2,15) \\
1.0\end{array}$ & $\begin{array}{l}1,29(0,40 ; 4,15) \\
0,53(0,14 ; 2,05) \\
1.0\end{array}$ \\
\hline $\begin{array}{l}\text { consumo de } \\
\text { proteína (g) } \\
\text { (tercil) }\end{array}$ & $\begin{array}{l}52,00 \text { a } 98,99 \\
99,00 \text { a } 111,99 \\
112,00 \text { a } 188,00\end{array}$ & $\begin{array}{l}0,42(013 ; 1,40) \\
0,46(0,14 ; 1,53) \\
1.0\end{array}$ & $\begin{array}{l}0,89(0,27 ; 2,94) \\
0,69(0,19 ; 2,50) \\
1.0\end{array}$ \\
\hline $\begin{array}{l}\text { consumo de } \\
\text { gordura }(\mathrm{g}) \\
\text { (tercil) }\end{array}$ & $\begin{array}{l}49,00 \text { a } 117,99 \\
118,00 \text { a } 128,99 \\
129,00 \text { a } 208,00\end{array}$ & $\begin{array}{l}0,89(0,26 ; 3,02) \\
0,88(0,28 ; 2,80) \\
1.0\end{array}$ & $\begin{array}{l}1,67(0,51 ; 5,49) \\
0,98(0,28 ; 3,50) \\
1.0\end{array}$ \\
\hline
\end{tabular}


Tabela 29 - Resultados da análise múltipla de regressão logística multinomial para o sexo feminino. Piracicaba, 2005.

\begin{tabular}{|c|c|c|c|}
\hline \multirow[t]{2}{*}{ Variável } & \multirow[t]{2}{*}{ categoria } & sobrepeso & obeso \\
\hline & & OR* $^{*}$ (IC95\%) & OR* (IC95\%) \\
\hline horas diante & até $2 \mathrm{~h} / \mathrm{dia}$ & $\begin{array}{l}1,34(0,33 ; 5,48) \\
\end{array}$ & $5,39(1,62 ; 17,9)$ \\
\hline da TV por dia & $\geq 2 \mathrm{~h} / \mathrm{dia}$ & 1.0 & 1.0 \\
\hline \multirow[t]{2}{*}{ idade (anos) } & 10,0 a 12,9 & $0,87(0,31 ; 2,39)$ & $0,76(0,26 ; 2,19)$ \\
\hline & 13,0 a 14,9 & 1.0 & 1.0 \\
\hline consumo de & 1200,00 a 2500,99 & $0,21(0,04 ; 1,06)$ & $0,46(0,13 ; 1,71)$ \\
\hline energia (kcal) & 2501,00 a 3800,99 & $0,54(0,18 ; 1,61)$ & $0,27(0,07 ; 1,01)$ \\
\hline (tercil) & 3801,00 a 7000,00 & 1.0 & 1.0 \\
\hline tempo min/dia & $<60 \mathrm{~min} / \mathrm{dia}$ & $1,28(0,47 ; 3,50)$ & $1,50(0,52 ; 4,31)$ \\
\hline pratica AF/exercic & $\geq 60 \mathrm{~min} / \mathrm{dia}$ & 1.0 & 1.0 \\
\hline
\end{tabular}

OR*: eutrófico é categoria de referência. 


\section{DISCUSSÃO}

A relevância do estudo do estado nutricional de adolescentes está no fato dessa população apresentar comportamentos inadequados por determinados períodos que possam repercutir na vida adulta. Esta é uma fase de construção da personalidade, determinante para as intervenções na área de saúde e da nutrição, tendo em vista a consolidação dos hábitos de vida (LEENSTRA et al., 2005). Portanto, avaliar o período da adolescência pode ser a última oportunidade de se amenizar déficits no desenvolvimento.

A desnutrição pode levar a um aumento na predisposição para adquirir doenças infecciosas, retardo no desenvolvimento cognitivo e psicomotor e redução na média da estatura final. No sexo feminino, a desnutrição pode comprometer a capacidade reprodutiva, tendendo a gerar recém-nascidos com baixo peso. Estes, por sua vez, têm maior risco de retardo no crescimento, além de e outros problemas (KLEBANOFF, 1987; MONTEIRO e WOLNEY 2000; GILBNEY et al., 2004).

Já o sobrepeso e a obesidade na infância e na adolescência podem gerar conseqüências a curto e a longo prazo. No primeiro grupo estão as desordens ortopédicas, os distúrbios respiratórios, o diabetes, a hipertensão arterial e as dislipidemias, além dos distúrbios psicossociais. A longo prazo, tem sido relatado o aumento na mortalidade por causas diversas, em especial por 
doença coronariana nos adultos que foram obesos durante este período (MUST, 1996).

Nesta pesquisa o objetivo foi estimar as prevalências de desnutrição, sobrepeso e obesidade, bem como analisar os fatores demográficos, atividade física, inatividade física, consumo de energia e de macronutrientes associados à ocorrência destes agravos.

Nesta discussão serão abordados, separadamente, os procedimentos metodológicos e os resultados.

\subsection{ASPECTOS METODOLÓGICOS}

\subsubsection{Delineamento do Estudo}

O presente estudo foi do tipo transversal, gerando informações sobre prevalência da doença e seus fatores de risco, o que é muito útil em planejamentos de saúde (GORDIS, 2000).

Entre as vantagens de um estudo transversal está o baixo custo, rapidez na coleta e facilidade para se obter amostras representativas; por outro lado, são incapazes de inferir causalidade (PEREIRA, 1995). Conforme os critérios estabelecidos por HILL (1965), ocorre a violação na seqüência temporal da exposição de interesse em relação ao desfecho, podendo, os dados, apresentarem o efeito de causalidade reversa. 
O processo de seleção dos indivíduos, deste estudo, evitou um possível viés de prevalência. A amostragem do tipo aleatória simples assegurou uma amostra com as mesmas características da população alvo (WALDMAN, 2006). Com relação à limitação do estudo às escolas públicas, não houve comprometimento na representatividade da amostra, pois há um número reduzido de escolas privadas $(n=64)$, localizadas somente na região urbana da cidade de Piracicaba.

As perdas no seguimento, que representaram $27,8 \%$ da amostra final, foram devidas, principalmente, pela não localização dos estudantes - que haviam se mudado de escola e a não localização do endereço residencial e telefônico. No entanto, neste estudo não se objetivou fazer o acompanhamento da coorte e, sim, estimar prevalências. Como as perdas, possivelmente, não tiveram relação com o estado nutricional, considera-se que a amostra teve poder e não foi viciada ao estimar as prevalências (PEREIRA, 1995).

\subsubsection{Avaliação do Estado Nutricional}

Diversos métodos têm sido desenvolvidos para medir a gordura corporal, entre eles a medida da densidade mineral óssea, as medidas da água e do potássio corpóreos, a ultra-sonografia, a tomografia computadorizada e a ressonância magnética. Contudo são métodos caros e demorados, que 
requerem pessoal especializado e ainda não estão amplamente disponíveis (GIBNEY et al., 2004 POWERS e HOLLEY, 2002).

As medidas antropométricas, peso e altura, por sua vez, são alternativas simples, não invasivas, rápidas e baratas. A WHO (1995) recomenda dois métodos para avaliar o estado nutricional de adolescentes: altura-para-idade e IMC-para-idade, ambos baseados nas curvas do NCHS (2000).

Outro referencial utilizado para diagnosticar o estado nutricional de crianças e adolescentes entre 2 e 18 anos de idade, foi divulgado pelo comitê formado por especialistas "International Obesity Task Force" - (IOTF, 2000), que se baseou no ponto de corte para excesso de peso e obesidade no IMC da população adulta (COLE et al., 2000). Porém, os critérios de ponto de corte e de classificação ainda não estão bem definidos.

A principal crítica ao IMC, exposta por SICHIERI e ALLAM (1996), é que o referencial estabelecido parte de um critério estatístico no qual o parâmetro se altera conforme a população base. Ressalta-se que, a população brasileira apresenta uma prevalência de sobrepeso e obesidade inferior e um déficit na estatura de 10 centímetros em comparação aos adolescentes norteamericanos.

Neste estudo, optou-se pela recomendação da WHO (1995) IMC-paraidade segundo sexo como único referencial para classificar os adolescentes. No caso da desnutrição, conforme a WHO (1995) seriam necessários mais de um critério para definir o evento. Entretanto, no estudo de MONTEIRO e WOLNEY 
(2000) que observou a tendência secular da desnutrição, a presença de um dos critérios estabelecidos foi o suficiente para classificar o indivíduo como desnutrido. Já para o sobrepeso e obesidade dos adolescentes, o ponto de corte estabelecido seguiu um padrão amplamente aceito e utilizado em estudos nacionais e internacionais (CONTI, 2002; OLIVEIRA et al., 2003; NEMET et al., 2005; TORAL, 2006).

\subsubsection{Avaliação das Variáveis Independentes}

Existem diferentes métodos para se avaliar o consumo alimentar e, dentre os mais utilizados, estão o recordatório de 24 horas e o diário alimentar de três dias. Apesar destes métodos serem de baixo custo e de rápida aplicação, eles avaliam somente à dieta atual do indivíduo (JAIME, 2001; GIBNEY et al., 2004; FISBERG et al., 2005). Para o presente estudo, optou-se pelo Questionário de Freqüência Alimentar (QFA) validado por SLATER et al. (2003), específico para adolescentes, que permitiu avaliar o consumo habitual dos últimos seis meses.

Conforme FISBERG et al. (2005), os QFAs são de grande utilidade em estudos epidemiológicos por serem de fácil aplicação e adequados para estimar o consumo habitual de alimentos e de bebidas de uma população. Entre as principais vantagens está a grande variedade de alimentos, que podem ser 
adaptados à realidade daquela população, o conhecimento da freqüência usual e o tamanho das porções (GIBNEY et al., 2004).

Entretanto, estes instrumentos possuem listas extensas de alimentos que podem levar os adolescentes ao cansaço e contam com a capacidade de memória dos indivíduos. Sendo assim, alimentos da preferência do adolescente podem ser recordados com maior facilidade, enquanto que, alimentos de menor agrado, tendem a ser esquecidos (SLATER, 2001). Para controlar um possível viés de memória, o questionário foi aplicado em forma de entrevista.

O viés de informação foi controlado ao realizar o ajuste dos macronutrientes pela ingestão de energia, por meio de modelo de regressão linear simples (JAIME, 2001), avaliando assim, o efeito isolado dos carboidratos, gorduras e proteínas na dieta habitual dos adolescentes.

Com relação aos estágios de maturação sexual, a auto-avaliação é freqüentemente utilizada em estudos epidemiológicos, devido à sua praticidade na aplicação. Vale ressaltar, que este método não é totalmente preciso, pois varia conforme a etnia de origem da população (WHO, 1995). Além disso, para WILLIAMS et al. (1988), os garotos tendem a superestimar o tamanho da genitália e as meninas subestimar o tamanho das mamas.

No entanto, existem trabalhos nacionais e internacionais de validação que mostram a confiabilidade do método auto-referido, não só para adolescentes com peso normal, como para adolescentes com variação na 
gordura corporal (DUKE et al., 1980; SAITO, 1984; WILLIAMS, 1988; BRATBERG et al., 2007).

Dos métodos auto-referidos, as Pranchas de Tanner são os mais aceitos para se avaliar os estágios de maturação sexual. Entretanto, neste estudo, optou-se pelo uso dos desenhos, pois se considerou que este método causaria menor constrangimento aos jovens do que as fotos das pranchas. Além do mais, MARTIN et al. (2001), por meio dos índices de KAPPA, mostram que a concordância entre as Pranchas de Tanner e a avaliação do médico para genitália foi entre 0,44 e 0,60 e entre os desenhos e a avaliação médica foi de 0,40 e 0,51 . Com isso, nota-se que a concordância com o exame clínico é semelhante pelas duas técnicas, permitindo ao profissional utilizar o método que julgar ser o mais adequado.

Para avaliar a atividade física habitual dos adolescentes, o instrumento utilizado neste estudo, a saber, o questionário proposto por FLORINDO et al. (2006), mostrou-se de fácil compreensão e pouco extenso. Destaca-se, que este é o primeiro questionário que avalia atividade física habitual em adolescentes validado no Brasil. Como todo questionário, está sujeito a vieses de memória, podendo superestimar a atividade física entre os mais ativos e subestimar entre os menos ativos. Acredita-se que os resultados aqui apresentados são consistentes em relação à variável atividade física, pois o instrumento é capaz de abranger todos os domínios, a saber: freqüência, intensidade e duração. 
Foram também perguntadas outras questões sobre inatividade física que têm sido utilizadas por pesquisadores para avaliar, de forma indireta, a questão da prática de atividade física.

Pelo exposto, considera-se que este estudo utilizou métodos adequados para a coleta das variáveis analisadas.

\subsection{ASPECTOS EPIDEMIOLÓGICOS}

\subsubsection{Caracterização da Amostra}

Neste estudo foram investigados 269 adolescentes de ambos os sexos. A população do estudo foi composta por $43,9 \%$ meninos e $56,1 \%$ meninas, distribuídos de forma homogênea entre 10 e 14,9 anos de idade. Os dados do IBGE (2004) mostram que, no Brasil, quase não há diferença nestes percentuais para essa faixa etária $(50,6 \%$ para meninos e $49,4 \%$ para meninas).

FRUTUOSO (2003) em uma pesquisa isolada no município de São Paulo, com escolares da rede de ensino público e privado, também verificou pequeno predomínio de meninas na amostra (59,3\%). No estudo de TORAL (2006), com dados analisados do primeiro momento da coorte de adolescentes de Piracicaba, o sexo feminino compôs $54,6 \%$ da amostra. 
A maioria das meninas e meninos foi classificada como púberes (respectivamente, $95,4 \%$ e $97,5 \%$ ).

A média de idade para a menarca, desta pesquisa, foi de 11,7 anos $(\mathrm{dp}=0,9)$, abaixo da indicada pelo WHO (12,8 anos) e de outro estudo realizado no estado de São Paulo (12,1 anos) apresentado por VITALLE et al. (2003). Porém, no presente estudo, constatou-se que esse valor médio foi igual ao encontrado por BRATBERG et al. (2006) em adolescentes classificadas como precoces em relação à maturação sexual. FREEDMAN et al. (2002), em estudo longitudinal, verificaram que em 1976 5\% das garotas negras e $7 \%$ das garotas brancas apresentavam a menarca aos 11 anos de idade; já na década de 1990 esse percentual elevou-se para $17 \%$ e $10 \%$, respectivamente.

Destaca-se que dos adolescentes do sexo masculino, 80,5\% possuíam a idade mínima de 12 anos. Segundo o WHO (1995), um dos eventos que marcam o início do processo de aceleração do desenvolvimento puberal é o estágio três da genitália que ocorre, em média, aos 12,4 anos de idade.

Outro ponto importante foi o excesso de peso detectado em meninos e meninas (34\% e $25,1 \%$, respectivamente). Em um artigo de revisão DUNGER et al. (2005) descreveram que o ganho excessivo de peso durante a infância pode acelerar o tempo de puberdade. BRATBERG et al. (2006) e SANDHU et al. (2006) encontraram em seus estudos de coorte, a relação entre maior adiposidade na infância com aceleração das características púberes na adolescência. 
Entretanto, neste estudo, não é possível afirmar a relação causal entre os eventos, pois não foi feito o acompanhamento desses adolescentes a partir da infância. Acredita-se que, nesta pesquisa, o processo de maturação sexual foi precoce, principalmente entre as meninas. Ao apresentar uma média de 11,7 anos de idade (mediana 12 anos) para menarca, as adolescentes começaram, provavelmente, seu desenvolvimento por volta dos nove anos de idade, pois esta coincide, geralmente, com os estágios quatro e cinco do desenvolvimento mamário (fase de desaceleração do crescimento) (POIT, 2002). Já nos meninos, não foi possível avaliar o tempo de puberdade com exatidão, pois precisaria ter sido avaliada a idade da primeira ejaculação e esta variável não foi coletada neste estudo.

Em relação à prática esportiva, $64,4 \%$ dos meninos tiveram o futebol como esporte preferencial. Nas meninas o vôlei aparece em primeiro lugar na escolha dentre os esportes (25,8\%). Resultados semelhantes ao encontrado por HALLAL et al. (2006a) num estudo com 4.413 adolescentes, de 10 a 12 anos de idade no município de Pelotas-RS.

Do mesmo modo, no estudo realizado por SILVA e MALINA (2000) em Niterói-RJ, com 325 escolares de ambos os sexos, entre 14 e 15 anos de idade, a atividade física mais praticada entre os meninos foi o futebol $(75 \%)$. Já entre as meninas a dança e a caminhada foram as mais relatadas. 
Os resultados encontrados, neste estudo, foram os esperados, tendo em vista que o futebol é o esporte mais difundido no Brasil e sua prática não requer ambientes específicos.

Dos adolescentes que participaram deste estudo, $75 \%$ indicaram que faziam uso de bicicleta ou se locomoviam a pé para locais como escolas, clubes, parques, entre outros. HALLAL et al. (2006a), no estudo de Pelotas-RS, também verificaram que $72 \%$ dos adolescentes faziam uso de transporte ativo. Sabe-se que a cidade de Piracicaba, bem como Pelotas, ainda mantém características favoráveis a esse tipo de comportamento, como menor densidade demográfica e urbanização comparada aos grandes centros (POPKIN, 2002b; KAIN et al. 2003).

Quanto ao escore de atividade física semanal, os adolescentes do sexo masculino foram significativamente mais ativos que as meninas $(p<0,001)$. A média geral de atividade física foi de 506,8 minutos por semana, similar a encontrado num estudo com adolescentes portugueses de 10 a 17 anos de idade (média $537 \mathrm{~min} / \mathrm{sem}$ ) (FONSECA e MATTOS, 2005).

O predomino masculino, nesta pesquisa, no tempo médio gasto em atividades físicas foi identificado em outros estudos (SILVA e MALINA, 2000; OEHLSCHLAEGER et al., 2004; HALLAL et al., 2006b). MANIOS et al. (2005) relatam que essa diferença não pode ser atribuída a diferenças fisiológicas e, sim, a questões sociais e culturais direcionadas por professores e familiares que acreditam em tipo de atividade física específica para cada sexo. Em estudo 
realizado por ORNELAS et al. (2007), a coesão familiar e a comunicação entre pais e filhos mostraram-se como influenciador para a prática da atividade física, principalmente em meninos.

Como já descrito por MANIOS et al. (2005), as diferenças na pratica de atividade física, verificada nos adolescentes de Piracicaba e nos demais estudos citados, podem ser devidas às questões sociais e culturais. Ressalta-se que o estímulo para atividades físicas ocorre, em grande maioria, em meninos, pois o exercício e o esporte estão associados com a força física e a liderança, características ditas como masculinas; enquanto que, socialmente, as meninas são rotuladas como frágeis e submissas.

$\mathrm{Na}$ análise das variáveis que caracterizaram a inatividade física (horas diante da televisão por dia, uso de vídeo-game e uso do computador) as médias observadas foram semelhantes entre meninos e meninas, para horas diante da televisão por dia da semana $(p=0,956)$ e horas diante da televisão somente nos finais de semana $(p=0,413)$.

A média de horas diante da televisão por dia da semana (3,4 h/dia), nesta pesquisa, foi superior a encontrada por HENRY et al. (2004) de 2,5 horas por dia. Ao analisar as horas por semana $(22,3 \mathrm{~h} / \mathrm{sem})$, o resultado desta pesquisa foi próximo a de um estudo longitudinal realizado por GORDONLARSEN et al. (2002) com adolescentes norte-americanos, entre 11 e 19 anos de idade (média= 21,8 h/sem). 
Conforme a recomendação do American Academy of Pediatrics Committee on Public Education o tempo gasto em aparelhos eletrônicos não deve ultrapassar 120 minutos ao dia.

Os minutos por dia de uso de video-game e de computador foram analisados separadamente nesta pesquisa. Porém, outros estudos tendem a mostrar os resultados em conjunto, video-game mais computador. Para efeito de comparação, os valores em minutos por dia de vídeo game foram somados aos minutos por dia de computador, e, nos resultados deste estudo entre as meninas, verificou-se proximidade no tempo gasto com essas atividades aos valores encontrados por BERKEY et al. (2003) $(213,4 \mathrm{~min} / \mathrm{d}$ x 208,9 $\mathrm{min} / \mathrm{d})$.

Para os meninos, os valores mostraram-se diferentes. No estudo de BERKEY et al. (2003), o uso médio de video-game mais o uso de computador foi de $484,7 \mathrm{~min} / \mathrm{dia}$, superior aos encontrados nos adolescentes de Piracicaba $(273,0 \mathrm{~min} / \mathrm{d})$.

Observa-se que, não existe estudo disponível para avaliar as mudanças de comportamento dos adolescentes de Piracicaba no que se refere ao estilo de vida. Os dados desta pesquisa apontam para a necessidade de políticas públicas que incentivem hábitos saudáveis como a prática de exercício físico fora do ambiente escolar, o que reduziria o número de horas utilizando equipamentos eletrônicos.

Discutindo agora as medidas antropométricas, verificou-se que a média do peso entre os meninos foi de $52,1 \mathrm{~kg}(\mathrm{dp}=16,2)$, havendo uma variação muito 
grande entre os valores mínino e máximo $(27,7 \mathrm{~kg}-142,0 \mathrm{~kg})$. O mesmo ocorreu entre as meninas (média de 48,4 kg dp=11,7 min 28,4 kg - máx 92,3 $\mathrm{kg})$. Quanto à altura, a variação foi baixa em ambos os sexos $(d p=0,1)$. Observa-se que os valores médios da altura dos adolescentes de Piracicaba (1,60 cm para meninos e $1,50 \mathrm{~cm}$ para meninas) estão dentro do padrão nacional.

No que diz respeito as variáveis dietéticas, o valor médio para o consumo de energia encontrado na presente pesquisa foi superior entre as meninas (3477,5 kcal x 3225,9 kcal). Valor este, bem acima do observado em um estudo nos Estados Unidos, parte do Growing Up Today Study, com 16.771 adolescentes de ambos os sexos. A média para o consumo de energia foi 2298,2 kcal para meninos e 2046,4 kcal para meninas (BERKEY et al., 2004). Já no estudo realizado por ANDERSEN et al. (1995) com 1654 adolescentes noruegueses, a média do consumo de energia (3777 kcal) ficou próxima a encontrada entre os adolescentes do presente estudo (3367,9 kcal).

No estudo de FONSECA et al. (1998) com adolescentes entre 15 e 17 anos de idade em Niterói-RJ, verificou-se o consumo de energia em jovens com peso normal e com sobrepeso. O consumo de energia entre meninos e meninas com peso normal foi de $3188 \mathrm{kcal} / \mathrm{dia}$ e $2462 \mathrm{kcal} / \mathrm{dia}$, respectivamente. Entre adolescentes com sobrepeso a média de consumo foi $2819 \mathrm{kcal} / \mathrm{dia}$ para os meninos e de $2209 \mathrm{kcal} / \mathrm{dia}$ para as meninas. 
Do mesmo modo, outro estudo nacional, na cidade do Rio de Janeiro, com 387 jovens, que utilizou um QFA semi-quantitativo, observou que meninos apresentaram médias de consumo de energia de $2890 \mathrm{kcal} / \mathrm{d}$ e $2697 \mathrm{kcal} / \mathrm{d}$, respectivamente para aqueles com e sem sobrepeso. Quanto às meninas, o consumo foi de $2848 \mathrm{kcal} / \mathrm{d}$ em meninas eutróficas e de $2920 \mathrm{kcal} / \mathrm{d}$ em meninas com sobrepeso (ANDRADE et al., 2003).

Em relação aos estudos que fizeram uso do recordatório alimentar de 24 horas, todos apresentaram consumo abaixo de 3000 kcal (GILLIS et al., 2002; EPSTEIN et al., 2005; MANIOS et al., 2005; HASSAPIDOU et al., 2006).

Entre os macronutrientes, o consumo de carboidrato (g) foi significativamente superior entre os meninos $(p=0,046)$, e as gorduras $(g)$ apresentaram maior ingestão pelas meninas $(p=0,029)$. Da mesma maneira, MAFFEIS et al. (2000) identificou maior consumo de gordura entre as meninas $(p<0,001)$. No estudo de FONSECA et al. (1998), tanto consumo de carboidratos quanto o consumo de gorduras foram superiores em meninos.

Neste estudo, o consumo de energia e de proteína não apresentaram diferenças entre os sexos. Faz-se importante evidenciar que os dados de consumo de macronutrientes foram ajustados pelo valor da ingestão energética, o que não ocorreu nos demais estudos analisados. 


\subsubsection{Análise do Estado Nutricional}

Os dados obtidos neste estudo mostram que a prevalência de desnutrição foi semelhante para os sexos $\left(5,1 \% \mathrm{IC}_{95 \%}=1,92-8,28\right.$ para meninos $x$ 4,0\% $\quad \mathrm{IC}_{95 \%}=0,32-7,68$ para meninas). Nestes resultados, verifica-se que 0 percentual no grupo masculino foi próximo a realidade brasileira que apresenta um percentual de 5,8\% para adolescentes de 10 a 19 anos de idade. Por outro lado, entre as meninas da mesma faixa etária, a prevalência de desnutrição foi inferior quando comparada a média nacional $(4,0 \% \times 9,0 \%)$. Ao comparar os resultados desta amostra com dados da região sudeste, observa-se que a prevalência de desnutrição entre os jovens são semelhantes $(4,5 \%)$ (POF 20022003, 2006).

ALBANO e SOUZA (2001) em um estudo isolado, numa escola da rede pública de São Paulo com 92 adolescentes, de ambos os sexos, entre 11 e 17 anos de idade, verificaram a prevalência de baixo peso de $9,3 \%$ para os meninos e de $2,0 \%$ entre as meninas, no entanto os autores não explicam esta diferença.

Quanto ao sobrepeso, houve uma prevalência muito alta para ambos os sexos (15,3\% para meninos e $13,2 \%$ para meninas), como para obesidade (18,6\% para meninos e $11,9 \%$ para meninas). Situação preocupante, pois o país nas últimas décadas segue em aceleração crescente, com índices próximos a de países desenvolvidos. 
No estudo de ALBANO e SOUZA (2001) os autores observaram elevada prevalência tanto para sobrepeso como para obesidade. Para os meninos $27,9 \%$ apresentou sobrepeso e $4,7 \%$ obesidade, enquanto que, para as meninas o sobrepeso foi de $10,2 \%$ e a obesidade de $16,3 \%$.

Outros estudos brasileiros, como o realizado por FONSECA et al. (1998) e CARVALHO et al. (2001), com adolescentes, mostraram prevalências elevadas de sobrepeso e obesidade tanto para meninos quanto para meninas.

Os dados aqui mostrados assemelharam-se aos últimos valores encontrados nos Estados Unidos entre 2003 e 2004. Observou-se que a prevalência de obesidade, desta pesquisa, foi de 18,6\% próximo aos índices verificados em países com Espanha $(21,0 \%)$, Inglaterra $(21,0 \%)$ e Grécia (22,0\%) (POPKIN e GORDON-LARSEN, 2004).

Os achados do presente estudo evidenciam que os níveis de prevalência para desnutrição são baixos, enquanto que, os índices de sobrepeso e obesidade nos adolescentes são preocupantes, demonstrando o processo de transição nutricional no qual a cidade de Piracicaba se encontra.

\subsubsection{Fatores Associados a Desnutrição}

A baixa prevalência de desnutridos identificados nesta amostra inviabilizou o uso da análise logística múltipla. Segundo CONCATO et al. (1993) seriam necessários, no mínimo, 10 eventos de interesse para cada variável 
independente do modelo. Sendo assim, um valor inferior a este poderia expressar um baixo poder na detecção de alguma significância estatística.

No presente estudo, o fator que mostrou associação com a desnutrição no grupo masculino foi a idade $(p=0,028)$. A prevalência de desnutrição nos meninos na faixa etária entre 13 e 14,9 anos foi superior à dos jovens de 10 a 12,9 anos de idade.

Da mesma maneira, SHI et al. (2005) analisaram 824 estudantes de 12 a 14 anos de idade na província de Jiangsu, China, e encontraram menor prevalência de desnutrição em meninos mais jovens com associação estatisticamente significativa $(p=0,011)$.

Este fato pode ser explicado, pois os meninos mais velhos (correspondendo a faixa etária de 13 a 14,9 anos), provavelmente, encontramse na fase de aceleração e pico do crescimento (G3 e G4). Nestas etapas do desenvolvimento há uma demanda maior por nutrientes e uma dieta inadequada pode levar o indivíduo a apresentar desnutrição (Sizer e Whitney, 2002).

Já para as meninas a idade não foi associada à presença de desnutrição, e sim, o estágio puberal $(p=0,005)$. Neste estudo, houve menor prevalência de desnutrição nas meninas púberes, que representam as idades mais velhas. Este fato pode parecer contraditório, pois, de acordo com a literatura, os adolescentes púberes passam por duas fases: aceleração e desaceleração do crescimento. Na fase inicial, na qual ocorre a aceleração, as meninas ganham 
de 8 a 9 centímetros na altura ao ano, portanto havendo uma demanda nutricional elevada. Já na fase de desaceleração, o ganho de peso se acentua. Por outro lado, entre os adolescentes impúberes a velocidade permanece constante, tendo assim, uma demanda nutricional estável.

Este mesmo resultado foi apresentado por LEENSTRA et al. (2005). Eles observaram no estudo com 928 escolares do sexo feminino entre 12 e 18 anos de idade no Kenya, que estar acima do estágio dois no desenvolvimento das mamas foi fator protetor para desnutrição $\left(\mathrm{IC}_{95 \%} 0,12 ; 0,32\right)$. Na pesquisa destes autores pode ter ocorrido um viés de seleção, pois a média de idade da amostra foi de 14 anos, assim, essas adolescentes já estariam na fase de desaceleração na qual a demanda energética está reduzida.

Neste sentido, acredita-se que, um critério de divisão mais rigoroso no qual fosse também levado em conta a fase de aceleração e desaceleração, seria a forma mais correta para se analisar o estado nutricional. Neste trabalho, esta classificação não foi possível de ser feita devido ao pequeno número de indivíduos em algumas categorias, o que inviabilizava a análise estatística.

Na presente pesquisa, a menarca ficou no limiar da significância $(p=$ 0,056), as meninas que não tiveram a menarca apresentaram maior prevalência de desnutrição. Do mesmo modo, em um estudo nacional, VITALLE et al. (2003) encontraram associação significativa entre a desnutrição em meninas que não haviam apresentado a menarca $(p<0,001)$. LEENSTRA et al. (2005) verificaram que a pós-menarca atuou como fator protetor para desnutrição 
$\left(\mathrm{IC}_{95 \%}\right.$ 0,07; 0,30). Sabe-se que a menarca, assim como o estágio dois do desenvolvimento mamário, são marcadores do processo de maturação sexual e acredita-se, que a desnutrição pode estar associada ao atraso na maturação sexual dessas adolescentes. FRICH e REVELLE, com base em estudos populacionais na década de 1970, levantaram a hipótese de que haveria um peso crítico necessário a ser atingido para desencadear o processo de maturação sexual na adolescência. Posteriormente, baseada na composição corpórea, foi levantada outra hipótese, de que para a ocorrência da menarca o corpo deveria apresentar no mínino 17\% em gordura (BARNES, 1975 - apud VITALLE et al., 2003)

Outro fator associado com a presença de desnutrição foi a variável horas diante da televisão por dia, a categoria permanecer diante da televisão até duas horas por dia mostrou maior prevalência em meninas desnutridas com associação estatisticamente significativa $(p=0,019)$. Contudo, não se encontraram pesquisas que fizessem uso dessa associação para adolescentes desnutridos.

As demais variáveis - idade, características escolares, de estilo de vida, de consumo de energia e de macronutrientes - não apresentaram associação com a presença de desnutrição para meninos e meninas. Este fato pode ser explicado pela baixa prevalência de desnutridos na amostra.

Evidencia-se, também que, os estudos realizados que buscam fatores associados a desnutrição caracterizam apenas os dados sobre estilo de vida e 
consumo alimentar, não apresentando bases para comparação com a presente pesquisa (VENKAIAH et al., 2002; BÉNÉFICE et al., 2003; SHI et al., 2005).

\subsubsection{Fatores Associados ao Sobrepeso e a Obesidade}

Na primeira parte da análise (teste de associação pelo qui-quadrado) não se encontrou associação estatística significativa para nenhuma das variáveis independentes entre os meninos. Para as meninas, apenas a variável horas diante da televisão por dia apresentou associação significativa com a presença do sobrepeso e obesidade $(p=0,034)$, mantida na análise de regressão logística multinomial.

$\mathrm{Na}$ análise univariada de regressão logística multinomial para os meninos, somente a energia mostrou associação significativa para grupo de obesos ( $\mathrm{IC}_{95 \%}$ 1,27-23,05). O mesmo foi verificado no estudo de ROLLANDCACHERA e BELLISLE, da década de 1980, com 2440 crianças francesas, de 7 a 12 anos.

VILLA et al. (2006) apresentaram que o consumo de energia está associado a presença de sobrepeso e obesidade em jovens entre 9 e 15 anos residentes na Suécia $\left(\mathrm{IC}_{95 \%}\right.$ 1,00-1,06). Li et al. (2007) também relataram que o consumo elevado de energia atua como fator de risco para o sobrepeso e obesidade ( $\left.\mathrm{IC}_{95 \%} 1,10-2,90\right)$. 
Por outro lado, FONSECA et al. (1998) relataram que a ingestão de energia $(p=0,04)$ e de carboidratos $(p=0,02)$ foram maiores entre meninos e meninas normais em relação aos adolescentes que apresentavam sobrepeso.

MANIOS et al. (2005) não encontraram associação significativa entre a ingestão de energia com o sobrepeso em adolescentes entre 12 e 13 anos de idade em Istambul, Turquia. Assim como McGLOIN et al. (2002) e TROIANO et al. (2000) que também não verificaram associação entre o consumo de energia e o aumento do IMC.

Da mesma maneira, GILLIS et al. (2002), ao analisarem crianças e adolescentes, de 4 a 16 anos de idade, participantes do Children's Exercise and Nutrition Center, Canadá, não encontraram associação entre ingestão de energia, tanto na análise de regressão logística univariada quanto na análise múltipla, ajustada pela idade.

TROIANO et al. (2000) e ALEXY et al. (2004) concluíram que há falta de evidencias de que a ingestão de energia acarrete a elevação na prevalência de sobrepeso, e que o IMC não pode ser explicado por diferentes padrões de dietas durante a infância e a adolescência.

No presente estudo, o consumo de energia, no modelo múltiplo para os adolescentes, manteve sua associação estatisticamente significativa, ajustado pela idade e tempo em minutos por dia de prática de atividade física e exercício físico $\left(\mathrm{OR}_{\text {ajustada }}=6,74\right)$. 
Na variável ingestão de energia, o segundo tercil, correspondente aos valores de $2501,00 \mathrm{kcal}$ a $3800,99 \mathrm{kcal}$, foi o segmento que mostrou associação estatisticamente significativa com a obesidade. Dado que, as recomendações Recommended Dietary Allowances (RDA - 1989) para meninos de ingestão de energia é por volta de $2500 \mathrm{kcal} / \mathrm{dia}$, os indivíduos que estivessem acima da recomendação ou acima deste segundo tercil poderiam apresentar excesso de consumo (SIZER E WHITNEY, 2002). O consumo energético elevado é explicado pela alta ingestão de lanches, salgadinhos e refrigerantes que possuem alta densidade energética e palatabilidade.

Em relação às adolescentes, a categoria permanecer diante da televisão até duas horas por dia mostrou-se como único fator de risco para obesidade $\left(\mathrm{OR}=3,90 ; \mathrm{IC}_{95 \%}\right.$ 1,11-11,65), associação também encontrada por McMURRAY et al. (2000) entre os meninos. No modelo múltiplo, a variável horas diante da televisão por dia, ajustada pela idade, consumo de energia e tempo em minutos por dia de pratica de atividade física e exercício, permaneceu estatisticamente significativa $\left(\mathrm{OR}_{\text {ajustada }}=5,39 ; \mathrm{IC}_{95 \%} 1,62-17,9\right)$.

Cabe ressaltar, que este é um estudo transversal, assim como o realizado por McMURRAY et al. (2000), portanto, os dados podem ter sofrido o efeito de causalidade reversa (HILL, 1965).

Por outro lado, FLEMING-MORAN e THIAGARAJAH (2005), numa pesquisa que compreendeu jovens entre 14 e 18 anos de idade ou mais, observaram que assistir mais de duas horas de televisão ao dia foi considerado 
fator de risco para o sobrepeso em meninos e meninas ( $\mathrm{IC}_{95 \%}$ 1,20-1,80; $\mathrm{IC}_{95 \%}$ 1,22-1,99, respectivamente). No estudo de KAUTIAINEN et al. (2005), meninos e meninas que assistiam entre uma e três horas de televisão apresentaram associação positiva com o sobrepeso. Porém, quando realizada a análise logística múltipla, ajustada por sexo e idade, somente as meninas continuaram com associação significativa ( $\left.\mathrm{IC}_{95 \%} 1,04-1,87\right)$.

Os estudos de FONSECA et al. (1998), GORDON-LARSEN et al. (2002), JANSSEN et al. (2004) e OCHOAS et al. (2007) também observaram a associação positiva entre tempo assistido de televisão com a presença de sobrepeso e obesidade.

Destaca-se que na análise multinomial múltipla, a energia, ajustada pela variável tempo em minutos por dia de prática de atividade física e exercício, ficou no limiar da significância estatística para o sobrepeso $(p=0,059)$ e para a obesidade $(p=0,051)$. Entre os meninos esta associação mostrou-se significativa.

As demais variáveis independentes - demográficas, de atividade física e de consumo de macronutrientes - para ambos os sexos, não apresentaram associação estatisticamente significativa com o sobrepeso e a obesidade. No entanto, diversos estudos que analisaram os fatores relacionados ao sobrepeso e a obesidade mostraram associações não encontradas na presente pesquisa.

RIBEIRO et al. (2006) encontraram associação significativa entre a maturação precoce e o sobrepeso para meninas ( $\left.\mathrm{IC}_{95 \%} 1,12-4,07\right)$, porém os 
mesmos autores concluem que o estágio de maturação sexual foi associado com o sobrepeso em um intervalo de $\mathrm{IC}_{95 \%} \quad 0,99-3,50$. TERRES et al. (2006) observaram que adolescentes com processo de maturação sexual tardio apresentam menos sobrepeso do que os que maturam precocemente $(p=0,01)$. Essa diferença foi significativa entre as meninas $(p=0,02)$, mas não entre os meninos.

O estudo de McMURRAY et al. (2000), com 2389 adolescentes entre 10 e 16 anos de idade (Carolina do Norte, Estados Unidos) mostrou que, para os meninos a atividade física foi fator protetor $(p<0,05)$. Já entre as meninas não foi encontrada associação significativa. Nos estudos de GORDON-LARSEN et al. (2002) e JANSSEN et al. (2004) observaram-se a associação significativa entre a falta de atividade física praticada durante a semana com a presença de sobrepeso e obesidade.

Na pesquisa de KRUGER et al. (2005) com 1257 adolescentes, entre 10 e 15 anos de idade da África do Sul, os autores observaram que a redução da atividade física semanal esteve associada ao aumento do sobrepeso e obesidade em garotos $(p=0,012)$.

FLEMING-MORAN e THIAGARAJAH (2005), numa pesquisa que compreendeu jovens entre 14 e 18 anos ou mais, não encontraram associação entre atividade física vigorosa ou moderada entre os meninos, enquanto que, para as meninas a atividade física vigorosa se mostrou como fator de risco $\left(\mathrm{IC}_{95 \%} 1,11-1,86\right)$. 
Relacionados aos macronutrientes (carboidratos, lipídios e proteínas), não existem dados confirmando que a energia proveniente das gorduras possa ser mais nociva do que a oriunda dos carboidratos ou proteínas no ganho excessivo do peso. Contudo, a partir de estudos randomizados, tem-se considerado o fato de que uma ingestão de alimentos de alta densidade energética pode promover ganho de peso inadequado (BARRETO et al., 2005).

ASTRUP et al. (2000), em uma metanálise, indicaram que a redução do peso em pessoas com sobrepeso ou obesas pode ser conseguida por uma diminuição na dieta de gorduras.

TRICHOPOULOU et al. (2002) em um estudo com a população adulta encontraram associação positiva do consumo de proteína com o aumento do IMC, porém foi verificado associação inversa para o consumo de carboidrato, entre homens e mulheres ( $p<0,001)$. O estudo de McGLOIN et al. (2002) com crianças irlandesas de 6 a 8 anos de idade, mostrou que a ingestão de lipídios esteve associada com maior adiposidade $(p<0,05)$.

Assim, considera-se que o sobrepeso e a obesidade podem ter origens multifatoriais. Conforme ROTHMAN e GREENLAND (2005), a multicausalidade ocorre quando uma dada doença pode ser causada por mais de um mecanismo, baseado na premissa de que não há uma única causa suficiente e causa componente.

Os resultados desta pesquisa demonstram que os fatores determinantes, para os alunos da rede de ensino público de Piracicaba, da desnutrição são a 
idade, entre os meninos, estagio puberal e as horas diante da televisão por dia, entre as meninas; enquanto que, para os determinantes da obesidade são a ingestão de energia, nos meninos e as horas diante da televisão por dia, nas meninas. Esses achados ajudam a elucidar os pontos de fragilidade a serem focados, visando subsidiar familiares, equipes de saúde e educação, a fim de se melhorarem aspectos nos hábitos de vida dos adolescentes.

Com isso, avaliar os diversos fatores que permeiam o comportamento de risco na adolescência e analisar o jovem no ambiente escolar é fundamental, pois permite conhecer as condições em que estes adolescentes estão se desenvolvendo.

Em conclusão, as instituições de ensino trabalham na formação do indivíduo em todas as suas dimensões - física, emocional e social - cabendo a elas estimular hábitos que prezem pela saúde dos jovens. As escolas são locais ideais para se realizar ações preventivas com caráter multidisciplinar. Há que se destacar, neste âmbito, o papel do profissional de Educação Física, a saber, disponibilizar informações e intervir em condutas inadequadas. Além disso, é importante encorajar os adolescentes através de programas que visem o desenvolvimento do comportamento ativo e alimentação adequada, conseqüentemente a melhora do estado nutricional. 


\section{CONCLUSÕES}

- As prevalências de desnutrição para meninos e meninas foram, respectivamente $5,1 \%$ e $4,0 \%$.

- As prevalências de sobrepeso foram entre os meninos $15,3 \%$ e entre as meninas 13,2\%. A obesidade apresentou prevalências de 18,6\% em meninos e $11,9 \%$ em meninas.

- A idade foi a única variável que apresentou associação estatisticamente significativa com a presença de desnutrição em meninos, observando-se menor prevalência de desnutrição na faixa etária de 13 a 14,9 anos.

- Houve associação estatisticamente significativa para estágio puberal e horas diante da televisão por dia com a presença de desnutrição em meninas. Maiores prevalências de desnutrição foram observadas nas meninas impúberes e naquelas que assistem até duas horas de televisão por dia.

- Para os meninos, a energia mostrou associação estatisticamente significativa com a presença de obesidade, verificando-se que quanto maior o consumo, maior a chance de ser obeso. 
- Para as meninas, a variável horas diante da televisão por dia apresentou associação estatisticamente significativa com a presença de obesidade, verificando-se maior chance de ser obesa em meninas que assistem até duas horas de televisão por dia. 


\section{REFERÊNCIAS}

Albano RD, Souza SB. Estado nutricional de adolescentes: risco de sobrepeso e sobrepeso em uma escola pública do município de São Paulo. Cad Saúde Pública. 2001;4:941-945.

Alexy U, Sichert-Hellert W, Kersting M, Schultze-Pawlitschko V. Pattern of longterm fat intake and BMI during childhood and adolescence - results of the DONALD Study. Int J Obesity. 2004; 28:1203-1209.

American Academy Pediatrics. Children, Adolescents and Television. Committrr on Public Education. 2001;107:423-426.

Andersen LF, Nes M, SAndstad B, Bjorneboe G-EAa, Drevon CA. Dietary intake among Norwegian adolescents. Eur J Clin Nutr. 1995; 49: 555-564.

Andrade RG, Pereira RA, Sichieri R. Consumo alimentar de adolescentes com e sem sobrepeso do município do Rio de Janeiro. Cad Saúde Pública. 2003; 19:1485-1495.

Astrup A. Macronutrient balances and obesity: the role of diet and physical activity. Public Health Nutrition. 1999;3a:341-347.

Astrup A, Ryan L, Grunwald GK, Storgaard M, Saris W, Melanson E et al. The role of dietary fat in body fatness: evidence from a preliminary meta-analysis of ad libitum low-fat dietary intervention studies. British Journal of Nutrition. 2000; 83(Suppl 1):25S-32S.

Baqui $\mathrm{AH}$, Black RE. Childhood infectious disease and their contribution to undernutrition. In: Black RE, Michaelsen FK, coordenador. Public health issues in infant and child nutrition. Philadelphia: Nestlé Nutrition Workshop Series, Pediatric Progran; 2002, v. 48. p. 19-51.

Barbosa FS. A epidemiologia como instrumento de transformação. Cad Saúde Pública. 1985;1:137.

Barreto SM, Pinheiro ARO, Sichieri R, Monteiro CA, Filho MB, Schimidt MI et al. Análise da estratégia global para alimentação, atividade física e saúde, da Organização Mundial da Saúde. Epidemiologia e Serviços de Saúde. 2005; 14:41-68. 
Bénéfice E, Caius N, Garnier D. Cross-cultura comparison of growth, maturation and adiposity indices of two contrasting adolescent populations in rural Senegal (West Africa) and Martinique (Caribbean). Public Health Nutrition. 2003;7:479485 .

Berkey CS, Rockett HRH, Field AE, Gillman MW, Colditz GA. Sugar-added beverages and adolescent weight change. Obesity Research. 2004; 12:778-788.

Berkey CS, Rockett HRH, Gillman MW, Colditz GA. One-year changes in activity and in inactivity among 10- to 15-year-old boys and girls: relationship to change in body mass index. Pediatrics. 2003; 111:836-843.

Berquó ES, Souza JMP, Gotlieb SLD. Bioestatística. São Paulo: EPU, 1981.

Birch LL. Childhood overweight: family environmental factors. In: Chen C, Dietz $\mathrm{WH}$, cordenador. Obesity in childhood and adolescence. Philadelphia: Nestlé Nutrition Workshop Series, Pediatric Progran, 2002, v. 49. p. 161-176.

Brabin L, Brabin BJ. The cost of successful adolescent growth and development in girls in relation to iron and vitamin A status. Am J Clin Nutr. 1992;55:955-958.

Bratberg GH, Nilsen TIL, Holmen TL, Vatten LJ. Combined influence of early sexual maturation and central adiposity on subsequent stature. Eur J Pediatr. 2006; 165:787-793.

Bratberg GH, Nilsen TIL, Holmen TL, Vatten LJ. Early sexual maturation, central adiposity and subsequent overweight in late adolescence. A four-year follow-up of 1605 adolescent norwegian boys and girls: the Young HUNT study. BMC Public Health. 2007; 54:1-7.

Caballero B. Symposium: obesity in developing countries: biological and ecological factors. J Nutr. 2001;131(Supl): 866S - 870S.

Carvalho CMRG, Nogueira AMT, Teles JBM, Paz SMR, Consumo alimentar de adolescentes matriculados em um colégio particular de Teresina, Piauí, Brasil. Rev Nutr Campinas. 2001; 14:85-93.

CDC - Center for Disease Control and Prevention. National Center for Health Statistics. CDC Growth Charts 2000. United States.Disponível em: http://www.cdc.gov/growcharts Acesso em: 8 novembro 2006.

Chen C, Dietz WH. Obesity in childhood and adolescence. Obesity in childhood and adolescence. Philadelphia: Nestlé Nutrition Workshop Series, Pediatric Progran, 2002, v. 49. 
Cole TJ, Bellizzi MC, Flegal KM, Dietz WH. Establishing a standart definition for child overweight and obesity worldwide: international survey. BMJ. 2000; 320:16.

ConcatoJ, Feinstein AR, Holford TR. The risk of determining with multivariable models. Basic Science Review. 1993;118:201-210.

Conti AP. Imagem corporal e estado nutricional de estudantes de uma escola particular. [dissertação de mestrado]. São Paulo: Faculdade de Saúde Pública da USP; 2002.

Crowe TC, La Fontaine HA, Gibbons CJ, Cameron-Smith D, Swinburn BA. Energy density of foods and beverages in the australian food supply: influence of macronutrients and comparison to dietary intake. Eur J Clin Nutr. 2004; 58:1485-1491.

DIETSYS - HHHQ - DietSys Analysis Software, Version 4.01. [programa de computador]. National Cancer Institute, 1999.

Doak CM, Adair LS, Bentley M, Monteiro C, Popkin BM. The dual burden household and the nutrition transition paradox. Int J Obesity. 2005;29:129-136.

Drachler ML, Macluf SPZ, Leite JCC, Aerts DRGC, Giugliani ERJ, Horta BL. Fatores de risco para sobrepeso em crianças no Sul do Brasil. Cad. Saúde Pública. 2003;(19):1073-1081.

Duke PM, Litt IF, Gross RT. Adolescewnts'self-assessment of sexual maturation. Pediatrics. 1980; 66:918-920.

Dunger DB, Ahmed ML, Ong KK. Effects of obesity on growth and puberty. Best Practice \& Research Clinical Endocrinology \& Metabolism. 2005; 19:375-390.

Epstein LH, Roemmich JN, Paluch RA, Raynor HA. Influence of changes in sedentary behavior on energy and macronutrient intake in youth. Am J Clin Nutr. 2005; 81:361-366.

Fisberg RM, Slater B, Marchioni DML, Martini LA. Inquéritos alimentares: métodos e bases científicos. Barueri: Manole, 2005.

Fleming-Moran M, Thiagarajah $\mathrm{K}$. Behavioral interventions and the role of television in the growing epidemic of adolescent obesity. Methods Inf Med. 2005;(44):303- 9 . 
Florindo AA, Romero A, Peres SV, Silva MV, Slater B. Desenvolvimento e validação de um questionário de atividade física para adolescentes. Rev Saúde Pública. 2006;4:1-8.

Fonseca $\mathrm{H}$, Matos MG. Perception of overweight and obesity among portuguese adolescents: an overview of associated factors. European Journal of Public Health. 2005; (419): 1-6.

Fonseca VM, Sichieri R, Veiga GV. Fatores associados à obesidade em adolescentes. Rev. Saúde Pública. 1998; 32:541 - 9.

Freedman DS, Khan LK, Serdula MK, Dietz WH, Srinivasan SR, Berenson GS. Relation of age at menarche to race, time periodo, and anthropometric dimensions: the Bogalusa Heart Study. Pediatrics. 2002;111:1-7.

Frich RE, Revelle R. Height and weight at menarche and a hypothesis of critical body eights and adolescent events. Science. 1970:397:399.

Frisancho R. Prenatal compared with parental origins of adolescent fatness. Am J Clin Nutr. 2000;(72):1186 - 90.

Frutuoso MF. Fatores associados ao sobrepeso e obesidade de 8 a 18 anos de idade [tese de doutorado] São Paulo: Faculdade de Saúde Pública da USP, 2003.

Garnier D, Bénéfice E. Habitual physical activity of senegalese adolescent girls under different working conditions, as assessed by a questionnaire and movement registration. Annals of Human Biology. 2001(28):79 - 97.

Gilbney MJ, Margetts BM, Kearney JM, Arab L. Public Health Nutrition.Great Britain: Blackwell Science. 2004.

Gillis LJ, Kennedy LC, Gillis AM, Bar-Or O. Relationship between juvenile obesity, dietary energy and fat intake and physical activity. Int J Obesity. 2002; 26:458-463.

Gordon-Larsen P, McMurray RG, Popkin B. Determinats of adolescents physical activity and inactivity patterns. J Pediatrics. 2000; 105:83e.

Gordon-Larsen P, Adair LS, Popkin B. Ethnic differences in physical activity and inactivity paterns and overweight status. Obesity Research. 2002;10:141-149.

Gordis L. Epidemiologia. Rio de Janeiro: Revinter; 2004. 
Hallal PC, Bertoli AD, Gonçalves H, Victora CG. Prevalência de sedentarismo e fatores adolescentes de 10-12 anos de idade. Cad. Saúde Pública. 2006a; 6:1277-1287.

Hallal PC, Wells JCK, Reichert FF, Anselmi L, Victora CG. Early determinants of physical activity in adolescence: prospective birth cohort study. BMJ. 2006b; 332:1002-1007.

Hassapidou M, Fotiadou E, Maglara E, Papadopoulou SK. Energy intake, diet composition, energy expenditure, and body fatness of adolescents in northern Greece. Obesity. 2006; 14:855-862.

Henry CJK, Lightowler HJ, Al-Hourani HM. Physical activity and levels of inativity in adolescent femeales ages 11-16 years in the United Arab Emirates. Am J Uman Biology. 2004; 16:346-353.

Hill AB. The environment and disease: association or causation?. Proccedings of the Royal Society of Medicine. 1965; 58:295-300.

IBGE. Fundação Instituto Brasileiro Geografia Estatística. Anuário Estatístico do Brasil, 2000.

IBGE. Fundação Instituto Brasileiro Geografia Estatística. População residente, 2004. Disponível em: http:/ www.ibge.org.br. Acesso em: 11 fevereirode 2006.

Jaime PC. Correções em medidas de consumo alimentar: aplicação na análise da correlação do consumo de cálcio, proteína e energia com a densidade mineral óssea em homens adultos e idosos [tese de doutorado]. São Paulo: Faculdade de Saúde Pública da USP; 2001.

Janssen I, Katzmarzyk PT, Boyce WF, King MA, Pickett W. Overweight and obesity in canadian adolescents and their associations with habits and physical activity patterns. J Adolesc Health. 2004; 35:360-367.

Jassen I, Katzmarzyk PT, Boyce WF, Vereecken C, Mulvihill C, Roberts C, et al. Comparison of overweight and obesity prevalence in school-aged youth from 34 countries and their relationships with physical activity and dietary patterns. Obesity Reviews. 2005;(6):123-132.

Kain J, Vio F, Albala C. Obesity trends and determinant factors in Latin America. Cad Saúde Pública. 2003; 19(Supl1):77S-86S. 
Kautiainen S, Koivusilta L, Lintonen T, Virtanen SM, Rimpelä A. Uso of information and communication technology and prevalence of overweight and obesity among adolescents. Int J Obesity. 2005;29:925-933.

Klebanoff MA, Yip R. Influence of maternal birth weight on rate of fetal growth and duration of gestation. J Pediatric. 1987;111:287-292.

Kruger R, Kruger HS, Maclntyre UE. The determinants of overweight and obesity 10- to 15- year-old schoolchildren in the North West Province, South Africa - the Thusa Bana (transition and health during urbanisation of south africans; Bana, children) study. Public Health Nutrition. 2005; 9:351-358.

Leenstra T, Petersen LT, Kariuki SK, Oloo AJ, Kager PA, Kuile FO. Prevalence and severity of malnutrition and age at menarche; cross-sectional studies in adolescent schoolgirls in wester Kenya. Eur J Clin Nut. 2005;59:41-48.

Levy-Costa RB, Schieri R, Pontes NS, Monteiro CA. Household food availability in Brazil: distribuition and trends (1974-2003). Rev Saúde Pública. 2005;39:110.

Li M, Dibley MJ, Sibbritt D, Yan $H$. Factors associated with adolescents'overweight ad obesity at community, school and household levels in Xi'an city, China: results of hieralchical analysis. Eur J Clin Nutr. 2007:1-9.

Ludwing DS, Peterson KE, Gortmaker SL. Relation between consumption of sugar-sweetned drinks and childhood obesity: a prospective, observational analysis. The Lancet. 2001;357:505-8.

Maffeis C, Provera S, Filippi L, Sidoti G, Schena S, Pinelli L et al. Distribuition of food intake as a risk factor for childhood obesity. Int J Obesity. 2000; 24:75-80.

Manary MJ, Solomons NW. Public health aspects of nutrition. In: Gilbney MJ, Margetts BM, Kearney JM, Arab L. Public Health Nutrition.Great Britain: Blackwell Science. 2004.p. 178-191.

Manios Y, Kolotourou M, Moschonis G, Sur H, Keskin Y, Kocaoglu B, et al. Macronutrient intake, physical activity, serum lipids and increased body weight in primary schoolchildren in Istambul. Pediatrics International. 2005;(47):159 166.

Martin PO, Trindade ZA, Almeida AMO. O Ter e o Ser: representações sociais da adolescência entre adolescentes de inserção urbana e rural. Psicologia: Reflexão e Crítica. 2003: 3: 555-568. 
Martin RHC, Uezu R, Parra AS, Arena SS, Bojikian LP, Böhme MTS. Autoavaliação da maturação sexual masculina por meio da utilização de desenhos e fotos. Rev Paulista de Educação Física. 2001; 2: 212-222.

Mcardle WD, Katch FI, Katch VL. Fisiologia do exercício: energia, nutrição e desempenho humano. 4 ed. Rio de Janeiro: Guanabara Koogan, 1996.

McGloin AF, Livingstone BEM, Greene LC, Webb SE, Gibson JMA, Jebb SA et al. Energy and fat intake in obese and lean children at varying risk of obesity. Int J Obesity. 2002; 26:200-207.

McMurray RG, Harrel JS, Deng S, Bradley CB, Cox LM, Bangdiwala SI. The influence of physical activity, socioeconomic status, and ethbicity on the weight status of adolescents. Obesity Research. 2000; 8:130-139.

Monteiro CA, Conde WL, Popkin BM. Is obesity replacing or adding to undernutrition? Evidence from different social classes in Brazil. Public Helth Nutrition. 2002;5:105-112.

Monteiro CA, Wolney WL. Tendência secular da desnutrição e da obesidade na infância na cidade de São Paulo (1974-1996). Rev Saúde Pública. 2000;34:5261.

Must A. Morbidity and mortality associated with elevated body weight in children and adolescents. Am J Clin Nutr. 1996; 63(Suppl3):445S-447S.

Nemet D, Barkan S, Epstein Y, Friedland O, Kowen G, Eliakim A. Short- and long-term beneficial effects of a combined dietary-behavioral-physical activity intervention for the treatment of childhood obesity. Pediatrics. 2005; 115:443449.

Ochoa MC, Moreno-Aliaga MJ, Martinez-González MA, Martinez JÁ, Marti A. Predictor factors for childhood obesity in a Spanish case-control study. Nutrition. 2007; 23:379-384.

Oehlschlaeger MHK, Pinheiro RT, Horta B, Gelatti C, San'tana P. Prevalência e fatores associados ao sedentarismo em adolescentes de área urbana. Rev Saúde Pública. 2004; 38:157-163.

Ogden CL, Carroll MD, Curtin LR, McDowell MA, Tabak CJ, Flegal KM. Prevalence od overweight and obesity in the United States, 1999-2004. JAMA. 2006; 295:1549-1555. 
Oliveira AMA, Cerqueira EMM, Oliveira AC. Prevalence of overweight and childhood obesity in Feira de Satana-BA: family detection $x$ diagnosis. Jornal de Pediatria. 2003;(79):325-8.

Ornelas IJ, Perreira KM, Ayala GX. Parental influences on adolescent physical activity: a longitudinal study. Int $\mathrm{J}$ Behavioral Nutrition and Physical Activity. 2007; 4:1-10.

Osório LC. Adolescente hoje. 3 ed. Porto Alegre: Artes Médicas, 1992.

Pate RR, Freedson PS, Sallis JF, Taylo WC, Sirard J, Trost SG et al. Compliance with physical activity guidelines: prevalence in a population of children and youth. Ann Epidemiol. 2002; 12:303-308.

Pereira MG. Epidemiologia: teoria e prática. Rio de Janeiro: Guanabara Koogan; 1995.

Poit ML. Desenvolvimento puberal. In: Série atualizações pediátricas. Sexualidade e saúde reprodutiva na adolescência. São Paulo: Atheneu, 2001, p. 21-32.

PNUD. Plano das Nações Unidas para o Desenvolvimento, 2000. [acesso em 11 fev 2006]. Disponível em : http:// www.pnud.org.br/

POF - Pesquisa de Orçamentos Familiares 2002-2003. Antropometria e análise do estado nutricional de crianças e adolescentes no Brasil. Rio de Janeiro; 2006.

Popkin BM, Gordon-Larsen P. The nutrition transition: worldwide obesity dynamics and their determinants. Int J Obesity. 2004: 28:52-59.

Popkin BM. The dynamics of the dietary transition in the developing world. In: Caballero B, Popkin BM coordenador. The nutrition transition: diet and disease in the developing world. London: Academy Press, 2002a.

Popkin BM. The shift in stages of the nutrition transition in the developing world differs from past experiences. Public Health Nutrition. 2002b;(5):205-214.

Powers SK, Howley ET. Fisiologia do Exercício: teoria e aplicação ao condicionamento e ao desempenho. 3 ed. Barueri: Manole; 2002.

Pratt M, Macera CA, Blanton C. Levels of physical activity and inactivity in children and adults in United States: current evidence and research issues. Med Sci Sport Exerc.1999; 31(Suppl11):526S-533S. 
Ramos AMPP, Filho AAB. Prevalência da obesidade em adolescentes de Bragança Paulista e sua relação com a obesidade dos pais. Arq Bras Endocrinol Metab. 2003; 47:663-668.

Ribeiro J, Santos P, Duarte J, Mota J. Association between overweight and early sexual maturation in portuguese boys and girls. Annals of Human Biology. 2006;33:55-63.

Rolland-Cachera MF, Bellisle F. No correlation between adiposity and food intake: why are working class children fatter?. Am j Clin Nutr. 1986; 44:779-787.

Rothman KJ, Greenland S. Causation and causal inference in epidemiology. Am J Public Health. 2005; 95(Suppl1): 144S-150S.

Saito MI. Maturação sexual: auto avaliação do adolescente. Pediatria. 1984; 6:111-115.

Sandhu J, Bem-Shlomo Y, Cole TJ, Holly J, Smith GD. The impact of childhood body mass index on timing of puberty, adult stature and obesity: a follow-up study based on adolescent anthropometry recorded at Christ's Hospital (19361964). Int J Obesity. 2006; 30:14-22.

Schrauwen P, Westerterp KR. The role of high-fat diets and physical activity in the regulation of body weight. British Journal of Nutrition. 2000; 84:417-427.

Shi Z, Lien N, Kumar BN, Dalen E, Holmboe-Ottesen G. The sociodemographic correlates of nutritional status of school adolescents in Jiangsu Province, China. J Adolescents Health. 2005;37:313-322.

Sichieri R, Allam VLC. Avaliação do estado nutricional de adolescentes brasileiros através do índice de massa corporal. Jornal de Pediatria. 1996 ; $72: 80-84$.

Silva GAP, Balaban G, Motta MEFA. Prevalência de sobrepeso e obesidade em crianças e adolescentes de diferentes condições socioeconômicas. Rev Bras Saúde Matern Ifant. $2005 ; 5: 53-59$.

Silva RR, Malina RM. Nível de atividade física em adolescentes do município de Niterói, Rio de Janeiro, Brasil. 2000 ; 16 :1091-1097.

Singh RB, Beegon R, Mehta AS, Niaz MA, De Ak, Mitra RK, et al. Social class, coronary risk factors and undernutrition, a double burden of diseases, in women 
during transition, in five Indian cities, International Journal of Cardiology. 1999;(69):139-147.

Sizer F, Whitney E. Nutrição: conceitos e controvérsias. 8 ed. Barueri: Manole, 2002.

Slater B. Desenvolvimento e validação de um questionário semi-quantitativo de freqüência alimentar para adolescentes [tese de doutorado]. São Paulo: Faculdade de Saúde Pública da USP, 2001.

Slater B, Philippi ST, Fisberg RM, Latorre MDR. Validation of a semi-quantitative adolescent food frequency questionnaire applied at a public school in São Paulo. Eur J Clin Nut. 2003;(57):629-635.

SPSS - Statistical Package for the social Sciences for Windows Student Version - SPSS [programa de computador].Release 12.0 Chicago Marketing Departament; 2002.

Tanner JM. Growth at Adolescence. $2^{\text {nd }}$ ed. Oxford: Blackwell Scientific Publications, 1962.

Terres NG, Pinheiro RT, Horta BL, Pinheiro KAT, HORTA LL. Prevalência e fatores associados ao sobrepeso e à obesidade em adolescentes. Rev Saúde Pública. 2006;40: 627-633.

Toral N. Estágios de mudança do comportamento e sua relação com o consumo alimentar de adolescentes [dissertação de mestrado]. São Paulo: Faculdade de Saúde Pública da USP; 2006.

Trichopoulou A, Gnardellis C, Benetou V, Lagiou P, Bamia C, Trichopoulos D. Lipid, protein and carbohydrate intake in relation to body mass index. Eur J Clin Nutr. 2002; 56:37-43.

Troiano RP, Briefel RR, Carroll MD, Bialostosky K. Energy and fat intake of children and adolescents in the United States: data from the National Health Examination Surveys. Am J Nutr. 2000; 72 (Suppl):1343S-1353S.

Venkaiah K, Damayanti K, Nayak MU, Vijayaraghavan K. Diet and nutritional status of rural adolescents in India. Eur J Clin Nut. 2002;56:1119-1125.

Villa I, Yngve A, Poortvliet E, Grjibovski A, Liiv K, Sjöström M, et al. Dietary intake among unde-, normal- and overweight 9- and 15-year-old estonian and swedish schoolchildren. Public Health Nutrition. 2006; 10:311-322. 
Vitalle MSS, Tomioka CY, Amancio OM. Índice de massa corporal, desenvolvimento puberal e sua relação com a menarca. Rev Assoc Med Bras. 2003; 49:429-433.

Waldman E. A epidemiologia em medicina. In: Lopes AC, Amato Neto V. tratado de clínica médica. São Paulo: Roca; 2006, p. 1-39.

WHO - World Health Organization.Diet, nutrition and prevention of chronic diseases. Technical Report 916. Geneva; 2003.

WHO - World Health Organization. Obesity: Preventing and managing the global epidemic. Geneva; 2000.

WHO - World Health Organization. Physical status: the use and interpretation of anthropometry. Report of a WHO Expert Committee.Geneva;1995.

WHO \& IDF. World Health Organization and International Diabets Federation. Fight childhood obesity to help prevent diabetes, say WHO \& IDF, 2005. [acesso em 11 fev 2006]. Disponível em: http:// www.pnud.org.br/

Williams RL, Ken L, Houtkooper LK, Lohman TG. Adolescent self-assessment of sexual maturation: effects of fatness classifi and actual sexual maturation stage. J Adolescent Health Care. 1988; 9:480-482. 
Anexos 
Anexo 1 - Questionário para pais e/ou responsáveis. Identificação da família, condições de vida do escolar. 
PESQUISA DA UNIVERSIDADE DE SÃO PAULO - CNPq

FACULDADE DE SAÚDE PÚBLICA DEPARTAMENTO DE NUTRIÇÃO

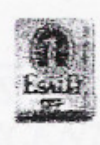

ESCOLA SUPERIOR DE AGRICULTURA "LUIZ DE QUEIROZ"

\section{QUESTIONÁRIO PARA PAIS E/OU RESPONSÁVEIS IDENTIFICACC̃̃O DA FAMÍLIA E CONDIÇÕES DE VIDA DO ESCOLAR}

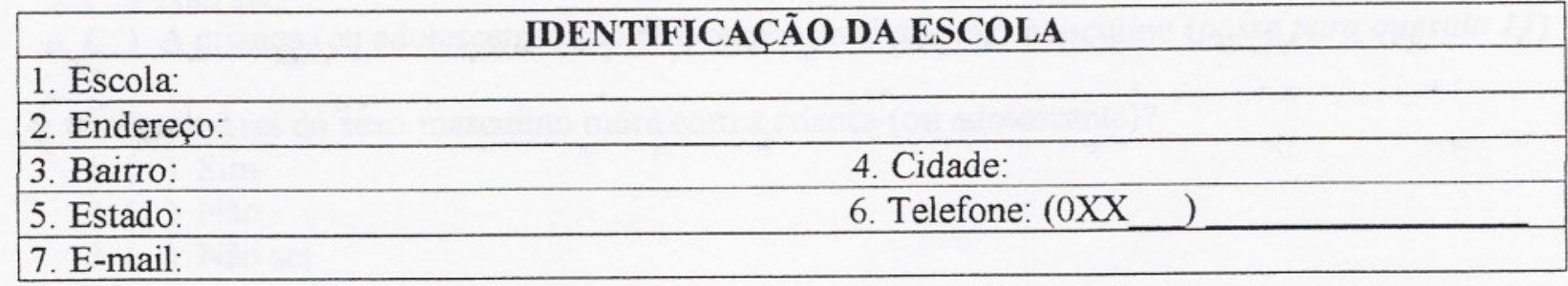

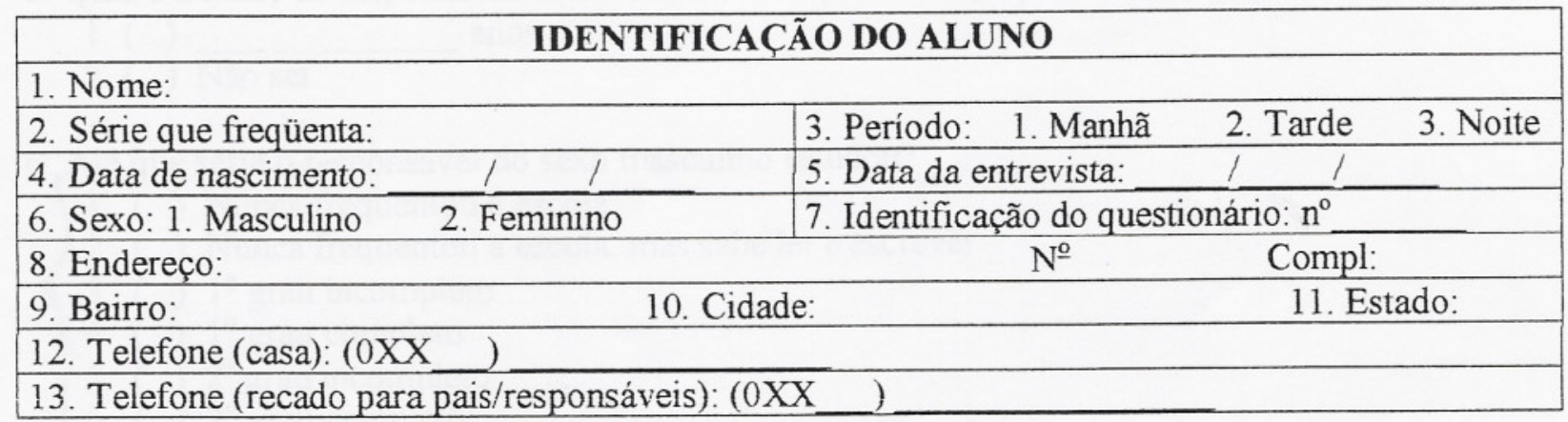

\begin{tabular}{|l|l|}
\hline \multicolumn{2}{|c|}{ IDENTIFICACC̃̃O DA PESSOA QUE RESPONDEU O QUESTIONÁRIO } \\
\hline 1. Data: & \\
\hline 2. Nome: & \\
\hline 4. Grau de parentesco com a criança / adolescente: & \\
1. ( ) Pai & \\
2. ( ) Mãe & \\
3. ( ) Irmão/Irmã & \\
4. ( ) Avô/Avó & \\
5. ( ) Outro. Especificar: & \\
\hline
\end{tabular}

1. A criança (ou adolescente) que está participando desta pesquisa freqüentou creche antes de completar 5 anos de idade?
1. ( ) $\mathrm{Sim}$
2. ( ) Não
3. ( ) Não sei

2. Se você respondeu que a criança freqüentou a creche, escreva por quanto tempo (escreva o tempo acompanhado, por exemplo dias, meses ou anos): 
3. Quem é o responsável do sexo masculino pela criança (ou adolescente)?

1. ( ) Pai

2. ( ) Padrasto

3. ( ) Avô

4. ( ) Outro. Especificar:

5. ( ) Não sei

6. ( ) A criança (ou adolescente) não tem responsável do sexo masculino (passe para questão 11)

4. O responsável do sexo masculino mora com a criança (ou adolescente)?
1. ( ) Sim
2. ( ) Não
3. ( ) Não sei

5. Qual é a idade do responsável do sexo masculino pela criança (ou adolescente)?
1. ( ) anos
2. ( ) Não sei

6. Até que série o responsável do sexo masculino estudou?

1. ( ) Nunca freqüentou a escola

2. ( ) Nunca freqüentou a escola, mas sabe ler e escrever

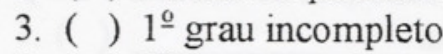

4. ( ) $1^{\circ}$ grau completo

5. ( ) $2^{\circ}$ grau incompleto

6. ( ) $2^{-}$grau completo

7. ( ) Curso técnico de nível médio incompleto

8. ( ) Curso técnico de nível médio completo

9. ( ) Curso superior incompleto

10. ( ) Curso superior completo

11. ( ) Não sei

7. Atualmente, o responsável do sexo masculino exerce alguma atividade remunerada (trabalho)?

1. ( ) $\mathrm{Sim}$

2. ( ) Sim, mas está afastado por motivo de doença

3. ( ) Sim, e também é aposentado

4. ( ) Não, porque está desempregado

5. ( ) Não, porque é aposentado ou pensionista

6. ( ) Não, porque é somente estudante

7. ( ) Outro. Especificar:

8. ( ) Não sei

8. O responsável do sexo masculino é:
1. ( ) Trabalhador assalariado (com carteira profissional assinada)
2. ( ) Trabalhador assalariado (sem carteira profissional assinada)
3. ( ) Trabalhador sem remuneração
4. ( ) Trabalhador por conta própria com estabelecimento
5. ( ) Trabalhador por conta própria sem estabelecimento
6. ( ) Não sei 
9. Escreva quanto o responsável do sexo masculino recebeu em dinheiro no mês passado (junte todos os ganhos, por exemplo, o salário do trabalho, pensão, aposentadoria ou outras rendas):

1. ( ) $\mathrm{RS}$

2. ( ) Não sei

10. Quem é a responsável do sexo feminino pela criança (ou adolescente)?
1. ( ) Mãe
2. ( ) Madrasta
3. ( ) Avó
4. ( ) Outra Especificar:
5. ( ) Não sei

6. ( )A criança (ou adolescente) não tem responsável do sexo feminino (passe para questão 18)

11. A responsável do sexo feminino mora com a criança (ou adolescente)?
1. ( ) $\mathrm{Sim}$
2. ( ) Não
3. ( ) Não sei

12. Qual é a idade da responsável do sexo feminino pela criança (ou adolescente)?
1. ( ) anos
2. ( ) Não sei

13. Até que série a responsável do sexo feminino estudou?
1. ( ) Nunca freqüentou a escola
2. ( ) Nunca freqüentou a escola, mas sabe ler e escrever
3. ( ) $1^{\circ}$ grau incompleto
4. ( ) $1^{\circ}$ grau completo
5. ( ) $2^{\circ}$ grau incompleto
6. ( ) $2^{\circ}$ grau completo
7. ( ) Curso técnico de nível médio incompleto
8. ( ) Curso técnico de nível médio completo
9. ( ) Curso superior incompleto
10. ( ) Curso superior completo
11. ( ) Não sei

14. Atualmente, a responsável do sexo feminino exerce alguma atividade remunerada (trabalho)?
1. ( ) Sim
2. ( ) Sim, mas está afastada por motivo de doença
3. ( ) Sim, e também é aposentada
4. ( ) Não, porque está desempregada
5. ( ) Não, porque é aposentada ou pensionista
6. ( ) Não, porque é dona-de-casa
7. ( ) Não, porque é somente estudante
8. ( ) Outro. Especificar:
9. ( ) Não sei 
15. A responsável do sexo feminino é:

1. ( ) Trabalhadora assalariada (com carteira profissional assinada)

2. ( ) Trabalhadora assalariada (sem carteira profissional assinada)

3. ( ) Trabalhadora sem remuneração

4. ( ) Trabalhadora por conta própria com estabelecimento

5. ( ) Trabalhadora por conta própria sem estabelecimento

6. ( ) Não sei

16. Escreva quanto a responsável do sexo feminino recebeu em dinheiro no mês passado (junte todos os ganhos, por exemplo, o salário do trabalho, pensão, aposentadoria ou outras rendas):

1. ( ) RS

2. ( ) Não sei

17. Alguma pessoa da família está inscrita em algum programa de donativo (exemplo: igreja, $\mathrm{ONG}, \ldots$ ) ou do governo (exemplo: prefeitura, governo federal,...)?
1. ( ) Sim
2. ( ) Não
3. ( ) Não sei

18. Se alguma pessoa família recebe dinheiro de algum programa, por favor escreva abaixo o(s) nome(s) do(s) programa(s) e o valor (total) recebido no último mês:

1. Nome do programa:

2. Valor (total) recebido: $\mathrm{R} \$$

\section{AS QUESTÕES A SEGUIR REFEREM-SE AO DOMICÍLIO ONDE A CRIANÇA OU} ADOLESCENTE MORA

19. Qual é o número de famílias que mora na residência?
1. ( ) Uma família
2. ( ) Mais de uma família. Quantas?
3. ( ) Não sei

20. Qual é o número de moradores na residência?
1. ( )
2. ( ) Não sei. moradores

21. Qual é o número total de crianças com idade até 10 anos que moram na residência?
1. ( )
2. ( ) Não sei. crianças

22. Características da residência:
1. ( ) Casa
2. ( ) Apartamento
3. ( ) Barraco
4. ( ) Casa de cômodos, quartos e/ou cortiço
5. ( ) Outra. Especificar:
6. ( ) Não sei 
23. A residência é:
1. ( ) Emprestada
2. ( ) Alugada
3. ( ) Própria já paga
4. ( ) Própria pagando
5. ( ) Outro. Especificar:
6. ( ) Não sei

24. Quantos CÔMODOS têm na residência, tirando o banheiro:
1. ( ) cômodos
2. ( ) Não sei.

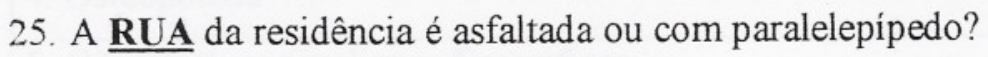
1. ( ) $\mathrm{Sim}$
2. ( ) Não
3. ( ) Não sei

26. O ABASTECIMENTO DE ÁGUA na residência é de:
1. ( ) Rede pública
2. ( ) Poço ou nascente
3. ( ) Outro. Especificar
4. ( ) Não sei

27. A INSTALACÃO SANITÁRIA (banheiros) é:
1. ( ) Dentro da residência
2. ( ) Fora da residência
3. ( ) Outro. Especificar:
4. ( ) Não sei

28. Qual é o destino do ESGOTO?
1. ( ) Rede Pública
2. ( ) Fossa
3. ( ) Céu aberto
4. ( ) Não sei

29. Qual é o destino do LIXO?
1. ( ) Coleta pública regular
2. ( ) Outro. Especificar:
3. ( ) Não sei

30. Dos equipamentos abaixo, faça um $\mathbf{X}$ naquele(s) que estão disponíveis na casa onde mora a criança (ou adolescente) que está participando desta pesquisa. Escreva na frente de cada um dos equipamentos, a quantidade (número) que tem na casa:
1. ( ) Geladeira:
2. ( ) Freezer:
3. ( ) Televisão:
4. ( ) Máquina de lavar roupas:
5. ( ) Aparelho de som:
6. ( ) Aparelho de vídeo:
7. ( ) Aparelho de DVD:
8. ( ) Aspirador de pó:
9. ( ) Máquina de lavar louça:

10. ( ) Ar condicionado:

11. ( ) Telefone fixo:

12. ( ) Telefone celular:

13. ( ) Computador:

14. ( ) Forno de microondas:

15. ( ) Carro:

16. ( ) Moto:

17. ( ) Não sei 
31. A criança (ou adolescente) apresenta alguma das doenças abaixo?

\begin{tabular}{|l|l|l|l|}
\hline \multicolumn{1}{|c|}{ DOENÇA } & 1. Sim & 2. Não & 3. Não sei \\
\hline 1. Hipertensão & & & \\
\hline 2. Doença renal crônica & & & \\
\hline 3. Artrite artrose, reumatismo & & & \\
\hline 4. Osteoporose & & & \\
\hline 5. Câncer, tumor maligno. Especificar: & & \\
\hline 6. Doença do coração & & & \\
\hline 7. Doença digestiva crônica (úlcera, gastrite) & & & \\
\hline 8. Doença crônica do pulmão (asma, bronquite,enfisema) & & & \\
\hline
\end{tabular}

32. Alguma pessoa da família apresenta alguma das doenças abaixo?

\begin{tabular}{|l|l|l|l|}
\hline \multicolumn{1}{|c|}{ DOENÇA } & $\begin{array}{c}\text { 1. Sim. } \\
\text { Quem? }\end{array}$ & 2. Não & 3. Não sei \\
\hline 1. Hipertensão & & & \\
\hline 2. Doença renal crônica & & & \\
\hline 3. Artrite artrose, reumatismo & & & \\
\hline 4. Osteoporose & & & \\
\hline 5. Câncer, tumor maligno. Especificar: & & & \\
\hline 6. Doença do coração & & & \\
\hline 7. Doença digestiva crônica (úlcera, gastrite) & & & \\
\hline 8. Doença crônica do pulmão (asma, bronquite,enfisema) & & & \\
\hline
\end{tabular}

33. Quantos Reais (R\$) a família gastou com saúde no último mês?

\begin{tabular}{|l|l|l|}
\hline \multicolumn{1}{|c|}{ Gastos } & 1. Valor & 2. Não sei \\
\hline 1. Medicamentos & RS & \\
\hline 2. Mensalidade de plano de saúde & $\mathrm{R} \$$ & \\
\hline 3. Tratamento dentário e prótese & $\mathrm{R} \$$ & \\
\hline 4. Gastos com óculos + lente de contato & $\mathrm{R} \$$ & \\
\hline 5. Outros gastos. Quais? & $\mathrm{R} \$$ & \\
\hline
\end{tabular}


Data:

\section{AS QUESTÕES A SEGUIR REFEREM-SE À MERENDA ESCOLAR E À CANTINA}

34. Na sua opinião, a merenda oferecida pela escola é:
1. ( ) Muito boa
2. ( ) Boa
3. ( ) Ruim
4. ( ) Muito Ruim
5. ( ) Não sei

35. A criança (ou adolescente) que está participando desta pesquisa consome a merenda oferecida pela escola?

1. ( ) Sim. Quantos dias por semana?

2. ( ) Não

3. ( ) Não sei

36. Na cidade onde o(a) Sr.(a) vive atualmente o Conselho de Alimentação Escolar - CAE tem atuação (com funcionamento regular)?

1. ( ) Sim

2. ( ) Não

3. ( ) Não sei se o Conselho de Alimentação Escolar existe

4. ( ) Não sei se o Conselho de Alimentação Escolar tem atuação regular

37. No caso do CAE ser atuante na cidade onde o(a) Sr.(a) vive, escreva qual(is) é(são) a(s) principal(is) atividades(s):

38. Na sua opinião, a existência de estabelecimentos que vendem alimentos nas escolas (exemplo: cantinas, lanchonetes,...) é:
1. ( ) Muito boa
2. ( ) Boa
3. ( ) Ruim
4. ( ) Muito Ruim
5. ( ) Não sei
6. ( ) Na escola não tem cantina

Assinatura do responsável pelo preenchimento 
Anexo 2 - Questionário de Freqüência Alimentar para Adolescentes (QFAA) 
Identificação: $\mathrm{n}^{\circ}$

Nome:

Data:

\section{QUESTIONÁRIO G: FREQÜÊNCIA ALIMENTAR (QFAA)}

I. Doces, salgadinhos e guloseimas:

\begin{tabular}{|c|c|c|c|c|c|c|c|c|}
\hline ALIMENTO & QUANTIDADE & Nunca & $\begin{array}{c}\text { menos } \\
\text { de } 1 X \\
\text { mês }\end{array}$ & $\begin{array}{c}1 \text { a } 3 X \\
\text { mês }\end{array}$ & $\begin{array}{l}1 X \\
\text { por } \\
\text { sem }\end{array}$ & $\begin{array}{c}2 \text { a } 4 X \\
\text { sem }\end{array}$ & $\begin{array}{l}1 X \\
\text { dia }\end{array}$ & \begin{tabular}{|c|}
2 ou \\
mais \\
$X$ dia \\
\end{tabular} \\
\hline $\begin{array}{l}\text { G1. Batatinha tipo chips ou } \\
\text { Salgadinho }\end{array}$ & $\begin{array}{l}1 / 2 \text { pacote } \\
\text { grande }\end{array}$ & & & & & & & \\
\hline G2. Chocolate/ Brigadeiro & $\begin{array}{c}1 \text { tablete/ } \\
1 \text { barrinha peq/ } \\
3 \text { unidades peq }\end{array}$ & & & & & & & \\
\hline G3. Bolo comum/ Bolo Pullman & 1 fatia média & & & & & & & \\
\hline G4. Sorvete massa/ palito & $\begin{array}{l}2 \text { bolas/ } \\
1 \text { unidade }\end{array}$ & & & & & & & \\
\hline $\begin{array}{l}\text { G5. Achocolatado em pó } \\
\text { (Nescau, Quick, etc.) }\end{array}$ & $\begin{array}{l}2 \text { colheres de } \\
\text { sopa rasa }\end{array}$ & & & & & & & \\
\hline $\begin{array}{l}\text { G6. Pipoca estourada (doce ou } \\
\text { salgada) }\end{array}$ & $\begin{array}{l}1 \text { saco médio de } \\
\text { pipoqueiro }\end{array}$ & & & & & & & \\
\hline $\begin{array}{l}\text { G7. Açúcar adicionado em café, } \\
\text { chá, leite, etc. }\end{array}$ & $\begin{array}{l}2 \text { colheres } \\
\text { sobremesa }\end{array}$ & & & & & & & \\
\hline G8. Balas & 2 unidades & & & & & & & \\
\hline $\begin{array}{l}\text { G9. Doces de frutas (goiabada, } \\
\text { marmelada, doce abóbora) }\end{array}$ & $\begin{array}{c}1 \text { fatia fina/ } \\
1 \text { unidade média }\end{array}$ & & & & & & & \\
\hline G10. Sobremesas tipo mousse & $\begin{array}{l}1 \text { taça/ } \\
1 \text { pote }\end{array}$ & & & & & & & \\
\hline G11. Croissant de chocolate & 1 unidade média & & & & & & & \\
\hline
\end{tabular}

II. Salgados e preparações:

\begin{tabular}{|c|c|c|c|c|c|c|c|c|}
\hline ALIMENTO & QUANTIDADE & Nunca & $\begin{array}{c}\text { menos } \\
\text { de } 1 X \\
\text { mês }\end{array}$ & $\begin{array}{c}1 \text { a } 3 X \\
\text { mês }\end{array}$ & $\begin{array}{l}1 \mathrm{X} \\
\text { por } \\
\text { sem }\end{array}$ & $\begin{array}{c}2 \text { a } 4 X \\
\text { sem }\end{array}$ & $\begin{array}{l}1 \mathrm{X} \\
\text { dia }\end{array}$ & $\begin{array}{l}2 \text { ou } \\
\text { mais } \\
X \text { dia }\end{array}$ \\
\hline $\begin{array}{l}\text { G12. Cheesebúrger de carne/ } \\
\text { frango }\end{array}$ & 1 sanduíche & & & & & & & \\
\hline $\begin{array}{l}\text { G13. Sanduiche (misto, queijo, } \\
\text { frios ou quentes) }\end{array}$ & 1 sanduíche & & & & & & & \\
\hline G14. Sanduíche natural & 1 sanduíche & & & & & & & \\
\hline $\begin{array}{l}\text { G15. Coxinha/ Risólis/ Pastel/ } \\
\text { Enroladinho frito de presunto e } \\
\text { queijo }\end{array}$ & $\begin{array}{l}1 \text { unidade } \\
\text { média }\end{array}$ & & & & & & & \\
\hline G16. Pão de queijo & $\begin{array}{l}1 \text { unidade } \\
\text { média }\end{array}$ & & & & & & & \\
\hline $\begin{array}{l}\text { G17. Esfiha / Empada / Pão de } \\
\text { Batata / Enroladinho assado de } \\
\text { presunto e queijo }\end{array}$ & $\begin{array}{l}1 \text { unidade } \\
\text { média }\end{array}$ & & & & & & & \\
\hline $\begin{array}{l}\text { G18. Salada de batata com } \\
\text { maionese }\end{array}$ & $\begin{array}{l}1 \text { colher de } \\
\text { servir }\end{array}$ & & & & & & & \\
\hline G19. Sopa (canja, feijão, legumes) & 1 prato fundo & & & & & & & \\
\hline $\begin{array}{l}\text { G20. Farofa (de farinha de } \\
\text { mandioca) }\end{array}$ & $\begin{array}{c}1 \text { colher de } \\
\text { servir }\end{array}$ & & & & & & & \\
\hline G21. Pizza & 1 fatia média & & & & & & & \\
\hline G22. Cachorro quente & 1 sanduíche & & & & & & & \\
\hline G23. Croissant presunto e queijo & $\begin{array}{l}1 \text { unidade } \\
\text { média }\end{array}$ & & & & & & & \\
\hline
\end{tabular}


III. Leites e produtos lácteos:

\begin{tabular}{|c|c|c|c|c|c|c|c|c|}
\hline ALIMENTO & QUANTIDADE & Nunca & $\begin{array}{c}\text { menos } \\
\text { de } 1 \mathrm{X} \\
\text { mês }\end{array}$ & $\begin{array}{c}1 \text { a } 3 X \\
\text { mês }\end{array}$ & $\begin{array}{l}1 \mathrm{X} \\
\text { por } \\
\text { sem }\end{array}$ & $\begin{array}{c}2 \text { a } 4 X \\
\text { sem }\end{array}$ & $\begin{array}{l}\text { 1X } \\
\text { dia }\end{array}$ & $\begin{array}{c}2 \text { ou } \\
\text { mais } X \\
\text { dia }\end{array}$ \\
\hline G24. Leite integral & $\begin{array}{l}1 \text { copo de } \\
\text { requeijão cheio }\end{array}$ & & & & & & & \\
\hline G25. Leite desnatado & $\begin{array}{l}1 \text { copo de } \\
\text { requeijão cheio }\end{array}$ & & & & & & & \\
\hline G26. Leite fermentado (Yakult ${ }^{\mathbb{Q}}$ ) & 1 garrafinha & & & & & & & \\
\hline G27. Iogurte natural/ frutas & 1 pote & & & & & & & \\
\hline G28. Iogurte diet & 1 pote & & & & & & & \\
\hline $\begin{array}{l}\text { G29. Queijo minas frescal/ ricota, } \\
\text { cottage }\end{array}$ & 1 fatia média & & & & & & & \\
\hline G30. Requeijão & $\begin{array}{c}1 \text { colher de } \\
\text { sopa }\end{array}$ & & & & & & & \\
\hline
\end{tabular}

IV. Óleos e Gorduras:

\begin{tabular}{|c|c|c|c|c|c|c|c|c|}
\hline ALIMENTO & QUANTIDADE & Nunca & $\begin{array}{c}\text { menos } \\
\text { de } 1 X \\
\text { mês }\end{array}$ & $\begin{array}{c}1 \text { a } 3 X \\
\text { mês }\end{array}$ & $\begin{array}{l}1 \mathrm{X} \\
\text { por } \\
\text { sem }\end{array}$ & $\begin{array}{c}2 \text { a } 4 X \\
\text { sem }\end{array}$ & $\begin{array}{l}1 X \\
\text { dia }\end{array}$ & $\begin{array}{r}2 \text { ou } \\
\text { mais } \\
X \text { dia } \\
\end{array}$ \\
\hline G31. Maionese tradicional & I colher de sopa & & & & & & & \\
\hline G32. Manteiga (origem animal) & 1 ponta de faca & & & & & & & \\
\hline G33. Margarina (origem vegetal) & 1 ponta de faca & & & & & & & \\
\hline G34. Azeite de Oliva & 1 colher de café & & & & & & & \\
\hline
\end{tabular}

V. Cereais, pães e tubérculos:

\begin{tabular}{|c|c|c|c|c|c|c|c|c|}
\hline ALIMENTO & QUANTIDADE & Nunca & $\begin{array}{c}\text { menos } \\
\text { de } 1 \mathrm{X} \\
\text { mês }\end{array}$ & $\begin{array}{c}1 \mathrm{a} \\
3 \mathrm{X} \\
\mathrm{mês}\end{array}$ & $\begin{array}{l}1 X \\
\text { por } \\
\text { sem }\end{array}$ & $\begin{array}{c}2 \text { a } 4 X \\
\text { sem }\end{array}$ & $\begin{array}{l}\text { 1X } \\
\text { dia }\end{array}$ & $\begin{array}{l}2 \text { ou } \\
\text { mais } \\
X \text { dia }\end{array}$ \\
\hline G35. Arroz cozido & $\begin{array}{l}4 \text { colhs. de sopa/ } \\
11 / 2 \text { colher de servir/ } \\
1 \text { escumad. grande }\end{array}$ & & & & & & & \\
\hline $\begin{array}{l}\text { G36. Macarrão/ instantâneo/ } \\
\text { ao sugo/ manteiga }\end{array}$ & $\begin{array}{l}3 \text { colheres de } \\
\text { servir/ pegador }\end{array}$ & & & & & & & \\
\hline $\begin{array}{l}\text { G37. Massas (lasanha, raviole, } \\
\text { capeleti) }\end{array}$ & $\begin{array}{l}1 \text { pedaço médio/ } \\
1 \text { prato raso }\end{array}$ & & & & & & & \\
\hline $\begin{array}{l}\text { G38. Biscoitos sem recheio/ } \\
\text { cream craker }\end{array}$ & 15 unidades & & & & & & & \\
\hline G39. Biscoitos com recheio & 7 unidades & & & & & & & \\
\hline $\begin{array}{l}\text { G40. Pão francês/ forma/ } \\
\text { integral/ caseiro/ pão de hot dog }\end{array}$ & $\begin{array}{l}11 / 2 \text { unidade/ } \\
3 \text { fatias }\end{array}$ & & & & & & & \\
\hline $\begin{array}{l}\text { G41. Cereal matinal tipo } \\
\text { Sucrilhos } / \text { Barra de cereal }\end{array}$ & $\begin{array}{l}1 \text { xícara de chál } \\
1 \text { unidade }\end{array}$ & & & & & & & \\
\hline G42. Batatas fritas de palito & $\begin{array}{c}\text { 1 saquinho } \\
\text { pequeno/ } \\
1 \text { colh.er de servir }\end{array}$ & & & & & & & \\
\hline G43. Batatas (purê, sautée) & 1 colher de servir & & & & & & & \\
\hline G44. Polenta (cozida ou frita) & $\begin{array}{l}5 \text { barrinhas médias/ } \\
5 \text { colheres de sopa }\end{array}$ & & & & & & & \\
\hline G45. Mandioca cozida & 2 pedaços médios & & & & & & & \\
\hline G46. Pamonha doce/ salgada & 1 unidade média & & & & & & & \\
\hline
\end{tabular}


VI. Verduras e legumes:

\begin{tabular}{|c|c|c|c|c|c|c|c|c|}
\hline ALIMENTO & QUANTIDADE & Nunca & $\begin{array}{c}\text { menos } \\
\text { de } 1 X \\
\text { mês }\end{array}$ & $\begin{array}{c}1 \text { a } 3 X \\
\text { mês }\end{array}$ & $\begin{array}{l}1 \mathrm{X} \\
\text { por } \\
\text { sem }\end{array}$ & $\begin{array}{c}2 \text { a } 4 X \\
\text { sem }\end{array}$ & $\begin{array}{l}1 \mathrm{X} \\
\mathrm{dia}\end{array}$ & $\begin{array}{c}2 \text { ou } \\
\text { mais } \\
X \text { dia }\end{array}$ \\
\hline G47. Alface & $\begin{array}{c}1 \text { porção / } \\
6 \text { folhas médias }\end{array}$ & & & & & & & \\
\hline G48. Acelga/ repolho & $\begin{array}{l}2 \text { colheres de } \\
\text { servir }\end{array}$ & & & & & & & \\
\hline G49. Agrião/ rúcula & $\begin{array}{c}3 \text { ramos/ } \\
5 \text { folhas médias }\end{array}$ & & & & & & & \\
\hline G50. Couve-flor & 2 ramos médios & & & & & & & \\
\hline G51. Beterraba & $\begin{array}{c}1 \text { colher de } \\
\text { servir }\end{array}$ & & & & & & & \\
\hline G52. Cenoura & $\begin{array}{l}1 \text { colher de } \\
\text { servir }\end{array}$ & & & & & & & \\
\hline G53. Espinafre/ couve & $\begin{array}{l}1 \text { colher de } \\
\text { servir }\end{array}$ & & & & & & & \\
\hline G54. Ervilha & $\begin{array}{c}2 \text { colheres de } \\
\text { sopa }\end{array}$ & & & & & & & \\
\hline G55. Milho verde & 1 colher de sopa & & & & & & & \\
\hline G56. Pepino & 6 fatias médias & & & & & & & \\
\hline G57. Tomate & 3 fatias médias & & & & & & & \\
\hline
\end{tabular}

\section{Frutas:}

\begin{tabular}{|c|c|c|c|c|c|c|c|c|}
\hline ALIMENTO & QUANTIDADE & Nunca & \begin{tabular}{|c|} 
menos \\
de $1 \mathrm{X}$ \\
mês \\
\end{tabular} & $\begin{array}{c}1 \text { a } 3 X \\
\text { mês }\end{array}$ & $\begin{array}{l}1 X \\
\text { por } \\
\text { sem }\end{array}$ & $\begin{array}{c}2 \text { a } 4 X \\
\text { sem }\end{array}$ & $\begin{array}{l}1 \mathrm{X} \\
\text { dia }\end{array}$ & $\begin{array}{c}2 \text { ou } \\
\text { mais } \\
\mathrm{X} \text { dia } \\
\end{array}$ \\
\hline G58. Abacate & $1 / 2$ unidade & & & & & & & \\
\hline G59. Abacaxi & 1 fatia média & & & & & & & \\
\hline G60. Banana & 1 unidade média & & & & & & & \\
\hline G61. Laranja/mexerica & 1 unidade média & & & & & & & \\
\hline G62. Maçã/ pêra & 1 unidade média & & & & & & & \\
\hline G63. Mamão & 1 fatia média & & & & & & & \\
\hline G64. Melão/ Melancia & 1 fatia média & & & & & & & \\
\hline G65. Manga & $\begin{array}{c}1 / 2 \text { unidade } \\
\text { média }\end{array}$ & & & & & & & \\
\hline G66. Morangos & 1/2 xícara de chá & & & & & & & \\
\hline G67. Uva & 1 cacho médio & & & & & & & \\
\hline
\end{tabular}

VIII. Feijão:

\begin{tabular}{|c|c|c|c|c|c|c|c|c|}
\hline ALIMENTO & QUANTIDADE & Nunca & $\begin{array}{c}\text { menos } \\
\text { de } 1 \mathrm{X} \\
\text { mês }\end{array}$ & $\begin{array}{c}1 \text { a } 3 X \\
\text { mês }\end{array}$ & $\begin{array}{l}1 \mathrm{X} \\
\text { por } \\
\text { sem }\end{array}$ & $\begin{array}{c}2 \text { a } 4 X \\
\text { sem }\end{array}$ & $\begin{array}{l}1 X \\
\text { dia }\end{array}$ & $\begin{array}{l}2 \text { ou } \\
\text { mais } \\
X \text { dia }\end{array}$ \\
\hline G68. Feijão (marrom ou preto) & $11 / 2$ concha média & & & & & & & \\
\hline
\end{tabular}


IX. Carnes e Ovos:

\begin{tabular}{|c|c|c|c|c|c|c|c|c|}
\hline ALIMENTO & QUANTIDADE & Nunca & $\begin{array}{c}\text { menos } \\
\text { de } 1 \mathrm{X} \\
\text { mês }\end{array}$ & $\begin{array}{c}1 \text { a } 3 X \\
\text { mês }\end{array}$ & $\begin{array}{l}1 \mathrm{X} \\
\text { por } \\
\text { sem }\end{array}$ & $\begin{array}{c}2 \text { a } 4 X \\
\text { sem }\end{array}$ & $\begin{array}{l}1 X \\
\text { dia }\end{array}$ & $\begin{array}{l}2 \text { ou } \\
\text { mais } \\
X \text { dia }\end{array}$ \\
\hline $\begin{array}{l}\text { G69. Carne cozida (bife role/ } \\
\text { moida/ de panela/ } \\
\text { picadinho) }\end{array}$ & $\begin{array}{l}1 \text { fatia média/ } \\
1 \text { C.de servir/ } \\
1 \text { unidade média }\end{array}$ & & & & & & & \\
\hline G70. Bife frito/ bife à milanesa & 1 unidade média & & & & & & & \\
\hline $\begin{array}{l}\text { G71. Frango cozido/ assado/ } \\
\text { grelhado/ frito }\end{array}$ & $\begin{array}{l}1 \text { pedaço médio/ } \\
1 \text { unidade média }\end{array}$ & & & & & & & \\
\hline G72. Peixe frito & $\begin{array}{l}1 \text { filé médio/ } \\
\text { posta }\end{array}$ & & & & & & & \\
\hline $\begin{array}{l}\text { G73. Carne suina (bisteca/ } \\
\text { lombo) }\end{array}$ & $\begin{array}{l}1 \text { unidade média/ } \\
1 \text { fatia média }\end{array}$ & & & & & & & \\
\hline $\begin{array}{l}\text { G74. Ovo frito/mexido/ } \\
\text { Omelete }\end{array}$ & $\begin{array}{l}1 \text { unidade médial } \\
1 \text { pedaço médio }\end{array}$ & & & & & & & \\
\hline $\begin{array}{l}\text { G75. Embutidos (presunto/ } \\
\text { peito de peru, mortadela, } \\
\text { salame etc) }\end{array}$ & 2 fatias médias & & & & & & & \\
\hline G76. Salsicha & $11 / 2$ unidade & & & & & & & \\
\hline G77. Lingüiça & 1 gomo médio & & & & & & & \\
\hline
\end{tabular}

X. Bebidas:

\begin{tabular}{|c|c|c|c|c|c|c|c|c|}
\hline ALIMENTO & QUANTIDADE & Nunca & $\begin{array}{c}\text { menos } \\
\text { de } 1 \mathrm{X} \\
\text { mês }\end{array}$ & $\begin{array}{c}1 \text { a } 3 X \\
\text { mês }\end{array}$ & $\begin{array}{l}\text { 1X } \\
\text { por } \\
\text { sem }\end{array}$ & $\begin{array}{c}2 \text { a } 4 X \\
\text { sem }\end{array}$ & $\begin{array}{l}1 \mathrm{X} \\
\text { dia }\end{array}$ & $\begin{array}{l}2 \text { ou } \\
\text { mais } \\
X \text { dia }\end{array}$ \\
\hline G78. Refrigerante normal & $\begin{array}{l}11 / 2 \text { copo de } \\
\text { requeijão/ } 1 \text { lata }\end{array}$ & & & & & & & \\
\hline G79. Refrigerante diet & $\begin{array}{l}11 / 2 \text { copo de } \\
\text { requeijão/ } 1 \text { lata }\end{array}$ & & & & & & & \\
\hline G80. Chá mate com sabor & 1 lata & & & & & & & \\
\hline $\begin{array}{l}\text { G81. Suco de abacaxi com } \\
\text { açúcar }\end{array}$ & $\begin{array}{l}1 \text { copo de } \\
\text { requeijão }\end{array}$ & & & & & & & \\
\hline $\begin{array}{l}\text { G82. Suco de laranja/mexerica } \\
\text { com açúcar }\end{array}$ & $\begin{array}{l}1 \text { copo de } \\
\text { requeijão }\end{array}$ & & & & & & & \\
\hline $\begin{array}{l}\text { G83. Suco de mamão com } \\
\text { açúcar }\end{array}$ & $\begin{array}{l}1 \text { copo de } \\
\text { requeijão }\end{array}$ & & & & & & & \\
\hline $\begin{array}{l}\text { G84. Suco de melão/ melancia } \\
\text { com açúcar }\end{array}$ & $\begin{array}{l}1 \text { copo de } \\
\text { requeijão }\end{array}$ & & & & & & & \\
\hline $\begin{array}{l}\text { G85. Limonada/ laranjada com } \\
\text { açúcar }\end{array}$ & $\begin{array}{l}1 \text { copo de } \\
\text { requeijão }\end{array}$ & & & & & & & \\
\hline $\begin{array}{l}\text { G86. Sucos naturais com leite/ } \\
\text { Vitaminas de frutas }\end{array}$ & $\begin{array}{l}1 \text { copo de } \\
\text { requeijão }\end{array}$ & & & & & & & \\
\hline G87. Sucos artificiais & $\begin{array}{l}1 \text { copo de } \\
\text { requeijão }\end{array}$ & & & & & & & \\
\hline G88. Café & $\begin{array}{c}1 \text { xícara de café } \\
\text { pequena }\end{array}$ & & & & & & & \\
\hline G89. Cerveja & 1 copo médio & & & & & & & \\
\hline G90. Vinho & 1 copo médio & & & & & & & \\
\hline G91. Batida & 1 copo médio & & & & & & & \\
\hline G92. Chimarrão & 1 cuia & & & & & & & \\
\hline
\end{tabular}


Identificação: $\mathrm{n}^{\circ}$

Nome:

Data:

$X I$. Outros:

\begin{tabular}{|c|c|c|c|c|c|c|c|c|}
\hline ALIMENTO & QUANTIDADE & Nunca & $\begin{array}{c}\text { menos } \\
\text { de } 1 \mathrm{X} \\
\text { mês }\end{array}$ & $\begin{array}{c}1 \text { a } 3 \mathrm{X} \\
\text { mês }\end{array}$ & $\begin{array}{c}1 \mathrm{X} \\
\text { por } \\
\text { sem }\end{array}$ & $\begin{array}{c}2 \text { a } 4 \mathrm{X} \\
\text { sem }\end{array}$ & $\begin{array}{c}1 \mathrm{X} \\
\text { dia }\end{array}$ & $\begin{array}{c}2 \text { ou } \\
\text { mais } \\
\mathrm{X} \text { dia }\end{array}$ \\
\hline G94. Adoçante gotas/ pó & $\begin{array}{c}\text { 1 envelope } \\
\text { pequeno }\end{array}$ & & & & & & & \\
\hline
\end{tabular}

XII. Não mencionados:

\begin{tabular}{|c|c|c|c|c|c|c|c|c|}
\hline ALIMENTO & QUANTIDADE & Nunca & $\begin{array}{c}\text { menos } \\
\text { de 1X } \\
\text { mês }\end{array}$ & $\begin{array}{c}1 \text { a } 3 X \\
\text { mês }\end{array}$ & $\begin{array}{l}1 X \\
\text { por } \\
\text { sem }\end{array}$ & $\begin{array}{c}2 \text { a } 4 X \\
\text { sem }\end{array}$ & $\begin{array}{l}\text { 1X } \\
\text { dia }\end{array}$ & $\begin{array}{l}2 \text { ou } \\
\text { mais } \\
X \text { dia }\end{array}$ \\
\hline G95. & & & & & & & & \\
\hline G96. & & & & & & & & \\
\hline G97. & & & & & & & & \\
\hline G98. & & & & & & & & \\
\hline G99. & & & & & & & & \\
\hline G100. & & & & & & & & \\
\hline G101. & & & & & & & & \\
\hline G102. & & & & & & & & \\
\hline G103. & & & & & & & & \\
\hline G104. & & & & & & & & \\
\hline
\end{tabular}

G105. Toma vitamina e/ou suplemento?

1. Sim (ङ passe para questão seguinte)

2. Não ( $\odot$ fim deste questionário; passe para a próxima seção)

G106. Qual (is) tipo (s)?

G107. Quanto?

G108. Freqüência:

1. Nunca

2. Menos de 1 vez por mês

3. De 1 a 3 vezes por mês

4. 1 vez por semana
5. De 2 a 4 vezes por semana

6. 1 vez ao dia

7. De 2 a mais vezes ao dia

\section{ASSINATURA:}


Anexo 3 - Questionário para Avaliação da Maturação Sexual (desenhos de Tanner) 
Identificação: $\mathrm{n}^{\circ}$

Nome:

Data:

QUESTIONÁRIO D: AVALIAÇÃo dA MATURAÇÃo SEXUAL

SEXO FEMININO

Estágios de Tanner: D1. Mamas:

D2. Pêlos Pubianos:
1. M1
1. $\mathrm{P} 1$
2. $\mathrm{M} 2$
2. $\mathrm{P} 2$
3. $\mathrm{M} 3$
3. $\mathrm{P} 3$
4. M4
4. P4
5. M5
5. P5

D3. Menarca:

1. Sim. D4. Idade da menarca: Anos

2. Não.

3. Não sabe/ não lembra.

\section{SEXO MASCULINO}

Estágios de Tanner: D5. Genitália
6. G1
7. $\mathrm{G} 2$
8. G3
9. G4
10. G5

D6. Pêlos Pubianos

6. P1

7. P2

8. P3

9. $\mathrm{P} 4$

10. P5

ASSINATURA:

\section{E. AVALIAÇÃO ANTROPOMÉTRICA}

E1. Peso aferido: $\square \mathrm{kg} \quad \square \mathrm{kg}$

E2. Altura aferida: $\square \mathrm{m} \quad \square \mathrm{m}$ 
Desenvolvimento Puberal Feminino Critérios de Tanner
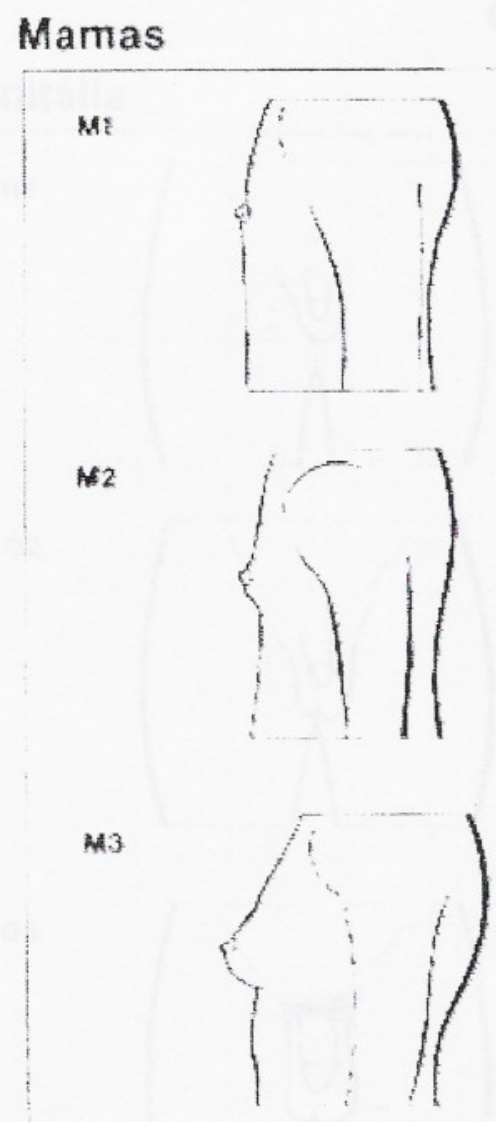

N4

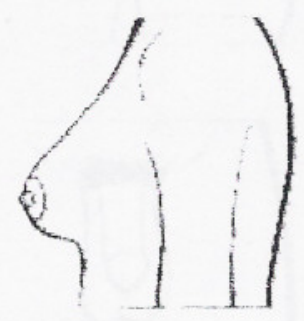

$M 5$

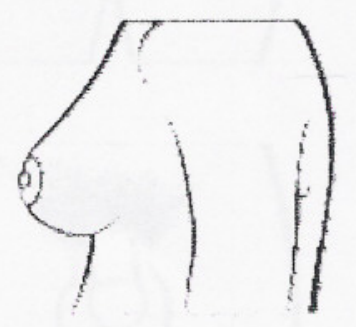

Pêlos pubianos
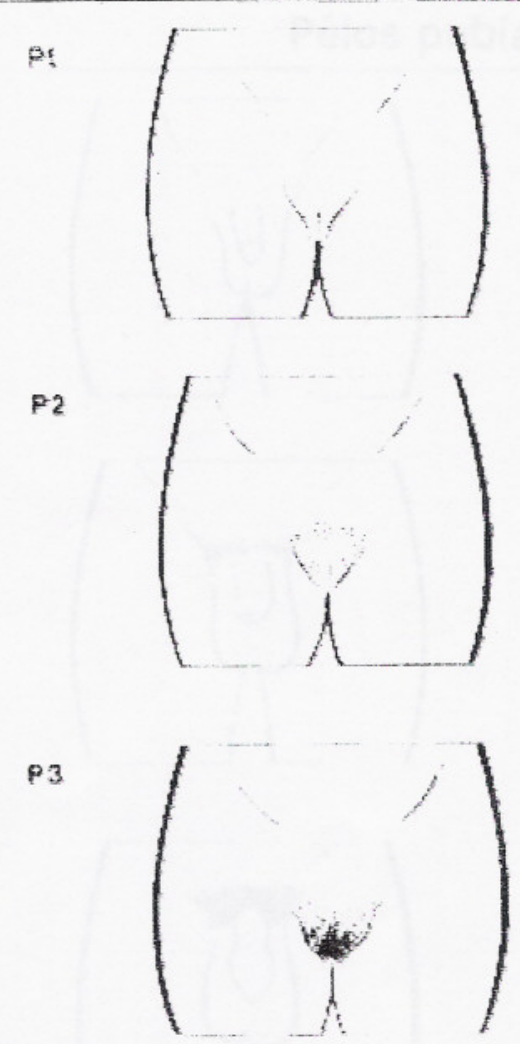

P4

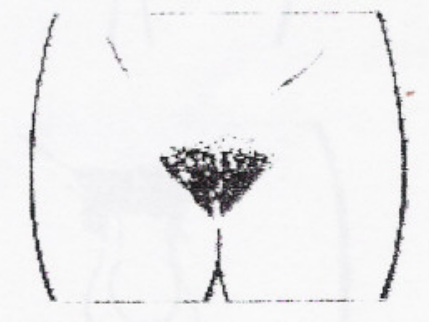

PE

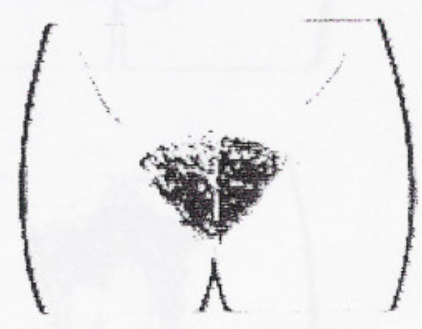




\section{Desenvolvimento Puberal Masculino Critérios de Tanner}

\section{Genitália}

G)

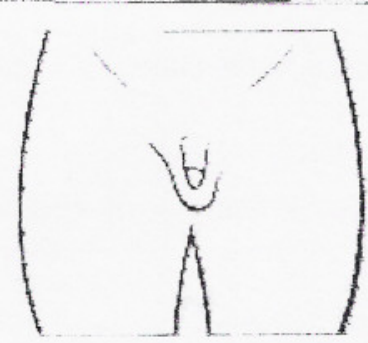

G2

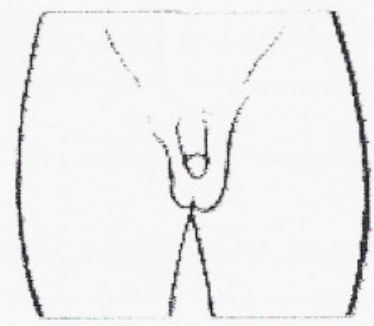

03

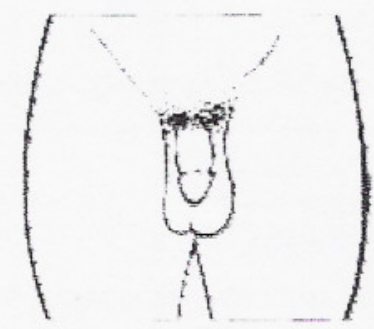

G4

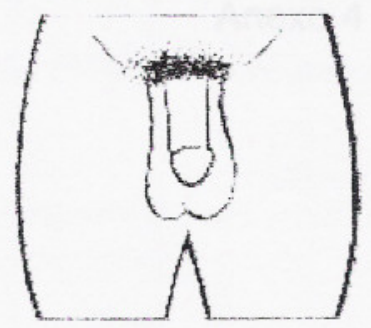

G5

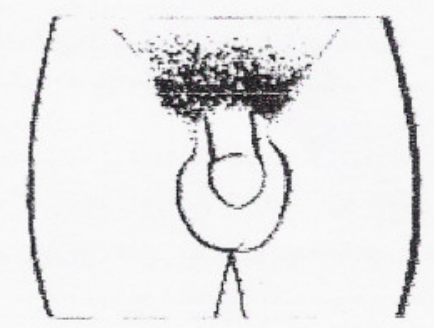

Pélos pubianos

$p 1$

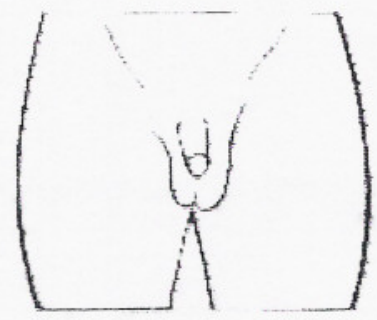

F2

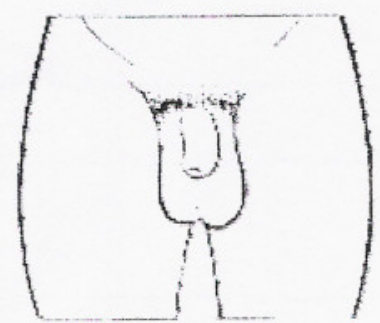

P3
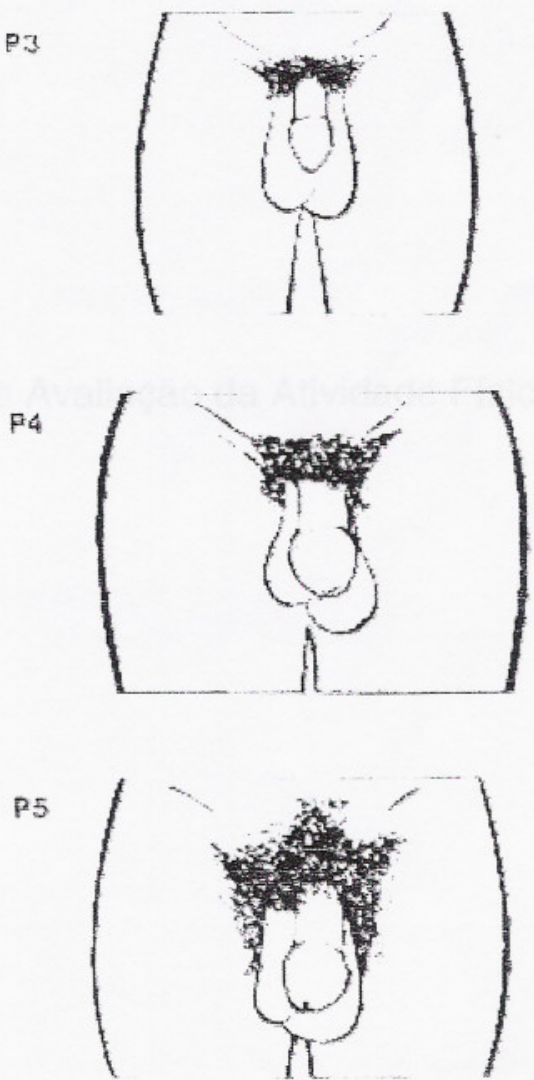
Anexo 4 - Questionário de Avaliação da Atividade Física para Adolescentes (QAFA) 


\section{QUESTIONÁRIO F: AVALIAÇÃO DA ATIVIDADE FÍSICA (QAFA)}

F1. Você pratica ou praticou esporte ou exercício físico em clubes, academias, escolas de esporttes, parques, ruas ou em casa nos últimos 12 meses?
1. Sim ( passe para questão seguinte)
2. Não ( passe para questão $F 16)$

F2. Qual esporte ou exercício físico você pratica ou praticou mais freqüentemente?

F3. Quantas horas por dia você pratica ou praticou?

F4. Quantas vezes por semana você pratica ou praticou?

F5. Quantos meses por ano você pratica ou praticou?

F6. Você pratica ou praticou um segundo esporte ou exercício físico?
1. Sim ( passe para questão seguinte)
2. Não ( ${ }^{5}$ passe para questão F16)

F7. Qual esporte ou exercício físico você pratica ou praticou?

F8. Quantas horas por dia você pratica ou praticou?

F9. Quantas vezes por semana você pratica ou praticou? 
F10. Quantos meses por ano você pratica ou praticou?

F11. Você pratica ou praticou um terceiro esporte ou exercício físico?

1. Sim ( passe para questão seguinte)

2. Não ( $\lessgtr$ passe para questão F16)

F12. Qual esporte ou exercício físico você pratica ou praticou?

F13. Quantas horas por dia você pratica ou praticou?

F14. Quantas vezes por semana você pratica ou praticou?

F15. Quantos meses por ano você pratica ou praticou?

F16. Você participa das aulas de Educação Física escolar?

1. Sim ( passe para questão seguinte)

2. Não ( $\$$ passe para questão F19)

3. É dispensado ( passe para questão F19)

F17. Quantas aulas por semana?

F18. Qual a duração de cada aula?

F19. Você costuma ir de bicicleta ou a pé para a escola, clube, academia ou cursos em geral?

1. Sim ( passe para questão seguinte)

2. Não ( passe para questão F21)

F20. Quantas horas por dia você gasta nessas atividades? 
Identificação: $\mathrm{n}^{\mathrm{o}}$

Nome:

Data:

\section{INATIVIDADE FÍSICA}

F21. Quantas horas por dia você costuma assistir à televisão nos dias de semana?

F22. Quantas horas você costuma assistir à televisão nos finais de semana, somando sábado e domingo?

F23. Você costuma jogar vídeo-game?

1. Sim ( passe para questão seguinte)

2. Não ( passe para questão F26)

F24. Quantas horas por dia você costuma jogar vídeo-game?

F25. Quantas vezes por semana você costuma jogar vídeo-game?

F26. Você costuma usar o computador?

1. Sim ( passe para questão seguinte)

2. Não (@ fim deste questionário; passe para a próxima seção)

F27. Quantas horas por dia você costuma usar o computador?

F28. Quantas vezes por semana você costuma usar o computador?

ANOTAÇÕES GERAIS:

\section{ASSINATURA:}


Anexo 5 - Documento de aprovação do Comitê de Ética em Pesquisa da Faculdade de Saúde Pública da Universidade de São Paulo (pesquisa mãe) 


\section{Universidade de São Paulo}

Faculdade de Saúde Pública

COMITÊ DE ÉTICA-COEP

Av. Dr. Arnaldo, 715 - CEP 01246-904 - São Paulo - Brasil

Telefones: (55-11) 3066-7734 - fone/fax (55-11) 3064-7314 - e-mail: mdgracas@usp.br

\section{Of.COEP/241/02}

11 e setembro de 2002

Pelo presente, informo que o Comitê de Ética em Pesquisa da Faculdade de Saúde Pública da Universidade de São Paulo-COEP, analisou e aprovou, em sua $7^{\mathrm{a}} . / 02$, realizada em 10.09 .02 , de acordo com os requisitos da Resolução CNS/196/96, o Protocolo de Pesquisa n. ${ }^{\circ} 848$, intitulado: "CONSUMO DIETÉTICO E ATIVIDADE FÍSICA COMO DETERMINANTES DAS MUDANÇAS DO ÍNDICE DE MASSA CORPORAL DE UMA COORTE DE ADOLESCENTE MATRICULADOS NA REDE PÚBLICA DE ENSINO DA CIDADE DE PIRACICABA, SÃO PAULO", apresentado- pela pesquisadora BETZABETH SLATER.

Atenciosamente,

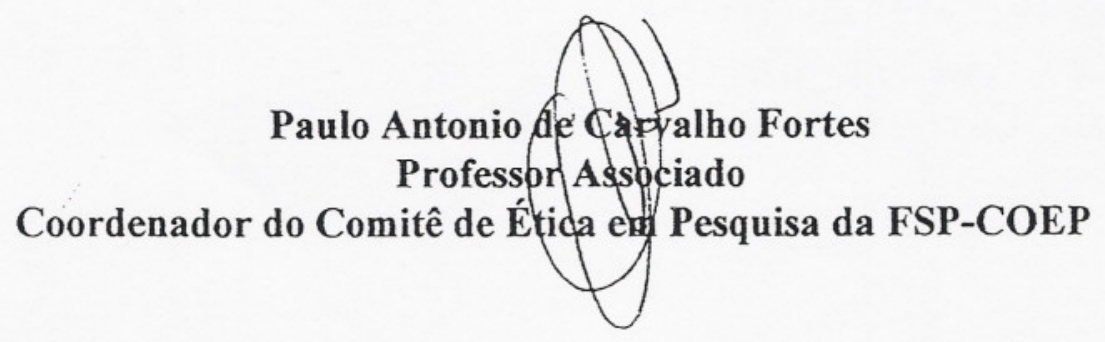


Anexo 6 - Documento de aprovação do Comitê de Ética em Pesquisa da Faculdade de Saúde Pública da Universidade de São Paulo (pesquisa atual) 


\author{
Protocolo $\quad 1550$ \\ Projeto do Pesquisa $\mathrm{O}$ estado nutricional de adolescentes da rede de ensino público da \\ cidade de Piracicaba (SP) e seus determinantes. \\ Pesquisador(a) Stela Verzinhasse Peres
}

Prezado(a) Orientador(a),

O Comitê de Ética em Pesquisa da Faculdade de Saúde Pública da Universidade de São Paulo - COEP analisou de acordo com os requisitos da Resolução CNS/196/96 e suas complementares, em sua $8 \% 06$ Sessão Ordinária, reálizada em 11.10 , p.p., o protocolo de pesquisa acima intitulado e considera que não há necessidade de apresentá-lo ao Comitê, tendo em vista que segundo o cronograma apresentado, a coleta de dados já teve inicio em 02/2006. O protocolo apresentado é subprojeto de um Projeto Mãe, que teve sua aprovação por este Comitê em 11.09.02.

Aproveitamos para lembrar, que em relação ao Projeto Mãe, conforme Resolução CNS/196/96 são deveres do(a) pesquisador(a):

1. Comunicar, de imediato, qualquer alteração no projeto e aguardar manifestação deste CEP (Comitê de Ética em Pesquisa), para dar continuidade à pesquisa;

2. Manter em local seguro pelo prazo de 5 (cinco) anos dados individuais de todas as etapas da pesquisa para eventual auditoria;

3. Ao(A) pesquisador(a), comunicar, formalmente a este Comitê, quando do encerramento deste projeto.

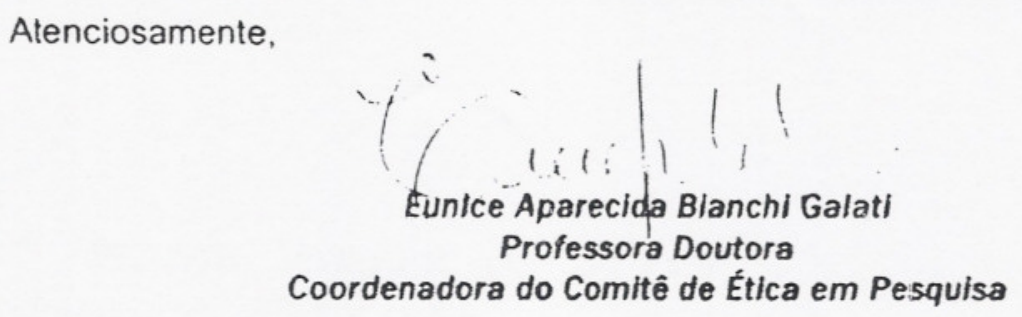

$1 \mathrm{Im} \cdot \mathrm{Sr}$.

Prof?. Dr". Maria do Rosário Dlas de Oliveira Latorre

Departamento de Epidemiologia

\footnotetext{
Av. Dr. Arnaldo, 715 - Assessoria Acadêmica - CEP: 01246-904 - São Paulo - SP

Telefones: (55-11) 3061-7779/7742 e-mail: coep@fsp.usp.br site www.fsp.usp.br
} 
Anexo 7 - Documento de aprovação do Dirigente Regional de ensino da Piracicaba 
Secretaria de Estado da Educação

Coordenadoria de Ensino do Interior Diretoria de Ensino - Rcgiào de Piracicaba

Rus João Sampaio, 666 - São Dimas

Piracicabs - SP

ofício $n^{\circ}: 084 / 2004$

Piracicaba, 19 de outubro de 2.004

Prezada Senhora:

Em atenção ao ofício expedido em 18/10/04 - Departamento Agroindústria, Alimentos e Nutrlço, informamos a V.Sa. que fica autorizada a continuidade da pesquisa coordenada pelas Professoras Doutoras Marina Vieira da Silva e Betzabeth slater Villar.

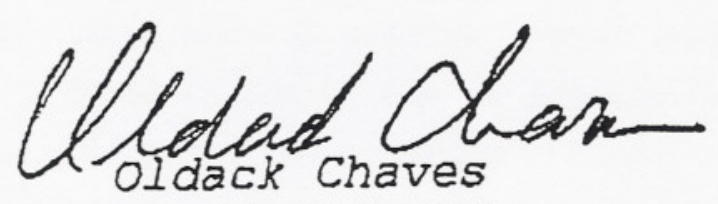

RG 11.137 .012

Dirigente Regional de Ensino

IIma.Sra.

Prof Dra Marina Vieira da Silva

Coordenadora da Pesquisa

ESALQ/USP

Depto Agroindústria, Alimentos e Nutrição 
Anexo 8 - Termo de Consentimento Livre e Esclarecido 


\title{
CARTA DE INFORMAÇÃO PARA OS PAIS/RESPONSÁVEIS DE ALUNOS E TERMO DE CONSENTIMENTO
} (Para escolares de 10 a 14 anos)

\author{
Pesquisa: "Consumo dietético e atividade física como determinantes das \\ mudanças do Índice de Massa Corporal de uma coorte de adolescentes \\ matriculados na rede pública de ensino da cidade de Piracicaba, São Paulo." ${ }^{\text {(*) }}$
}

A pesquisa que estamos desenvolvendo é financiada (Processo $n^{\circ}$ 02/9521-9) pela Fundação de Amparo à Pesquisa do Estado de São Paulo - FAPESP. Integram a equipe do projeto pesquisadores da Escola Superior de Agricultura "Luiz de Queiroz" - ESALQ/USP (Piracicaba) e da Faculdade de Saúde Pública - FSP/USP da área de alimentação e nutrição.

Esta pesquisa terá início no mês de outubro (2004) e terá duração média, em cada uma das escolas que integram a amostra, de uma semana. Os(as) alunos(as) cujos pais/responsáveis concordarem com a participação dos filhos serão entrevistados por pesquisadores treinados e preencherão os seguintes questionários, em três períodos/fases a saber:

- 1 Recordatório alimentar de 24 horas (avalia o consumo de todos os alimentos ingeridos pelo(a) aluno(a) nas últimas 24 horas;

- 1 Questionário de atividade física (que tem por objetivo avaliar as atividades físicas do aluno e esportes do dia-a-dia praticados em academias, escolas de esporte, aulas de Educação Física escolar, utilização de bicicleta ou caminhada e tempo que permanece em atividades de estudo);

- 1 Avaliação da maturação sexual - planilhas de Tanner (avalia o grau de desenvolvimento físico e características sexuais secundárias);

- 1 Questionário de Freqüência Alimentar (avalia a dieta habitual nos últimos seis meses através da descrição do número de vezes em que determinados alimentos são consumidos em um período);

\footnotetext{
(*) Complementa a pesquisa do CNPq: "Contrastes regionais nos custos, qualidade e operacionalização do Programa Nacional de Alimentação Escolar - PNAE e seu impacto sobre os padrões alimentares da população brasileira".
} 
- 1 Questionário com perguntas sobre as condições econômicas e de estilo de vida da família do(a) aluno(a). Esse questionário será levado para casa para que os pais/responsáveis respondam e devolvam (no dia marcado) o questionário na escola. O(a ) aluno(a) poderá levá-lo e entregá-lo ná Diretoria da Escola.

- Aferição de peso corporal e a altura.

\section{A pesquisa foi avaliada pelo Comitê de Ética da Faculdade de Saúde Pública (USP)} tendo como identificação do protocolo o número 848 .

A seguir, são apresentados alguns itens que devem ser analisados atentamente por V.S ${ }^{a}$. No caso do(a) senhor(a) se considerar esclarecido(a) e concordar com os itens apresentados, por favor assine o termo de consentimento (apresentado na folha seguinte) que deverá ser devolvido aos pesquisadores responsáveis (nomes e endereço para contatos de esclarecimento no final desta página).

- fui esclarecido sobre os objetivos da pesquisa;

- fui esclarecido sobre as informações que deverão ser fornecidas sobre alimentação, atividade física e maturação sexual;

- que as crianças serão pesadas e medidas;

- que o presente estudo não trará nenhum risco para a integridade física ou moral do menor;

- que poderei obter informações, diretamente com os pesquisadores responsáveis, sobre o conjunto de procedimentos adotados durante a pesquisa;

- que não terei quaisquer gastos relacionados à pesquisa;

- que tenho a liberdade de não colaborar ou desistir a qualquer momento, durante a realização da pesquisa;

- que o conjunto dos resultados da pesquisa serão fornecidos para a escola, sem a identificação/divulgação do nome dos participantes;

- que apenas devo concordar (consentir) com a participação do menor se o mesmo não apresentar problemas de saúde importantes tais como: pressão alta, problemas cardíacos ou outra doença.

\section{Os pesquisadores responsáveis garantem que:}

- as informaç̃os obtidas junto ao aluno são de caráter confidencial, sendo que essas poderão ser divulgadas em congressos científicos e publicadas em revistas especializadas, sem a identificação/divulgação do nome dos participantes;

- esta pesquisa/ estudo não prejudicará as atividades dos alunos, durante a jornada de aula.

Prof ${ }^{\mathrm{B}} \mathrm{Dr}^{\mathrm{a}}$ Betzabeth Slater Villar

Tel.: (11) 3066-7701-R. 243

Faculdade de Saúde Pública - USP - São Paulo
Prof ${ }^{\mathrm{a}} \mathrm{Dr}^{\mathrm{a}}$ Marina Vieira da Silva

Tel.: (19) 3429-4225

ESALQ - USP - Piracicaba

Observação: devolver somente a última página. 
Senhor Responsável: este termo de consentimento deverá ser devolvido preenchido e assinado até I I na Escola.

\section{TERMO DE CONSENTIMENTO}

$$
\mathrm{Eu},
$$

responsável

pelo(a) aluno(a)

da escola matriculado(a) na série, declaro que entendi e não tenho qualquer dúvida a respeito da carta contendo as informações sobre a pesquisa. Assim sendo, autorizo o(a) aluno(a) pelo qual sou responsável a participar desta pesquisa.

Local: de de 2004 .

Assinatura do responsável pelo aluno RG do responsável 